Ribeiro, F.; Sena-Cruz, J.; Branco, F.; Júlio, E. (2018) "Hybrid FRP jacketing for enhanced confinement of circular concrete columns in compression." Construction \& Building Materials, 184: 681-704.

\title{
Hybrid FRP jacketing for enhanced confinement of circular concrete columns in compression
}

\author{
Filipe Ribeiro $^{1}$, José Sena-Cruz ${ }^{2 *}$, Fernando Branco ${ }^{3}$, Eduardo Júlio ${ }^{4}$
}

\begin{abstract}
The main goal of the study herein described was to evaluate the performance of an innovative confining unidirectional hybrid FRP solution for circular concrete columns, exploiting the hybrid effect and pseudo-ductility of FRP jackets made of different fibres. First, an experimental study on the compressive stress-strain curves of small-scale plain circular concrete columns confined with hybrid FRP was conducted. Jackets were produced with dry unidirectional fabrics of high-modulus carbon, standard-modulus carbon, E-glass, and basalt. Different combinations were tested, varying the number of layers of each material. Next, two new simple design-oriented models were developed in order to predict the compressive peak stress of compressed concrete columns confined with hybrid FRP jacketing. Predictions were in close agreement with test results. Finally, an existing analysisoriented model developed for non-hybrid FRP-confined concrete was adapted to also predict dilation and the compressive stress-strain curve of hybrid FRP-confined concrete. Likewise, predictions were in close agreement with test results. It was concluded that hybridisation can effectively contribute to maximize the lateral strain efficiency of FRP jacketing and its behaviour can be predicted with the developed analytical models.
\end{abstract}

Keywords: hybrid FRP jacketing, concrete confinement, circular concrete columns

\footnotetext{
${ }^{1} \mathrm{PhD}$ Student, CERIS, Instituto Superior Técnico, Universidade de Lisboa, Portugal. E-mail: filipe.t.ribeiro@tecnico.ulisboa.pt

${ }^{2}$ Associate Professor, ISISE, Department of Civil Engineering, University of Minho, Portugal. E-mail: jsena@civil.uminho.pt *Corresponding Author

${ }^{3}$ Assistant Professor, ISISE, Department of Civil Engineering, University of Coimbra, Portugal. E-mail: fjbranco@,dec.uc.pt

${ }^{4}$ Full Professor, CERIS, Instituto Superior Técnico, Universidade de Lisboa, Portugal.

E-mail: eduardo.julio@tecnico.ulisboa.pt
} 
Ribeiro, F.; Sena-Cruz, J.; Branco, F.; Júlio, E. (2018) "Hybrid FRP jacketing for enhanced confinement of circular concrete columns in compression." Construction \& Building Materials, 184: 681-704.

\section{INTRODUCTION}

Fibre Reinforced Polymers (FRP) composites have been effectively used as passive jacket of concrete columns in the last three decades. It is known that concrete in compression expands radially leading to internal cracking [1]. The confinement, first, delays cracking and, then, prevents the relative displacement of disaggregated concrete pieces, thus allowing concrete to reach higher compressive strength and higher ultimate axial and lateral strains [2]. FRP jackets are typically produced through the wet lay-up method [2]. These systems have been implemented mainly in two situations: (i) in rehabilitation of existing concrete structures, being columns retrofitted through FRP wrapping (positioning the fibres transversely oriented, relatively to the longitudinal axis of the member) and (ii) in new construction, adopting composite columns made of concrete-filled FRP tubes (CFFTs) [3-5].

Confinement of concrete columns is more effective in the case of circular cross-sections, than in the case of square/rectangular cross-sections because, in the former situation, concrete is uniformly confined. For this reason, as addressed in [6], the behaviour of FRP-confined concrete in circular cross-sections has been widely studied since the mid-1980s. A database built from an extensive literature review covering 1063 test results is published in $[7,8]$. The behaviour of FRP-confined concrete in square/rectangular cross-sections has received relatively less attention. Thus, in a similar database, published in [9], it was possible to assemble 484 test results.

Although the performance of FRP-confined concrete is well studied, it can be improved. For instance, results in bibliography have shown that the ultimate tensile strain of conventional FRP jackets is lower than that observed in tensile tests of laminates of non-hybrid FRP of the same material [10-12]. This phenomenon has been designated as lateral strain efficiency of FRP jackets. A several number of factors has been reported as cause of lower efficiency in FRP jackets [10]. These factors include differences between FRP jackets and laminate specimens in variables such as the form, the methods of measurement and testing, the quality of workmanship, the geometric imperfections, the presence of an overlap region in the jacket, and the curvature and multiaxial stress state of the FRP jacket. Lim and Ozbakkaloglu [10] has presented the results of an analytical study that closely examined factors influencing the lateral rupture strains and axial strains in FRP-confined concrete. It has been concluded that ultimate tensile strain of non-hybrid FRP jackets are significantly affected by (i) concrete strength, and (ii) type of FRP material. It has been demonstrated that the FRP lateral strain at failure decreases with an increase in the unconfined concrete strength and elastic modulus of fibres. In addition, conventional FRP materials are brittle, exhibiting a linear elastic behaviour up to failure. For this reason, when submitted to pure compression, 
the compressive stress of the confined concrete continuously increase with the strain up to FRP failure. Since the confinement material is brittle, failure is abrupt, even explosive, dominated by FRP failure.

In the present work, an innovative solution to overcome these drawback is presented. The strategy passed by combining commercially available unidirectional dry fabrics of different materials in the same matrix obtained a hybrid composite that promotes synergies between the involved reinforcing materials, conducting, for instance, a pseudo-ductile tensile response (characterized by fragmentation in the low strain material and dispersed delamination, please see details in [13]), and an increase (until 50\% [13, 24]) of the apparent failure strain of low

strain fibres, known as 'hybrid effect'. The present research focus on the results of pure compression tests, performed on small-scale plain concrete columns confined with 16 unidirectional interlayer hybrid composite combinations, exploiting the demonstrated hybrid effect and pseudo-ductility of this confining material [14]. All the unidirectional hybrid composites used in the jacketing has been tensile characterized before in [14]. This paper aims at demonstrating that the hybrid effect can maximize the efficiency of the FRP jackets and pseudo-ductility can avoid abrupt failures, and thus, improve safety. To the best of the authors' knowledge, it is the first time that fragmentation of low strain material and dispersed delamination is explored in this type of applications. Moreover, it is intended to prove that the model of Jalalvand et al. [13] and the bilinear rule of mixtures (ROM) [14] can be used to predict satisfactorily the confining pressure of hybrid composites. A new design-oriented model to predict the ultimate condition of hybrid FRP-confined concrete is proposed in this paper. Lastly, an analysis-oriented model for hybrid FRP-confined concrete, developed by modifying the calculation method of the confining pressure of Lim and Ozbakkaloglu $[15,16]$ model, is also presented.

\subsection{Tensile behaviour of hybrid unidirectional composites}

Aiming at achieving pseudo-ductile tensile response (so called to describe a mechanical non-linear behaviour characterized by presenting a flat-topped stress-strain curve in monotonic tensile tests), exhaustive work has been carried out with a combination of different unidirectional FRP composites [13, 14, 17-22]. This type of combination consist of two types of fibres, namely low strain (LS) and high strain (HS) fibres, within the same polymeric matrix. Please note that to non-catastrophic tensile curve, achievable with some configuration of unidirectional hybrid FRP composites, is not repeatable on subsequent unloadings/reloadings [17, 23].

In addition to pseudo-ductility, as referred to above hybridisation also promotes the appearance of the 'hybrid effect', i.e., an increase of strain at the failure of LS material. This was reported, for the first time, in 1972, 
by Hayashi [24]. The restriction caused by HS fibres adjacent to a broken LS fibre has been reported as the main factor contributing for the hybrid effect, since HS fibres inhibit the formation of critical clusters [21, 23].

Ribeiro et al. [14] conducted an experimental study on the tensile stress-strain curves of interlayer (layerby-layer) unidirectional hybrid FRP composites, aiming at evaluating the corresponding hybrid effect and pseudoductility of this innovative solution. A maximum hybrid effect of circa $45 \%$ was achieved, by combining unidirectional fabrics of high-modulus carbon with standard-modulus carbon. In four tested hybrid combinations, that included HM carbon as LS material, pseudo-ductile tensile responses with fragmentation and dispersed delamination of LS fibres were achieved. In these combinations, the mean 'yielding' stress varied between circa 730 and $1500 \mathrm{MPa}$ and the pseudo-ductile strain between 0.4 and $2.0 \%$.

At the present moment, although the documentation on hybrid solutions applied in the confinement of concrete columns is very scarce, the few studies already carried out allow assuming these as very promising [2529]. Generally, experimental results have demonstrated that failure of hybrid composites do not lead to explosive failure of confined concrete. However, as emphasized in Ribeiro et al. [14], these attempts have been performed without a complete understanding of the material behaviour and the factors controlling the failure mode of the hybrid composites have not been clearly explained. Moreover, the pseudo-ductility concept, resulting from the fragmentation phenomena and controlled delamination of LS fibres, has not been explained either.

However, even with the above mentioned advantages of hybrid composites, it is important to be aware that, if the hybrid configuration is not carefully designed, the hybrid composite may not only break suddenly, but it may also show a strength lower than its constituents individually.

\section{ANALYTICAL MODELS FOR FRP-CONFINED CONCRETE}

Over time a large number of models has been proposed to predict the behaviour of non-hybrid FRPconfined concrete [6]. These models can be classified into two categories [11]: (i) design-oriented models and (ii) analysis-oriented models.

Typically, design-oriented models are closed form equations developed through regression analyses from axial compression test results. These models allow to predict the ultimate conditions of confined concrete without capturing the confinement mechanisms [15]. In the work of Ozbakkaloglu et al. [6], an exhaustive critical review of 59 design-oriented models was performed. It was concluded that the models developed by Lam and Teng [11] and Tamuzs et al. [30] are the most accurate for predicting, respectively, the ultimate strength and the ultimate 
axial strain of confined concrete. In the work of Ozbakkaloglu et al. [6] were contemplated the prediction of 832 test results, leading to average errors of $11.8 \%$ for the first model and $26.3 \%$ for the second [7].

Analysis-oriented models are capable of establishing all the axial stress-strain behaviour of FRP-confined concrete, considering the interaction between the confining material and the concrete core. In these models, it is assumed that the axial stress and the axial strain of FRP-confined concrete are those of concrete actively confined with a constant confining pressure (equal to that supplied by the FRP at every moment) [15]. This way, the accuracy of this type of models depends on two input parameters: (1) the lateral strain-to-axial strain relationship, and (2) the stress-strain base curves of the actively confined concrete [15].

Recently, Lim and Ozbakkaloglu [15] proposed a generic model to describe the lateral strain-to-axial strain relationship of confined concrete. This model emerged following an in-depth evaluation of previous models in the literature. The predictions of the proposed model are well above of previous models for both FRP-confined and actively confined concretes. The lateral strain-to-axial strain relationship of confined concrete is shown to be a function of the confining pressure, type of confining material and concrete strength. In [16], the same authors, presented an analysis-oriented model to describe the stress-strain relationships of both actively confined concretes and FRP-confined concretes. It was proved that the model provides improved predictions compared to the previous models presented in the literature. For this reasons the models presented in [15] and [16] were used in present work. Since these models proved to be quite efficient, it is not expected to get improved predictions with other models.

\subsection{Analysis-oriented model}

Analysis-oriented models assume that, for a given confining pressure ( $f(i)$, an active confinement model for concrete can be used to evaluate the corresponding FRP-confined concrete compressive stress. This way, the complete stress-strain curve of FRP-confined concrete can be obtained by repeating the next incremental procedure until FRP failure:

i. $\quad$ Lateral strain ( $(\varepsilon)$ is the input parameter to estimate the $f$ of FRP-confined concrete (see section 2.1.1);

ii. $\quad \varepsilon l$ and $f i$ are used to estimate the axial strain $\left(\varepsilon_{\mathrm{c}}\right)$ of FRP-confined concrete (see Section 2.1.2);

iii. Simultaneously, $f i$ is used to define the stress-strain model of actively confined concrete (see Section 2.1.3);

iv. The latter allows to determine the compressive stress $\left(f_{\mathrm{c}}\right)$ of FRP-confined concrete, assuming that it is equal to the compressive stress of actively confined concrete for the estimated $\varepsilon_{c}$. 


\subsubsection{Confining pressure modelling}

\subsubsection{Non-hybrid FRP jackets}

Under concentric compression, the lateral tensile stress (or hoop tensile stress) from the FRP jacket in circular confined columns results in uniform $f$. The latter increases proportionally with the lateral expansion of concrete up to the failure of the system. Based on the deformation compatibility between the jacket and the concrete surface, the lateral confining pressure applied to concrete by the FRP jacket can be computed according to the following equation [6]:

$$
f_{l}=\frac{2 E_{f r p} \varepsilon_{l} t_{f r p}}{D}
$$

where $E_{\text {frp }}$ is the elastic modulus of FRP, $t_{f r p}$ is the total thickness of FRP and $D$ is the diameter of the concrete specimen.

In the present work, the exact volume of the epoxy resin was not directly controlled during the application. For this reason, the total thickness of the FRP was computed considering only the thickness of the dry fabrics, according to the usual practice of the wet lay-up method and suggested by codes, e.g., [31].

\subsubsection{Hybrid FRP jackets}

In a unidirectional (UD) hybrid FRP submitted to uniaxial tension, the first damage mode is always the failure of the LS fibres. However, the other damage modes depend on the properties and configuration of the composite reinforcing materials [19]. The analytical approach proposed by Jalalvand et al. [13], validated in the scope of the present work in [14], considers that four different damage modes may occur after LS fibres failure: (i) premature HS failure, (ii) unstable delamination, (iii) LS layer fragmentation, and (iv) LS fragmentation and stable delamination. For each hybrid configuration, three stress levels can be computed [13]: (i) the stress at which the first crack in the LS material occurs, $\sigma @ L F$, (ii) the stress at which delamination starts, $\sigma @ d e l$, and (iii) the stress at which the HS material fails, $\sigma @ H F$, in accordance with equations (2) to (4), respectively.

$$
\begin{aligned}
& \sigma @ L F=S_{L} \frac{\alpha \beta+1}{\alpha(\beta+1)} \\
& \sigma @ d e l=\frac{1}{1+\beta} \sqrt{\left(\frac{1+\alpha \beta}{\alpha \beta}\right)\left(\frac{2 G_{I I C} E_{H}}{t_{H}}\right)} \\
& \sigma @ H F=\frac{1}{(1+\beta)} \frac{S_{H}}{K_{t}{ }^{m_{H}} \sqrt{V}}
\end{aligned}
$$


where $S_{\mathrm{L}}$ is the reference strength of the LS material, $\alpha$ and $\beta$ are the modulus and thickness ratios of the LS to HS fibre, $G_{I I C}$ is the mode II interlaminar fracture toughness of the interface between LS layers and HS layers of the hybrid composite, $E_{\mathrm{H}}$ is the elastic modulus of the HS fibres, $t_{H}$ is the half thickness of the HS fibre, $m_{H}$ is the Weibull strength distribution modulus of the HS fibre, $S_{\mathrm{H}}$ is the reference strength of the HS material, $K_{t}$ is the stress concentration factor in the high strain material, and $V$ is the volume of the specimen (free length $\times$ width $\times$ total fibre layer thickness).

Knowing the magnitude of all three possible stresses allows assessing their order of occurrence and, consecutively, the identification of the damage modes, according to Table 1. The details of the adopted analytical approach are fully discussed in [13].

After the determination of the damage modes, it is possible to plot the tensile stress-strain curve of hybrid FRP using the characteristic points given in Table 2. In the latter, $E_{\text {sat }}$ is the saturated modulus of the composite (according to equation (5)), $\varepsilon_{\mathrm{H}}$ is the failure strain of the HS fibres, and $\varepsilon_{@ \mathrm{H}-\mathrm{PS}}$ is the strain in the composite at the post-saturation phase when the high strain material fails (according equation (6)) [13].

$$
\begin{aligned}
& E_{\text {sat }}=E_{H} \frac{\alpha \beta+1}{(\beta+1)\left(1+\frac{11}{18} \alpha \beta\right)} \\
& \varepsilon_{@ H-P S}=\frac{\varepsilon_{H}}{K_{t} \sqrt[m_{H}]{V}}-\frac{7}{18} \frac{S_{L} \beta}{E_{H}}
\end{aligned}
$$

In the present work, the definitions of 'yield' stress and pseudo-ductile strain suggested by Jalalvand et al. [13] were considered. Thus, the 'yield' stress is the stress at the point that response deviates from the initial linear elastic line, i.e., equal to $\sigma @ \mathrm{LF}$ and the pseudo-ductile strain is defined as the extra strain between the final failure strain and the strain on the extrapolated initial slope line at the failure stress of the stress-strain diagram (see Figure 1).

In confining applications, FRP is essentially subjected to tensile stress. For this reason, in the present work, $f i$ of different hybrid combinations was computed assuming a modified equation (1):

$$
f_{l}=\frac{2 \sigma_{\text {hybrid }} t_{f r p}}{D}
$$

where $\sigma_{\text {hybrid }}$ is the stress of hybrid FRP for a given tensile strain, assuming that the tensile strain is the same in all layers of the hybrid composites. The stress was computed according to the described stress-strain model of Jalalvand et al. [13]. The length and width of tensile specimens were assumed equal to $L=150 \mathrm{~mm}$ and $W=15$ $\mathrm{mm}$, respectively. The interlaminar toughness, $G_{\mathrm{IIC}}$, for the different hybrid interfaces was estimated, assuming that for combinations with experimental pseudo-ductile behaviour, the fragmentation \& dispersed delamination damage mode was analytically determined (see details in [14]). Weibull modulus of HS fibres was assumed 
constant and equal to the value used by Jalalvand et al. [13], $m_{\mathrm{H}}=29.3$. The value of the stress concentration factor was assumed constant, $K_{t}=0.97$, for all of the specimens. This value is slightly lower than the one used by Jalalvand et al. [13] but it led to the best predictions.

\subsubsection{Lateral strain-to-axial strain relationship}

The prediction of $\varepsilon_{\mathrm{c}}$ based on $f_{i}$ of the FRP-confined concrete is fundamental to estimate $f_{\mathrm{c}}$. According to Lim and Ozbakkaloglu [15], lateral strains of active confined and FRP-confined concrete match, for the same $f$. The use of FRP as passive jacket means that a specific $f_{i}$ is reached for a certain $\varepsilon_{\mathrm{c}}$. This assumption allows developing a model to describe the dilation behaviour of confined concrete, i.e., to describe the evolution of $\varepsilon_{\mathrm{c}}$ with $\varepsilon$, see equation (8) [15]:

$$
\varepsilon_{c}=\frac{\varepsilon_{l}}{v_{i}\left[1+\left(\frac{\varepsilon_{l}}{v_{i} \varepsilon_{c 0}}\right)^{n}\right]^{1 / n}}+0.04 \varepsilon_{l}^{0.7}\left[1+21\left(\frac{f_{l}}{f_{c 0}}\right)^{0.8}\right]
$$

where $v_{\mathrm{i}}$ is the initial Poisson's ratio of concrete $\left(\varepsilon_{\mathrm{l}} / \varepsilon_{\mathrm{c}}\right)[32]$ :

$$
v_{i}=8 \times 10^{-6} f_{c 0}^{2}+0.0002 f_{c 0}+0.138
$$

$\varepsilon_{\mathrm{c} 0}$ is the axial strain at the peak stress $\left(f_{c 0}\right)$ of the unconfined concrete:

$$
\varepsilon_{c 0}=\left(-0.067 f_{c 0}^{2}+29.9 f_{c 0}+1053\right) \times 10^{-6}
$$

$n$ is the curve shape parameter:

$$
n=1+0.03 f_{c 0}
$$

This way, the trend of the lateral strain-to-axial strain relationship of confined concrete is shown to be a function of $f$, type of confining material, and concrete strength. The model described by equation (8) is adopted in the present study.

\subsubsection{Stress-strain model}

The stress-strain model for active confined concrete comprises both an ascending and a descending branch. The former is computed according to equation (12), proposed by Popovics [33], and the latter is computed according to equation (13), proposed by Lim and Ozbakkaloglu [16]:

$$
f_{c}=\frac{f_{c c}^{*}\left(\varepsilon_{c} / \varepsilon_{c c}^{*}\right) r}{r-1+\left(\varepsilon_{c} / \varepsilon_{c c}^{*}\right)^{r}}, \text { if } 0 \leq \varepsilon_{c} \leq \varepsilon_{c c}^{*}
$$




$$
f_{c}=f_{c c}^{*}-\frac{f_{c c}^{*}-f_{c, r e s}}{1+\left(\frac{\varepsilon_{c-}-\varepsilon_{c c}^{*}}{\varepsilon_{c, i}-\varepsilon_{c c}^{*}}\right)^{-2}}, \text { if } \varepsilon_{c}>\varepsilon_{c c}^{*}
$$

where $f_{\text {cc }}^{*}$ and $\varepsilon^{*}$ cc are the peak stress and the peak strain of actively confined concrete $[15,34], r$ is the concrete brittleness [35], $f_{\mathrm{c}, \text { res }}$ is the residual stress [16], and $\varepsilon_{\mathrm{c}, \mathrm{i}}$ is the axial strain corresponding to the inflection point of the descending branch of stress-strain curve [16]:

$$
\begin{aligned}
& f_{c c}^{*}=f_{c 0}+5.2 f_{c 0}^{0.91}\left(\frac{f_{l}}{f_{c 0}}\right)^{a} \text { where } a=f_{c 0}^{-0.06} \\
& \varepsilon_{c c}^{*}=\varepsilon_{c 0}+0.045\left(\frac{f_{l}}{f_{c 0}}\right)^{1.15} \\
& r=\frac{E_{c}}{E_{c}-f_{c c}^{*} / \varepsilon_{c c}^{*}} \\
& f_{c, r e s}=1.6 f_{c c}^{*}\left(\frac{f_{l}^{* 0.24}}{f_{c 0}{ }^{0.32}}\right) \text { and } f_{c, r e s} \leq f_{c c}^{*}-0.15 f_{c 0} \\
& \varepsilon_{c, i}=2.8 \varepsilon_{c c}^{*}\left(\frac{f_{c, r e s}}{f_{c c}^{*}}\right) f_{c 0}^{-0.12}+10 \varepsilon_{c c}^{*}\left(1-\frac{f_{c, r e s}}{f_{c c}^{*}}\right) f_{c 0}^{-0.47}
\end{aligned}
$$

In equation (16), $E_{\mathrm{c}}$ is the elastic modulus of plain concrete [16]:

$$
E_{c}=4400 \sqrt{f_{c 0}}
$$

\subsection{Design-oriented models}

In the present work, ultimate condition models were developed to predict the peak axial stress $\left(f_{\mathrm{cc}}\right)$ and the peak axial strain $\left(\varepsilon_{\mathrm{cc}}\right)$ of hybrid FRP-confined concrete. These are simple linear models based on the general form of the expressions proposed by Richart et al. [36], as usual in the vast majority of works dedicated to non-hybrid FRP-confined concrete [6], for the calculation of ultimate conditions of confined concrete:

$$
\begin{aligned}
& \frac{f_{c c}}{f_{c 0}}=c_{1}+k_{1}\left(\frac{f_{l u}}{f_{c 0}}\right) \\
& \frac{\varepsilon_{c c}}{\varepsilon_{c 0}}=c_{2}+k_{2}\left(\frac{f_{l u}}{f_{c 0}}\right)
\end{aligned}
$$

where $c_{1}$ and $c_{2}$ are calibration constants and $k_{1}$ and $k_{2}$ are strength and strain enhancement coefficients for FRPconfined concrete, respectively.

The tensile strength of all hybrid combinations was predicted according to the model of Jalalvand et al. [13], described in Section 2.1.1.2, and to bilinear ROM:

$$
\sigma_{\text {hybrid }}=\left\{\begin{array}{l}
V_{L} S_{L}+V_{H} E_{H} \varepsilon_{L} ; V_{H}<V_{\text {crit }} \\
V_{H} S_{H} ; V_{H}>V_{\text {crit }}
\end{array}\right.
$$

where $\sigma_{\text {hybrid }}$ is the tensile strength of hybrid composites, $\varepsilon L$ is the failure strain of the LS fibre, $V_{\mathrm{L}}$ and $V_{\mathrm{H}}$ is the volume of low and high strain material. 
From Eq. (22), one realizes that if $V_{\mathrm{H}}$ is lower than the critical value, $V_{\text {crit, }}$, the hybrid composite will fail prematurely. On the contrary, if $V_{\mathrm{H}}$ is higher than $V_{\text {crit, }}$, the hybrid composite will keep its integrity up to the failure of the HS fibres. $V_{\text {crit }}$ was calculated by equating the two branches of equation (23), taking into account that $V_{\mathrm{L}^{+}}$ $V_{\mathrm{H}}=1$, i.e., $V_{\mathrm{L}}$ is equal to $1-V_{\mathrm{H}}$ :

$$
V_{\text {crit }}=\frac{S_{L}}{S_{L}+S_{H}-E_{H} \varepsilon_{L}}
$$

The properties of 1 layer non-hybrid composites were used as input variables for both models (Jalalvand et al. [13] and bilinear ROM [14]).

Analytical tensile strength values were used to compute the ultimate confining pressure, $f_{\text {lu }}$, of different combinations, according to equation (7). This way, it was possible to compute the confinement ratio $\left(f_{\mathrm{l}} / f_{\mathrm{c} 0}\right)$ and to compare the evolution of this ratio with both the strength enhancement $\left(f_{c c} / f_{\mathrm{c} 0}\right)$ and the strain enhancement $\left(\varepsilon_{c c} / \varepsilon_{\mathrm{c} 0}\right)$, resulting in the determination of $c_{1}, c_{2}, k_{1}$ and $k_{2}$.

\section{EXPERIMENTAL PROGRAM}

\subsection{Materials}

\subsubsection{Concrete}

A ready-mix concrete, prepared by an external concrete company, was used in the present work. The maximum aggregate size was $12.5 \mathrm{~mm}$. The experimental campaign of the confined concrete specimens herein described (see details in Section 3.2) was conducted in 15 consecutives working days. During this time, the concrete age varied between 294 and 315 days. Until the testing date, all specimens were kept in standard laboratory conditions (temperature around $20^{\circ} \mathrm{C}$, relative humidity around 50\%). In the end of the experimental campaign, 3 plain cylindrical concrete specimens, with a diameter of $150 \mathrm{~mm}$ and a height of $300 \mathrm{~mm}$, were tested. The mean values of elastic modulus, according to [37], and compressive strength, according to [38], were 30.29 $\mathrm{GPa}(\mathrm{CoV}=6.57 \%)$ and $33.49 \mathrm{MPa}(\mathrm{CoV}=1.33 \%)$, respectively.

\subsubsection{FRP constituents (unidirectional fabrics and epoxy resin)}

Four types of dry UD fabrics, with a similar areal mass of $400 \mathrm{~g} / \mathrm{m}^{2}$, were used in the present study: (i) UD high-modulus (HM) carbon (S\&P C-Sheet 640), (ii) standard-modulus (ST) carbon (S\&P C-Sheet 240), (iii) Eglass (S\&P G-sheet E 90/10) and (iv) basalt (Dalla Betta Group U400B-40-50-03), denoted as “CHM", "C", "G” and "B", respectively. In Table 3 the density, areal mass, fibre layer thickness (areal mass density divided by the 
volumetric mass density), as reported by the manufacture, and the basic tensile properties of the mentioned materials assessed experimentally are presented.

The tensile properties of the fibres were determined according ASTM D3379-75 [39]. For each dry fabric, a large number of single fibres (see the details in Table 3) were randomly taken from the dry fabrics and tested in tension. The initial idea was to test 50 fibres of each fabric. However, during the preparation of tests, it was impossible to prevent the breaking of some fibres. The tests were carried out in a Hounsfield H100KS universal testing machine with a maximum load cell capacity of $2.5 \mathrm{~N}$ (with an accuracy of $\pm 0.2 \%$ of applied force across load cell force range). Fibres were individually assembled in the tensile jig by means of a paper template with a fixed gauge length of $20 \mathrm{~mm}$. Fibre ends were glued to the paper template by an ethyl cyanoacrylate-based adhesive. Then the tab ends were gripped in the jaws of the machine. The paper template was cut across, so that just the fibre was fixed as a continuous length within the jig, before starting the tensile tests. The measurements were performed at a rate of $1.5 \mathrm{~mm} / \mathrm{min}$, until breakage occurred. For each fibre, records of applied load against extension were taken, and using an average mean diameter, determined through the analysis of microscopy images of fibres obtained with Scanning Electronic Microscopy (SEM), the data were converted to stress against strain.

In Table 3 is also presented the tensile proprieties of non-hybrid composites. An epoxy-based resin (S\&P Resin Epoxy 55) was used as matrix for laminating the studied composites. According to the supplier, this epoxy resin has the following main properties [40]: (i) tensile strength of $35.8 \mathrm{MPa}$; (ii) strain failure of 2.3\%; and (iii) elastic modulus of 2.6 GPa. In Table 3 is even possible to observe that elastic modulus of single fibres is lower than the elastic modulus of cured composites. This is due to the fact that in case of composites the tensile properties were evaluated ignoring the contribution of the resin, according to the usual practice of the wet lay-up method and the guidelines [31]. This means that tensile strength was computed considering only the dry fabric thickness which conducted to overestimation of the tensile strength and, consequently, large elastic modulus. Differences of experimental results related to the number layers are due to a size effect, i.e., the higher probability of finding a cluster of weaker fibre in a larger volume of material [21].

\subsection{Test specimens}

In the present work, a total of 63 cylindrical specimens, comprising 48 hybrid FRP-confined specimens, 12 non-hybrid FRP-confined specimens and 3 unconfined specimens (referred to in Section 3.1.1), were prepared and tested under monotonic uniaxial compression. Each specimen was $150 \mathrm{~mm}$ in diameter and $300 \mathrm{~mm}$ in height. The experimental variables included (i) the LS fibres relative volume (vol\%) and (ii) the type of FRP of jacket. 
All possible symmetrical hybrid FRP combinations up to 5 layers were applied as confining material. Whenever possible, LS layers were sandwiched between HS layers. In total, 16 hybrid series were considered: 12 combinations with 3 reinforcing material layers and 6 combinations with 5 reinforcing material layers. Each series was composed of 3 specimens of confined concrete. The combinations of 3 symmetrical layers allowed to analyse the following approximate levels of LS fibres vol $\%: 0 \%, 33 \%, 66 \%$ and $100 \%$. In addition, combinations with 5 layers allowed to analyse the following approximate levels of LS fibres vol\%: $20 \%, 40 \%$ and $60 \%$. It should be noted that specimens with 5 layers were only tested on 2 hybrid combinations: HM carbon/glass and ST carbon/glass. In addition to hybrid series, 4 series of non-hybrid composites (1 for each reinforcing material) were produced with 3 layers. All the specimens involved in the experimental campaign are resumed in Table 4 . In the present work, in case of composite materials nomenclature, numbers placed before letters are used for indicating number of layers. The sequence according to which these letters appear indicate the stacking sequence of the reinforcing materials. The UD fabrics had slightly different thicknesses and, for this reason, the relative volume of LS fibres (Vol\% LS) was computed in the next sections, according to Equation (24):

$$
\text { Vol\% } L S=\frac{t_{L}}{t_{L}+t_{H}} \times 100
$$

where $t_{\mathrm{L}}$ is the half thickness of the LS layers and $t_{\mathrm{H}}$ is the half thickness of the HS layers.

\subsection{Specimen manufacturing and test setup}

In order to ensure concentric loading and distributed stress throughout the cross-section during the test, both ends of each cylinder were capped. Furthermore, the entire lateral surface of each confined specimen was roughened with an angle grinder and then cleaned with a compressed air blower in order to improve bonding between the jacket and the concrete.

Before the application of the jacket, dry fabrics pieces with $620 \mathrm{~mm}$ in fibre direction and $300 \mathrm{~mm}$ in perpendicular direction were cut. The total length allowed an overlap length of $150 \mathrm{~mm}$, being this value suggested and adopted by other authors $[10,41,42]$ and it has been proved to prevent FRP debonding failure during tests. The FRP jacket was manufactured by wet lay-up method, following the best practices suggested in [31], according to the following protocol: (i) application of a layer of epoxy resin over the dry concrete surface with a brush; (ii) saturation of the fabric layer with epoxy resin; (iii) application of an FRP layer over the epoxy resin wetted concrete surface, adjusting it manually; (iv) pressure application by means of a ribbed rigid roller, in order to expel both the epoxy resin excess and air in the composite, and also stretching the latter; (v) repetition of steps ii to iv for 
subsequent layers, avoiding coincidence between overlap zones of different layers. All the specimens were then cured at room laboratory for 230 days.

Axial deformations of the specimens were measured with 3 linear variable displacement transducers (LVDTs), which were positioned, equally spaced around the specimen, between the steel plates of the universal testing machine (UTM), with $2000 \mathrm{kN}$ capacity, as shown in Figure 2. In this case, the measured displacements using full-height LVDTs were amplified because deformations of the testing machine parts and closure of the gaps in the setup were considered. For this reason, the results of three mid-height LVDTs measurements applied directly on plain concrete specimens, using an aluminium ring, were considered to correct the full-height LVDTs measurements of all specimens, as also adopted in [42]. As illustrated in Figure 3, the lateral strains were measured by 3 or 5 unidirectional $5 \mathrm{~mm}$ gauge length strain gauges (one for each layer of fabric). These were bonded to the FRP equally spaced along the circumference.

The specimens were tested under axial compression using a UTM at room temperature. The loading force was applied to the specimen at a displacement rate of $1.20 \mathrm{~mm} / \mathrm{min}$. up to failure.

\section{RESULTS AND DISCUSSION}

\subsection{Non-hybrid FRP-confined concrete}

\subsubsection{Ultimate conditions}

The summary of the test results of each series of non-hybrid FRP-confined concrete are shown in Table 5, which include the mean peak axial stress $\left(f_{\mathrm{cc}}\right)$, the peak axial strain $\left(\varepsilon_{\mathrm{cc}}\right)$, strength enhancement $\left(f_{\mathrm{cc}}\left(f_{\mathrm{co}}\right)\right.$, the strain enhancement $\left(\varepsilon_{\mathrm{cc}} / \varepsilon_{\mathrm{c} 0}\right)$, and the FRP strain reduction factor $\left(k_{\varepsilon, \text { frp }}\right)$. It should be noted that the unconfined concrete strain $\left(\varepsilon_{\mathrm{c} 0}\right)$ was computed according equation (10) and $k_{\varepsilon, \text { frp }}$ was computed according to equation (25):

$$
k_{\varepsilon, f r p}=\frac{\varepsilon_{l, r u p}}{\varepsilon_{f r p}}
$$

where $\varepsilon 1$, ,rup is the FRP lateral strain at failure, assessed in the test of cylinders, and $\varepsilon_{\mathrm{frp}}$ is the FRP strain at failure, assessed with tensile tests. The latter were previously presented, in Table $\mathbf{3}$, for composites with 3 layers. The $\varepsilon$,rup is the mean value of the maximum lateral strain values of each series.

Comparing Table 3 and Table 5, it is possible to observe that, in general, larger tensile strengths of FRP materials imply larger $f_{c c}$ and $\varepsilon$, rup. However, this tendency is affected by the reduction of efficiency relative to the strain at failure of FRP applied in the jacking, characterised by the reduction factor. The computed reductions factors varied between 0.72 , for the $3 \mathrm{CHM}$ series, and 0.96 , for the $3 \mathrm{C}$ series. Although a reduction of strain at 
failure of FRP materials has been observed in all cases, apparently the basalt and HM carbon composites were the most affected. Lim and Ozbakkaloglu [8] indicate that reductions factors vary with the elastic modulus of FRP composite, but this tendency was not evidenced in the present work. Similar reductions factors were obtained for FRP composites with very different elastic modulus (e.g. glass and ST carbon). The reduction factor is discussed for hybrid jacketing in Section 4.2.1. Relatively to $\varepsilon_{\mathrm{cc}}$, no evident tendency was observed.

In Figure 4, the dispersion of the obtained results and their mean values are plotted. Very similar results were obtained with glass and basalt combinations. The $t$ statistical test (t-test) was adopted to assess whether the mean values of these two materials are statistically different from each other. The results are exposed using the $p$ value. This value varies between 0 and 1 and it is the smallest level of significance that would lead to rejection of the null hypothesis (in the present case, the null hypothesis is that the mean value of glass equals the mean value of basalt). In turn, the level of significance is the probability of rejecting the null hypothesis when it is true. The computed $p$-values for $f_{c c}, \varepsilon_{\mathrm{cc}}$, and $\varepsilon \varepsilon_{\text {,rup }}$ were $0.952,0.386$, and 0.230 , respectively. Given the large computed $p$ values (above 0.05), it can be stated that the null hypothesis cannot be rejected, i.e., glass and basalt lead to identical results.

\subsubsection{Dilation behaviour and axial stress-strain behaviour}

The analysis-oriented model of Lim and Ozbakkaloglu $[15,16]$ was developed to predict the compressive stress-strain curve of non-hybrid FRP-confined concrete. The aim of the work described in this section was to validate (or not) the developed approach for the set of materials and fabrication method used in the present work.

Results of non-hybrid FRP with 3 layers, presented in Table 3, were used as input variables to compute $f$, according to equation (1). The lateral strain at failure of the different material combinations was assumed as the mean of the corresponding experimental values. The diameter of all specimens was assumed as $D=150 \mathrm{~mm}$ and $f_{\mathrm{c} 0}=33.49 \mathrm{MPa}$ was used as input variable in equations (8) to (19).

In Figure 5 and Figure 6 the lateral strain-axial strain curves (dilation behaviour) and the compressive stress-strain curves of non-hybrid FRP-confined concrete are presented, respectively. In the specimen designation, the last number (i.e., 1, 2 or 3) was used to make the distinction between the three identical specimens. Furthermore, analytical curves are also plotted to allow the comparison with the corresponding experimental curves. A good agreement between theoretical and experimental results is observed. 
The analysis of the lateral strain-axial strain curves show that these typically present an initial slope, in agreement with initial Poisson's ratio of concrete (equation (18)). Moreover, this initial phase is similar for all combinations. After the compressive stress-strain peak of plain concrete $\left(f_{\mathrm{c} 0}, \varepsilon_{\mathrm{c} 0}\right)$, microcracking initiation and propagation occurs and leads to a rapid increase of the lateral strain [15]. The different applied confining materials induce different confining pressures leading to different trends after stress-strain peak of the plain concrete (see Figure 6). The development of the compressive stress-strain curves follows approximately a bilinear law, where the slope of the first branch depends primarily on the properties of plain concrete, whereas the slope of the second (hardening branch) is controlled by the confining pressures induced by the jacket. It can be observed that the higher the FRP elastic modulus, the higher the slope of the hardening branch. It is evident that, when HM carbon is used in jacketing, the highest slope of the hardening branch is achieved (Figure 6(d)). However, the low lateral strain efficiency of this material make it the worst to use in the non-hybrid jacketing, since the lowest $f_{\mathrm{cc}}$ and $\varepsilon_{\mathrm{cc}}$ are achieved with this combination. For other hand, the highest $f_{\mathrm{cc}}$ and $\varepsilon_{\mathrm{cc}}$ are achieved with ST carbon jacketing (Figure 6(c)).

The typical failure modes the non-hybrid FRP-confined specimens tested are illustrated in Figure 7. It is possible to observe from the figure, that all specimens failed by the FRP jacket rupture. All the failures occurred in an abrupt way, with a rapid release of energy characterized by the projection of small concrete fragments. The failure occurred approximately at mid-height of the specimens, except in the case of HM carbon jackets in which a full height failure occurred.

\subsection{Hybrid FRP-confined concrete}

\subsubsection{Ultimate conditions}

Table 6 presents the elastic modulus, tensile strength, and failure strain of LS fibres of cured hybrid composite materials; the peak axial stress $\left(f_{c c}\right)$, the strength enhancement $\left(f_{\mathrm{cc}}\left(f_{\mathrm{co}}\right)\right.$, the peak axial strain $\left(\varepsilon_{\mathrm{cc}}\right)$, the strain enhancement $\left(\varepsilon_{\mathrm{cc}} / \varepsilon_{\mathrm{c} 0}\right)$, the lateral failure strain of LS fibres, the lateral strain of HS fibres (for the cases that composites keep their integrity beyond the LS fibres failure; and the strain reduction factor of LS fibres of hybrid FRP-confined concrete.

As expected, from Table 6, it can be observed that, in similar combinations, the replacement of ST carbon by HM carbon resulted in significate reductions of $f_{c c}$ and $\varepsilon_{c c}$ because, as it is shown in Table 3, HM series tensile results are lower than ST series results. Analysing the strength enhancement $\left(f_{\mathrm{cc}} / f_{\mathrm{c} 0}\right)$ of combinations of ST carbon with glass and HM carbon with glass, it is possible to note that the results varied between 2.44 and 3.57, for the 
first case, and 1.63 and 2.40 , for the second case. Relatively to strain enhancement $\left(\varepsilon_{\mathrm{cc}} / \varepsilon_{\mathrm{c} 0}\right)$, it is possible to verify that similar observation can be done, the results varied between 6.15 and 10.65 for the combinations of ST carbon with glass, and between 1.95 and 6.10 for the combination of HM carbon with glass. In this way, the use of HM carbon conducts to the worst $f_{c c}$ and $\varepsilon_{\mathrm{ccc}}$. However, the use of HM carbon in some hybrid combination allow to avoid premature failures of the composite. This happens because HM carbon have a low tensile strength and, for this reason, the stress level at which the first failure in HM carbon material occurs is not sufficient to release significant amounts of energy that lead to catastrophic delamination or high strain material failure [43]. Catastrophic failures of the composite were avoided in five combinations $(2 \mathrm{G} / 1 \mathrm{CHM} / 2 \mathrm{G}, 1 \mathrm{G} / 1 \mathrm{CHM} / 1 \mathrm{G}$, 1G/1CHM/1G/1CHM/1G, 1B/1CHM/1B and 1C/1CHM/1C) exposed in Table 6. In these cases it was possible to present two values: (i) the lateral failure strain of LS fibres and (ii) the lateral failure strain of HS fibres. This is according to the tensile test results presented in [14], in which catastrophic failures were avoided exactly in the same combinations. A detailed discussion of these results is presented in Section 4.2.3.

From Table 6, it can also be observed that, for each combination, failure strain of LS fibres increases with the decrease of LS fibres vol\%. This tendency is reflected in the strain reduction factor that as well increases as the volume of LS fibres decreases. In some cases, the strain reduction factor is higher than 1, which proves that hybridisation, discussed in Section 4.2.2, allows to fully eliminate the reduction of LS fibres strain efficiency.

The same table reveals that the failure strain of HS fibres is significantly lower in hybrid than in non-hybrid jacketing. Sometimes, this is observation has been done even in tensile tests of hybrid composites [43]. Since no substantiated explanation exists today in literature, this subject should be further investigate. Moreover, the failure strain of HS fibres appears to increase as the volume of LS fibres decreases.

The relationship between the confinement ratio $\left(f_{\mathrm{lu}} / f_{\mathrm{c} 0}\right)$ and the strength enhancement $\left(f_{c c} / f_{\mathrm{c} 0}\right)$, as well as the relationship between the confinement ratio and the strain enhancement $\left(\varepsilon_{c c} / \varepsilon_{c 0}\right)$, are presented in Figure 8 and Figure 9, respectively. The $f_{\text {lu }}$ was established based on the $\sigma_{\text {hybrid }}$ input computed according the model of Jalalvand et al. [13] and the bilinear ROM model [14]. In the present work, the $\sigma_{\text {hybrid }}$ is designated J- $\sigma_{\text {hybrid }}$, in the cases that the value was computed according to the model of Jalalvand et al. [13], and B- $\sigma_{\text {hybrid }}$, in the cases that the value was computed according to the bilinear ROM model [14]. In Figure 8 and Figure 9 the corresponding linear regression models (design-oriented models) and their coefficient of determination $\left(R^{2}\right)$ are also presented. Relatively large values of $R^{2}(0.84$ and 0.80$)$ were found between predictions of $f_{c c} / f_{\mathrm{c} 0}$ and the corresponding experimental values. The resulting regression models are in fact very similar to the Lam and Teng [11] model, 
referred to in [6] as the most accurate model to predict the strength of non-hybrid confined concrete. Relatively to $\varepsilon_{c c} / \varepsilon_{c 0}$ predictions, lower values of $R^{2}(0.62)$ in both cases were achieved.

The tensile strength of the composite of all hybrid combinations, ultimate confining pressure, peak axial stress and peak axial strain predictions are presented in Table 7. For $f_{c c}$ predictions, the relative error varied between $-13.3 \%$ and $18.1 \%$, when $f_{\mathrm{u}}$ values were computed based on $\mathrm{J}-\sigma_{h y b r i d}$, and varied between $-18.6 \%$ and $16.7 \%$, when $f_{\mathrm{u}}$ values were computed based on B- $\sigma_{\text {hybrid. }}$. This error magnitude (maximum absolute value of $20 \%$ ) is acceptable and is in agreement with other published studies [6]. Thus, it can be stated that both models (Jalalvand et al. [13] and bilinear ROM [14]) can be used to accurately predict $f_{\mathrm{u}}$ and, consequently, the $f_{\mathrm{cc}}$.

For $\varepsilon_{c c}$ predictions the obtained relative errors varied between $-104.0 \%$ and $29.8 \%$, when $f_{\mathrm{lu}}$ values were computed based on $\mathrm{J}-\sigma_{\text {hybrid }}$, and varied between $-115.7 \%$ and $25.6 \%$, when $f_{\mathrm{u}}$ values were computed based on the B- $\sigma_{h y b r i d}$. With this error magnitude, it can be stated that the suggested models cannot be used to predict $\varepsilon_{c c}$. This statement is in agreement with the bibliography [6]. In fact, usually, the relative errors associated to $\varepsilon_{c c} / \varepsilon_{c 0}$ predictions are much higher than those associated to $f_{c c} / f_{c 0}$ predictions [6] and, for this reason, some authors propose a model for the peak stress only [6].

\subsubsection{Hybrid effect}

In the present work, different ways of computing the hybrid effect were considered, varying the numerator and denominator of equation (26):

$$
\text { Hybrid effect }=\frac{\Delta \varepsilon_{L}}{\varepsilon_{L}} \times 100
$$

where $\Delta \varepsilon_{L}$ is the absolute variation between the strain of LS material at failure in hybrid and non-hybrid composites and $\varepsilon_{L}$ is the reference strain of the non-hybrid LS composite at failure.

Firstly, the hybrid effect was computed only considering tensile tests results. In this case, the failure strain values of both 1 and 3 layers non-hybrid composites, presented in Table 3, were assumed as reference to compute the hybrid effect. Secondly, the hybrid effect of lateral strains, registered in compression tests, was computed considering 3 reference failure strain values: the failure strain results of both 1 and 3 layers non-hybrid composites and the lateral failure strain of the 3 layers jacket, presented in Table 5. The different values obtained are presented

\section{in Table 8.}

Associations between hybrid effects computed according cited different ways were analysed by a Spearman's rank test, using SPSS version 23 [44]. Spearman's correlation coefficient, $r$, is a statistical measure of 
the "strength" of a monotonic relationship between paired data [45]. Additionally, associations between the hybrid effects and the FRP strain reduction factor were also analysed. Results are presented in Table 9. The $p$-value are also presented in Table 9. In this case, the null hypothesis is defined as: there is no monotonic correlation between the variables. When very low $p$-values (below 0.05 ) are presented the null hypothesis should be reject, i.e., there is evidences to believe that variables are monotonically correlated. In the same table, $\mathrm{N}$ is the number of considered different hybrid composite combinations.

Spearman's rank of data revealed both moderately strong (above 0.5 ) and strong (above 0.7 ) correlations between all ways of calculating the hybrid effect. As expected, this indicate that the magnitude of hybrid effect depends on the considered reference strain to failure of LS fibres.

Excluding the correlation between the hybrid effect (computed using the failure strain obtained with 3 layers non-hybrid composite as reference) and FRP strain reduction factor, moderately strong (above 0.5) and strong (above 0.7) correlations exist as well between hybrid effects and FRP strain reduction factors. This proves that the hybrid effect actually contributes to eliminate the reduction of the FRP strain efficiency. This is clear from Figure 10, in which it is possible to observe that the uniaxial failure strains of LS fibres are almost coincident with the lateral failure strain of LS fibres, for all of the analysed hybrid FRP combinations.

\subsubsection{Dilation behaviour and axial stress-strain behaviour}

Lateral strain-axial strain curves (dilation behaviour) of hybrid FRP-confined concrete can be significantly different of the ones obtained in non-hybrid cases. Figure 11 illustrate the different stages observed on a lateral strain-axial strain curves of the specimens exhibiting pseudo-ductile behaviour. The different stages are marked on this curve. It is possible to observe that the first two branches of the curve are very similar to the curve obtained for the non-hybrid cases, i.e., there is an initial phase, herein named first ascending branch, that depends on Poisson's ratio of concrete (equation (18)) and next, from approximately stress-strain peak of plain concrete $\left(f_{\mathrm{c} 0}\right.$, $\varepsilon_{\mathrm{c} 0}$ ), a second ascending branch in which microcrack initiation and propagation occurs resulting in a rapid increase in the lateral strain. After, in specimens with pseudo-ductile behaviour, a last branch, which corresponds to the flat-topped stress-strain curve observed in monotonic tensile tests of hybrid FRP, can be achieved, after the failure of LS fibres.

Experimental lateral strain-axial strain curves of hybrid FRP-confined concrete as well as the corresponding analytical curves are plotted in Figure 12 to Figure 16. In general, there is a good agreement between predicted 
and measured values. In combination $1 \mathrm{C} / 1 \mathrm{~B} / 1 \mathrm{C}$, there are two outlier experimental results which were ignored because they are abnormally low.

It is possible to notice that, in most part of the cases, hybrid FRP-confined concrete has a behaviour similar to that of non-hybrid FRP-confined concrete. As explained before, the different applied confining materials induce different confining pressures leading to curves exhibiting different trends after stress-strain peak of plain concrete $\left(f_{\mathrm{c} 0}, \varepsilon_{\mathrm{c} 0}\right)$. This similarity between hybrid and non-hybrid behaviours exists because almost all the analysed hybrid combinations have premature tensile failure modes of the HS fibres [14], i.e., the tensile behaviour of these hybrid combinations is linear elastic up to failure. However, in 3 hybrid combinations, pseudo-ductile behaviour with simultaneous multiple fractures of LS fibres and dispersed delamination occurred in tensile tests, namely in 2G/1CHM/G, 1G/1CHM/1G, and 1B/1CHM/1B combinations [14]. The corresponding lateral strain-axial strain curves of the combinations referred to (Figure 12(a), Figure 12(b), Figure 14(a)) show a last branch that corresponds to the flat-topped stress-strain curve observed in monotonic tensile tests. According to [14], it was expected that the same behaviour occurred in $1 \mathrm{C} / 1 \mathrm{CHM} / 1 \mathrm{C}$ combination (Figure 16(a)). However, in this combination apparently very short pseudo-ductile branches took place that, in practice, lead to the consideration that premature failure of HS fibres occurred. This is according to the fact that in this combination a low lateral failure strain of HS fibres $(0.61 \%)$ was registered (see Table 6). For this reason, the hybrid FRP failure of composite occurs too soon.

As discussed in [14], tensile tests of $1 \mathrm{G} / 1 \mathrm{CHM} / 1 \mathrm{G} / 1 \mathrm{CHM} / 1 \mathrm{G}$ combination reveals that failure mode is in a transition zone, for this reason, it is expected that there is some random alternation between catastrophic delamination and premature HS fibres failure modes (see Figure 12(c)).

The compressive stress-strain curves are presented in Figure 17 to Figure 21. It can be seen in these that there is as well a good agreement between predicted and measured values. Similarly to non-hybrid cases, most curves development follows approximately a bilinear law. However, an approximately flat-topped curve is evident in Figure 17(a), Figure 17(b) and Figure 19(a). This was expected because in 3 used hybrid combination $(2 \mathrm{G} / 1 \mathrm{CHM} / \mathrm{G}, 1 \mathrm{G} / 1 \mathrm{CHM} / 1 \mathrm{G}$, and 1B/1CHM/1B) a pseudo-ductile behaviour occurred in tensile tests [14]. However, this plateau exhibits a slight hardening component, which is not captured by the model. In tensile test results, it has been already observed some hardening at the 'yielding' plateau [14], which again confirms the relationship between $f_{i}$ and $f_{\mathrm{c}}$. In compressive stress-strain curve obtained with $1 \mathrm{~B} / 1 \mathrm{CHM} / 1 \mathrm{~B}$ combination, the extension of the predicted plateau is significantly lower than the experimental one. This is due to a slight 
overestimation of lateral failure strain of LS fibres, which defines the 'yield' point, as it can be seen in Figure 14(a).

Comparing HM carbon/glass and HM carbon/basalt (Figure 17 and Figure 19) with ST carbon/glass and ST carbon/basalt confined concrete results (Figure 18 and Figure 20), it is possible to notice that the formers lead to the worst $f_{\mathrm{cc}}$ and $\varepsilon_{\mathrm{cc}}$ values. The previous observation make sense because ST carbon have higher tensile strength than HM carbon composite, which lead to major $f_{\mathrm{lu}}$ and, consecutively, to larger $f_{\mathrm{cc}}$ and $\varepsilon_{\mathrm{cc}}$.

The HM carbon/glass and ST carbon/glass confined concrete failure modes are illustrated in Figure 22 and Figure 23. It was decided to show these combinations because the translucence of the glass allow to visualize the possible fragmentation and delamination that may occur in LS material. As expected, fragmentation is evident in 2G/1CHM/2G (Figure 22(a) and Figure 22(b)) and 1G/1CHM/1G (Figure 22(c)) jackets because they promoted pseudo-ductile behaviours. In these combinations, the specimens were initially black due to the carbon natural colour but, after fragmentation and delamination, light was reflected from the interface, and these zones of specimens looked white, as it is marked in the figures. In the remaining cases, there are no evidences of fragmentation of LS material.

With exception of two cited cases $(2 \mathrm{G} / 1 \mathrm{CHM} / 2 \mathrm{G}$ and $1 \mathrm{G} / 1 \mathrm{CHM} / 1 \mathrm{G})$ in which fragmentation took place, all specimens failed explosively with the projection of small concrete fragments. Again, the jacket with highest elastic modulus (1CHM/1G/1CHM) promoted an almost a full height failure.

\section{CONCLUSIONS}

The compression behaviour of several hybrid FRP-confined small-scale plain concrete columns has been investigated using experimental testing and analytical modelling. All the jackets were made through the hand lamination of four different commercially available dry UD fabrics: HM carbon (CHM), ST carbon (C), E-glass (G) and basalt (B). Typically in the literature this technique is called externally bonded reinforcement (EBR) with wet lay-up systems. Additionally to hybrid FRP series, few non-hybrid confined concrete columns were also analysed in order to obtain reference values. Main observations and conclusions drawn are presented next.

Analysing non-hybrid FRP-confined concrete results, a minimum FRP strain reduction factor of 0.72 and a maximum of 0.96 were achieved respectively in the CHM and C series. This way, it was concluded that FRP tensile strain at failure is not reachable in situ with FRP jackets. However, it was demonstrated that this reduction of efficiency can be minimized, or even eliminated, with hybridisation. In fact, it was observed that for a large number of hybrid combinations the strain reduction factor was even higher than 1 . It was verified that moderately 
strong (above 0.5 ) and strong (above 0.7) correlations exist between the hybrid effect and the FRP strain reduction factor. This means that there is an increase of the strain reduction factor as the volume of LS fibres decreases, i.e, hybrid effect increases.

Two models to predict the tensile strength of hybrid FRP were adopted, namely the model of Jalalvand et al. [13] and bilinear ROM [14] and it was proven that these can be used to accurately predict the ultimate confining pressure provided by the hybrid composites. Consequently, two new design-oriented models, in which the confining pressure is used as input variable, were proposed to predict the peak stress of hybrid FRP-confined concrete. Relatively large $\mathrm{R}^{2}$ of 0.84 and 0.80 were found in predictions of peak axial stress with the proposed models, respectively, for first and second models.

In the three tested hybrid combinations, which included HM carbon as LS material $(2 \mathrm{G} / 1 \mathrm{CHM} / \mathrm{G}$, $1 \mathrm{G} / 1 \mathrm{CHM} / 1 \mathrm{G}$ and $1 \mathrm{~B} / 1 \mathrm{CHM} / 1 \mathrm{~B})$, pseudo-ductile tensile responses with fragmentation and dispersed delamination of the jacket were observed, leading that, in the compressive stress-strain curves of these combinations, a flat-topped curve is evident. In these combinations abrupt and explosive failure modes were avoided.

Finally, the presented analysis-oriented confinement model, based on the modification of the approach of Lim and Ozbakkaloglu $[15,16]$, allowed to accurately simulate both the dilation behaviour and the compressive stress-strain behaviour of all hybrid confined concrete series analysed.

It should be noted that the results obtained with small-scale cylinders of hybrid FRP-confined concrete cannot be taken as representative of large scale concrete columns. Although the obtained results regarding concrete behaviour are an important part of the overall input required for the structural analysis of concrete structures, further work needs to be conducted in large scale specimens before hybrid composites can be implemented in real cases.

\section{Acknowledgments}

The authors wish to thank to FCT - Portuguese Foundation for Science and Technology and to the Doctoral Program Eco-Construction and Rehabilitation for supporting the PhD grant (PD/BD/52660/2014). Acknowledgements are extended to the following programs that partially supported the study herein presented: European Funds for Regional Development (FEDER) through the Operational Program for Competitiveness Factors (COMPETE), Operational Program for Competitiveness and Internationalization (POCI), and again FCT through both FRPLongDur POCI-01-0145-FEDER-016900 (FCT reference PTDC/ECM-EST/1282/2014) and 
POCI-01-0145-FEDER-007633 projects. Last but not least, the authors also acknowledge the support of S\&P Clever Reinforcement Ibérica Lda and the Dalla Betta Group Company. 
Ribeiro, F.; Sena-Cruz, J.; Branco, F.; Júlio, E. (2018) "Hybrid FRP jacketing for enhanced confinement of circular concrete columns in compression." Construction \& Building Materials, 184: 681-704.

\section{REFERENCES}

[1] Pellegrino C, Sena-Cruz J. Design Procedures for the Use of Composites in Strengthening of Reinforced Concrete Structures. State-of-the-Art Report of the RILEM Technical Committee 234-DUC, Springer, ISBN $978-$ 94-017-7335-5. 2016.

[2] Bank L. Composites for Construction - Structural Design with FRP Materials. John Wiley \& Sons, Inc. 2006.

[3] Zheng J, Ozbakkaloglu T. Sustainable FRP-recycled aggregate concrete-steel composite columns: Behavior of circular and square columns under axial compression. Thin-Walled Structures. 2017;120(Supplement C):60-9. [4] Vincent T, Ozbakkaloglu T. Influence of fiber orientation and specimen end condition on axial compressive behavior of FRP-confined concrete. Construction and Building Materials. 2013;47(Supplement C):814-26.

[5] Ozbakkaloglu T. Compressive behavior of concrete-filled FRP tube columns: Assessment of critical column parameters. Engineering Structures. 2013;51(Supplement C):188-99.

[6] Ozbakkaloglu T, Lim JC, Vincent T. FRP-confined concrete in circular sections: Review and assessment of stress-strain models. Engineering Structures 2013;49 1068-88.

[7] Ozbakkaloglu T, Lim JC. Axial compressive behavior of FRP-confined concrete: Experimental test database and a new design-oriented model. Composites: Part B. 2013;55:607-34.

[8] Lim JC, Ozbakkaloglu T. Confinement Model For FRP-Confined High-Strength Concrete. Journal of Composites for Construction doi:101061/(ASCE)CC1943-56140000376. 2013.

[9] Lim JC, Ozbakkaloglu T. Design model for FRP-confined normal- and high-strength concrete square and rectangular columns. Magazine of Concrete Research. 2014;66(20):1020-35.

[10] Lim J, Ozbakkaloglu T. Hoop strains in FRP-confined concrete columns: experimental observations. Materials and Structures DOI 101617/s11527-014-0358-8. 2014.

[11] Lam L, Teng JG. Design-oriented stress-strain model for FRP-confined concrete. Constr Build Mater. 2003;17(6-7):471-89.

[12] Wu Y-F, Jiang J-F. Effective strain of FRP for confined circular concrete columns. Composite Structures. 2012;95:479-91.

[13] Jalalvand M, Czél G, Wisnom MR. Damage analysis of pseudo-ductile thin-ply UD hybrid composites - A new analytical method. Composites: Part A. 2015;69:83-93.

[14] Ribeiro F, Sena-Cruz J, Branco FG, Júlio E. Hybrid effect and pseudo-ductile behaviour of unidirectional interlayer hybrid FRP composites for civil engineering applications. Construction and Building Materials. 2018;171:871-90.

[15] Lim JC, Ozbakkaloglu T. Lateral Strain-to-Axial Strain Relationship of Confined Concrete. Journal of Structural Engineering. 2014;141(5).

[16] Lim JC, Ozbakkaloglu T. Unified Stress-Strain Model for FRP and Actively Confined Normal-Strength and High-Strength Concrete. Journal of Composites for Construction, ASCE, ISSN 1090-0268/04014072 (14). 2014.

[17] Czél G, Wisnom MR. Demonstration of pseudo-ductility in high performance glass/epoxy composites by hybridisation with thin-ply carbon prepreg. Composites: Part A: Applied Science and Manufacturing. 2013;52:2330.

[18] Jalalvand M, Czél G, Wisnom MR. Numerical modelling of the damage modes in UD thin carbon/glass hybrid laminates. Composites Science and Technology. 2014;94:39-47.

[19] Jalalvand M, Czél G, Wisnom MR. Parametric study of failure mechanisms and optimal configurations of pseudo-ductile thin-ply UD hybrid composites. Composites: Part A. 2015; 74:123-31.

[20] Czél G, Jalalvand M, Wisnom MR. Design and characterisation of advanced pseudo-ductile unidirectional thin-ply carbon/epoxy-glass/epoxy hybrid composites. Composite Structures. 2016;143:362-70.

[21] Wisnom MR, Czél G, Swolfs Y, Jalalvand M, Gorbatikh L, Verpoest I. Hybrid effects in thin ply carbon/glass unidirectional laminates: Accurate experimental determination and prediction. Composites: Part A. 2016;88:1319.

[22] Yu H, Longana ML, Jalalvand M, Wisnom MR, Potter KD. Pseudo-ductility in intermingled carbon/glass hybrid composites with highly aligned discontinuous fibres. Composites: Part A 2015;73:35-44.

[23] Swolfs Y, Gorbatikh L, Verpoest I. Fibre hybridisation in polymer composites: a review. Composites Part A: Applied Science and Manufacturing. 2014;67:181-200.

[24] Hayashi T. On the improvement of mechanical properties of composites by hybrid composition. Proc 8th Intl Reinforced Plastics Conference. 1972:149-52.

[25] Wu G, Wu ZS, Lu ZT, Ando YB. Structural Performance of Concrete Confined with Hybrid FRP Composites. Journal of reinforced plastics and composites. 2008;27(12).

[26] Luca AD, Nardone F, Matta F, Nanni A, Lignola GP, Prota A. Structural Evaluation of Full-Scale FRPConfined Reinforced Concrete Columns. J Compos Constr. 2011;15:112-23. 
[27] Li L-J, Xu S-D, Zeng L, Guo Y-C. Study on mechanical behavior of circular concrete columns confined by HFRP under axial compressive load. Research and Applications in Structural Engineering, Mechanics and Computation - Zingoni (Ed) Taylor \& Francis Group, London, ISBN 978-1-138-00061-2. 2013.

[28] Long Y-L, Zhu J. Experimental Study on Concrete Columns with Various Sizes Confined by BFRP and hybrid FRP under Axial Compression. Advanced Materials Research. 2014;838-841:407-11.

[29] Deng Z-c, Qu J-l. The Experimental Studies on Behavior of Ultrahigh-Performance Concrete Confined by Hybrid Fiber-Reinforced Polymer Tubes. Advances in Materials Science and Engineering, Article ID 201289, 18 pages. 2015.

[30] Tamuzs V, Tepfers R, Zile E, Ladnova O. Behavior of concrete cylinders confined by a carbon composite III: deformability and the ultimate axial strain. Mech Compos Mater. 2006;42(4):303-14.

[31] CNR-DT200. Guide for the Design and Construction of Externally Bonded FRP Systems for Strengthening Existing Structures. Advisory Committee on Techincal Recommendations for Construction, National Research Council, Rome, Italy. 2013.

[32] Candappa DC, Sanjayan JG, Setunge S. Complete Triaxial Stress-Strain Curves of High-Strength Concrete. Journal of Materials in Civil Engineering. 2001;13(3):209-32.

[33] Popovics S. A Numerical Approach to the Complete Stress-Strain Curves for Concrete. Cement and Concrete Research. 1973;3(5):583-99.

[34] Lim JC, Ozbakkaloglu T. Stress-strain model for normal- and light-weight concretes under uniaxial and triaxial compression. Construction and Building Materials. 2014;71(Supplement C):492-509.

[35] Domingo JC, Kuang-Han C. Stress-Strain Relationship for Plain Concrete in Compression. Journal Proceedings.82(6).

[36] Richart F, Brandtzaeg A, Brown R. A study of the failure of concrete under combined compressive stresses. Bulletin no 185, Engineering Experimental Station, University of Illinois. 1928.

[37] CEN. EN 12390-13:2013 - Testing hardened concrete - Part 13: Determination of secant modulus of elasticity in compression. 2013.

[38] CEN. EN 12390-3:2009 - Testing hardened concrete - Part 3: Compressive strength of test specimens. 2009.

[39] ASTM. D 3379 - 75 - Standard Test Method for Tensile Strength and Young's Modulus for High-Modulus Single-Filament Materials. 1989.

[40] S\&P. Technical Data Sheet S\&P Resin 55. 2015.

[41] Lim JC, Ozbakkaloglu T. Influence of silica fume on stress-strain behavior of FRP-confined HSC. Construction and Building Materials. 2014;63(Supplement C):11-24.

[42] Lim JC, Ozbakkaloglu T. Influence of concrete age on stress-strain behavior of FRP-confined normal- and high-strength concrete. Construction and Building Materials. 2015;82(Supplement C):61-70.

[43] Czél G, Jalalvand M, Wisnom MR, Czigány T. Design and characterisation of high performance, pseudoductile all-carbon/epoxy unidirectional hybrid composites. Composites Part B. 2017;111 348-56.

[44] IBM-Corp. IBM SPSS Statistics for Windows, Version 23.0. Armonk, NY: IBM Corp. 2015.

[45] Hinton PR, McMurray I, Brownlow C. SPSS explained. 2 ed: Routledge 27 Church Road, Hove, East Sussex BN3 2FA; 2014. 
Ribeiro, F.; Sena-Cruz, J.; Branco, F.; Júlio, E. (2018) "Hybrid FRP jacketing for enhanced confinement of circular concrete columns in compression." Construction \& Building Materials, 184: 681-704.

\section{Nomenclature}

El lateral strain

ficonfining pressure

$\varepsilon_{\mathrm{c}}$ axial strain

$f_{\mathrm{c}}$ compressive stress

$E_{\text {frp }}$ elastic modulus of FRP

$t_{f r p}$ total thickness of FRP

$D$ diameter of the concrete specimen

$\sigma @ L F$ stress at which the first crack in the LS material occurs

$\sigma @ d e l$ stress at which delamination starts

$\sigma @ H F$ stress at which the HS material fails

$S_{\mathrm{L}}$ reference strength of the LS material

$\alpha$ modulus ratios of the LS to HS fibre

$\beta$ thickness ratios of the LS to HS fibre

$G_{I I C}$ is the mode II interlaminar fracture toughness of the interface between LS layers and HS layers

$E_{\mathrm{H}}$ is the elastic modulus of the HS fibres

$t_{H}$ is the half thickness of the HS fibre

$m_{H}$ Weibull strength distribution modulus of the HS fibre

$S_{\mathrm{H}}$ reference strength of the HS material

$K_{t}$ stress concentration factor in the high strain material

$V$ volume of the specimen

$E_{\text {sat }}$ saturated modulus of the composite

$\varepsilon_{\mathrm{H}}$ failure strain of the HS fibres

$\varepsilon @ \mathrm{H}-\mathrm{PS}$ strain in the composite at the post-saturation phase when the high strain material fails

$K_{t}$ stress concentration factor

$v_{\mathrm{i}}$ initial Poisson's ratio of concrete

$f_{c 0}$ peak stress of the unconfined concrete

$\varepsilon_{\mathrm{c} 0}$ axial strain at the peak stress of the unconfined concrete

$n$ curve shape parameter

$f_{\text {cc }}^{*}$ peak stress of actively confined concrete 
$\varepsilon^{*}$ cc peak strain of actively confined concrete

$r$ concrete brittleness

$f_{\mathrm{c}, \text { res }}$ residual stress

$\varepsilon_{\mathrm{c}, \mathrm{i}}$ axial strain corresponding to the inflection point of the descending branch of stress-strain curve

$E_{\mathrm{c}}$ is the elastic modulus of plain concrete

$k_{1}$ strength enhancement coefficient for FRP-confined concrete

$k_{2}$ strain enhancement coefficient for FRP-confined concrete

$\sigma_{\text {hybrid }}$ tensile strength of hybrid composites

$\varepsilon L$ failure strain of the LS fibre

$V_{\mathrm{H}}$ volume of high strain material

$V_{\mathrm{L}}$ volume of low strain material

$f_{\mathrm{u}}$ ultimate confining pressure

Vol\% LS relative volume of LS fibres

$t_{\mathrm{L}}$ half thickness of the LS layers

$t_{\mathrm{H}}$ half thickness of the HS layers

$f_{\text {cc }}$ peak axial stress

$\varepsilon_{\mathrm{cc}}$ peak axial strain

$k_{\varepsilon \text {,frp }}$ FRP strain reduction factor

$\varepsilon 1$, rup FRP lateral strain at failure

$\varepsilon_{\text {frp }}$ FRP strain at failure

$\Delta \varepsilon_{L}$ absolute variation between the strain of LS material at failure in hybrid and non-hybrid composites $\varepsilon_{L}$ reference strain of the non-hybrid LS composite at failure 
Ribeiro, F.; Sena-Cruz, J.; Branco, F.; Júlio, E. (2018) "Hybrid FRP jacketing for enhanced confinement of circular concrete columns in compression." Construction \& Building Materials, 184: 681-704.

\section{List of Tables}

Table 1 - Summary of different damage modes in function of stress level (adapted from [19])

Table 2 - Characteristic points of different damage processes on stress-strain graph (adapted from [13])

Table 3 - Properties of the dry fabrics, fibres and cured composite materials. 30

Table 4 - Summary of tested compression specimens.

Table 5 - Ultimate conditions of non-hybrid FRP-confined concrete ......

Table 6 - Properties of cured hybrid composite materials and ultimate conditions of hybrid FRP-confined concrete

Table 7 - Ultimate conditions of hybrid FRP-confined concrete predictions.

Table 8 - Hybrid effect computed considering different failure strains of non-hybrid composite as reference. 35

Table 9 - Correlation matrix between different ways of compute hybrid effect (considering different failure strains of non-hybrid composite as reference) and strain reduction factor. 36 
Ribeiro, F.; Sena-Cruz, J.; Branco, F.; Júlio, E. (2018) "Hybrid FRP jacketing for enhanced confinement of circular concrete columns in compression." Construction \& Building Materials, 184: 681-704.

Table 1 - Summary of different damage modes in function of stress level (adapted from [19]).

\begin{tabular}{cc} 
Damage mode & Stress level \\
\hline Premature failure & $\sigma @ H F \leq \sigma @ L F \leq \sigma @ d e l$ \\
Catastrophic delamination & $\sigma @ H F \leq \sigma @ d e l \leq \sigma @ L F$ \\
& $\sigma @ d e l \leq \sigma @ H F \leq \sigma @ L F$ \\
Fragmentation & $\sigma @ d e l \leq \sigma @ L F \leq \sigma @ H F$ \\
& $\sigma @ L F \leq \sigma @ H F \leq \sigma @ d e l$
\end{tabular}

Fragmentation \& dispersed delamination $\sigma @ L F \leq \sigma @ d e l \leq \sigma @ H F$ 
Ribeiro, F.; Sena-Cruz, J.; Branco, F.; Júlio, E. (2018) "Hybrid FRP jacketing for enhanced confinement of circular concrete columns in compression." Construction \& Building Materials, 184: 681-704.

Table 2 - Characteristic points of different damage processes on stress-strain graph (adapted from [13]).

\begin{tabular}{|c|c|c|c|c|c|}
\hline Damage mode & Point 1 & Point 2 & Point 3 & Point 4 & Point 5 \\
\hline Premature failure & $(0,0)$ & $\left(\varepsilon_{L}, \sigma @ L F\right)$ & -- & -- & -- \\
\hline $\begin{array}{l}\text { Catastrophic } \\
\text { delamination }\end{array}$ & $(0,0)$ & $\left(\varepsilon_{L}, \sigma @ L F\right)$ & $\left(\varepsilon_{L}, \sigma @ d e l\right)$ & $\left(\frac{\sigma @ \operatorname{del}(1+\beta)}{E_{H}}, \sigma @ d e l\right)$ & $\left(\frac{\varepsilon_{H}}{K_{t} \sqrt[m_{H}]{V}}, \sigma @ H F\right)$ \\
\hline Fragmentation & $(0,0)$ & $\left(\varepsilon_{L}, \sigma @ L F\right)$ & $\left(\frac{\sigma @ L F}{E_{\text {sat }}}, \sigma @ L F\right.$ & $\left(\varepsilon_{H-P S}, \sigma @ H F\right)$ & -- \\
\hline $\begin{array}{c}\text { Fragmentation \& } \\
\text { dispersed delamination }\end{array}$ & $(0,0)$ & $\left(\varepsilon_{L}, \sigma @ L F\right)$ & $\left(\frac{\sigma @ L F}{E_{\text {sat }}}, \sigma @ L F\right.$ & $\left(\frac{\sigma @ \operatorname{del}(1+\beta)}{E_{H}}, \sigma @ d e l\right)$ & $\left(\frac{\varepsilon_{H}}{K_{t} \sqrt[m_{H}]{V}}, \sigma @ H F\right)$ \\
\hline
\end{tabular}


Table 3 - Properties of the dry fabrics, fibres and cured composite materials.

\begin{tabular}{|c|c|c|c|c|c|c|c|c|c|c|c|c|}
\hline \multirow[t]{2}{*}{ Material ID } & \multicolumn{3}{|c|}{ Properties of the dry fabric } & \multicolumn{5}{|c|}{ Properties of the fibres (tested according to ASTM D3379) } & \multicolumn{4}{|c|}{ Properties of composites [14]* } \\
\hline & $\begin{array}{c}\text { Density } \\
{\left[\mathrm{g} / \mathrm{m}^{3}\right]}\end{array}$ & $\begin{array}{l}\text { Areal } \\
\text { mass } \\
{\left[\mathrm{g} / \mathrm{m}^{2}\right]}\end{array}$ & $\begin{array}{c}\text { Fibre layer } \\
\text { thickness } \\
\text { [mm/layer] }\end{array}$ & $\begin{array}{c}\text { N. of } \\
\text { samples }\end{array}$ & $\begin{array}{c}\text { Fibre } \\
\text { diameter } \\
{[\mu \mathrm{m}]} \\
(\mathrm{CoV}[\%])\end{array}$ & $\begin{array}{c}\text { Elastic } \\
\text { modulus } \\
{[\mathrm{GPa}]} \\
(\mathrm{CoV}[\%])\end{array}$ & $\begin{array}{c}\text { Tensile } \\
\text { strength } \\
{[\mathrm{MPa}]} \\
(\mathrm{CoV}[\%])\end{array}$ & $\begin{array}{c}\text { Strain at } \\
\text { the failure } \\
{[\%]} \\
(\mathrm{CoV}[\%])\end{array}$ & Series ID** & $\begin{array}{c}\text { Elastic } \\
\text { modulus } \\
{[\mathrm{GPa}]} \\
(\mathrm{CoV}[\%])\end{array}$ & $\begin{array}{c}\text { Tensile } \\
\text { strength } \\
{[\mathrm{MPa}]} \\
(\mathrm{CoV}[\%])\end{array}$ & $\begin{array}{c}\text { Strain at } \\
\text { the failure } \\
{[\%]} \\
(\mathrm{CoV}[\%])\end{array}$ \\
\hline Basalt (B) & 2.67 & 420 & 0.157 & 50 & $\begin{array}{l}18.14 \\
(3.56)\end{array}$ & $\begin{array}{l}61.41 \\
(31.14)\end{array}$ & $\begin{array}{l}1886.70 \\
(40.79)\end{array}$ & $\begin{array}{c}3.10 \\
(27.73)\end{array}$ & 3B & $\begin{array}{c}102.5 \\
(15.46) \\
92.6 \\
(13.55)\end{array}$ & $\begin{array}{l}2244.2 \\
(20.17) \\
1974.6 \\
(15.76)\end{array}$ & $\begin{array}{c}2.46 \\
(10.61) \\
2.40 \\
(8.26)\end{array}$ \\
\hline E-glass $(G)$ & 2.60 & 400 & 0.154 & 50 & $\begin{array}{l}14.98 \\
(16.25)\end{array}$ & $\begin{array}{c}76.92 \\
(27.97)\end{array}$ & $\begin{array}{l}2662.06 \\
(33.88)\end{array}$ & $\begin{array}{c}3.72 \\
(20.45)\end{array}$ & $3 \mathrm{G}$ & $\begin{array}{c}81.6 \\
(7.39) \\
80.6 \\
(10.10)\end{array}$ & $\begin{array}{l}1671.2 \\
(8.59) \\
1254.8 \\
(15.05)\end{array}$ & $\begin{array}{c}2.31 \\
(3.78) \\
2.00 \\
(13.95)\end{array}$ \\
\hline ST carbon $(\mathrm{C})$ & 1.79 & 400 & 0.223 & 36 & $\begin{array}{r}7.88 \\
(5.15)\end{array}$ & $\begin{array}{l}213.95 \\
(43.36)\end{array}$ & $\begin{array}{l}3920.67 \\
(39.37)\end{array}$ & $\begin{array}{c}1.38 \\
(17.37)\end{array}$ & $3 \mathrm{C}$ & $\begin{array}{l}231.3 \\
(12.50) \\
227.6 \\
(5.80)\end{array}$ & $\begin{array}{l}2565.9 \\
(10.18) \\
2363.2 \\
(7.44)\end{array}$ & $\begin{array}{c}1.09 \\
(8.81) \\
1.02 \\
(6.02)\end{array}$ \\
\hline HM carbon (CHM) & 2.10 & 400 & 0.190 & 26 & $\begin{array}{l}11.03 \\
(6.66)\end{array}$ & $\begin{array}{l}558.07 \\
(24.67)\end{array}$ & $\begin{array}{l}2934.24 \\
(19.16)\end{array}$ & $\begin{array}{c}0.53 \\
(18.99)\end{array}$ & $3 \mathrm{CHM}$ & $\begin{array}{l}624.1 \\
(11.13) \\
588.2 \\
(3.97)\end{array}$ & $\begin{array}{l}1749.4 \\
(24.39) \\
1073.9 \\
(18.27)\end{array}$ & $\begin{array}{c}0.27 \\
(19.61) \\
0.18 \\
(15.84)\end{array}$ \\
\hline
\end{tabular}

Notes: *The tensile properties were computed considering only the thickness of the dry fabrics, according the recommendation suggested in the guidelines [31];** the number before letters in series ID shows the number of layers. 
Table 4 - Summary of tested compression specimens.

\begin{tabular}{|c|c|c|c|c|c|}
\hline Jacketing type & Designation & $\begin{array}{c}\text { Non corrected } \\
\text { layer ratio } \\
\text { (LS/HS fibres) } \\
\text { [\%] }\end{array}$ & $\begin{array}{l}\text { Stacking } \\
\text { sequence }\end{array}$ & Jacketing material combinations & $\begin{array}{l}\text { Number of tests per type } \\
\text { of stacking sequence }\end{array}$ \\
\hline Non-hybrid & -- & $100 / 0$ & $\mathbf{\square}$ & $\mathrm{G}, \mathrm{B}, \mathrm{CHM}, \mathrm{C}$ & 12 \\
\hline \multirow[t]{5}{*}{ Hybrid } & $1 \mathrm{LS} / 1 \mathrm{HS} / 1 \mathrm{LS}$ & $66 / 33$ & & $\mathrm{C} / \mathrm{B}, \mathrm{CHM} / \mathrm{B}, \mathrm{CHM} / \mathrm{C}, \mathrm{C} / \mathrm{G}, \mathrm{CHM} / \mathrm{G}$ & 15 \\
\hline & $1 \mathrm{HS} / 3 \mathrm{LS} / 1 \mathrm{HS}$ & $60 / 40$ & & $\mathrm{C} / \mathrm{G}, \mathrm{CHM} / \mathrm{G}$ & 6 \\
\hline & $1 \mathrm{HS} / 1 \mathrm{LS} / 1 \mathrm{HS} / 1 \mathrm{LS} / 1 \mathrm{HS}$ & $40 / 60$ & & $\mathrm{C} / \mathrm{G}, \mathrm{CHM} / \mathrm{G}$ & 6 \\
\hline & 1HS/1LS/1HS & $33 / 66$ & & $\mathrm{C} / \mathrm{B}, \mathrm{CHM} / \mathrm{B}, \mathrm{CHM} / \mathrm{C}, \mathrm{C} / \mathrm{G}, \mathrm{CHM} / \mathrm{G}$ & 15 \\
\hline & $2 \mathrm{HS} / 1 \mathrm{LS} / 2 \mathrm{HS}$ & $20 / 80$ & $\square$ & $\mathrm{C} / \mathrm{G}, \mathrm{CHM} / \mathrm{G}$ & 6 \\
\hline None & Unconfined & -- & -- & -- & -- \\
\hline
\end{tabular}

Notes: $\mathbf{D}_{\text {- HS fibres layer; }} \boldsymbol{\square}_{\text {- LS fibres layer. }}$ 
Ribeiro, F.; Sena-Cruz, J.; Branco, F.; Júlio, E. (2018) "Hybrid FRP jacketing for enhanced confinement of circular concrete columns in compression." Construction \& Building Materials, 184: 681-704.

Table 5 - Ultimate conditions of non-hybrid FRP-confined concrete

\begin{tabular}{ccccccc}
\hline Series ID $^{*}$ & $\begin{array}{c}f_{\mathrm{cc}}[\mathrm{MPa}] \\
(\mathrm{CoV}[\%])\end{array}$ & $f_{\mathrm{cc}} / f_{\mathrm{c} 0}$ & $\varepsilon_{\mathrm{cc}}[\%](\mathrm{CoV}$ & $\varepsilon_{\mathrm{cc}} / \varepsilon_{\mathrm{c} 0}{ }^{* *}$ & $\begin{array}{c}\varepsilon l_{\text {,rup }}[\%] \\
(\mathrm{CoV}[\%])\end{array}$ & $k_{\varepsilon, \text { frp }}$ \\
\hline 3B & $64.80(3.48)$ & 1.93 & $1.09(15.87)$ & 5.45 & $1.79(16.92)$ & 0.75 \\
3G & $64.67(4.21)$ & 1.93 & $1.48(30.89)$ & 7.40 & $1.88(15.90)$ & 0.94 \\
3C & $89.02(7.03)$ & 2.65 & $1.40(27.48)$ & 7.00 & $0.98(35.98)$ & 0.96 \\
$3 \mathrm{CHM}$ & $54.89(12.91)$ & 1.64 & $0.38(39.84)$ & 1.90 & $0.13(17.17)$ & 0.72 \\
\hline
\end{tabular}

Note: * the number before letters in series ID shows the number of layers; ** it was assumed $\varepsilon_{\mathrm{c} 0}=0.0020$ (according equation (10)). 
Table 6 - Properties of cured hybrid composite materials and ultimate conditions of hybrid FRP-confined concrete

\begin{tabular}{|c|c|c|c|c|c|c|c|c|c|c|c|c|}
\hline \multirow{2}{*}{$\begin{array}{c}\text { Material } \\
\text { combination }\end{array}$} & \multirow[t]{2}{*}{ Series ID* } & \multirow{2}{*}{$\begin{array}{c}\text { Volume } \\
\text { of LS } \\
\text { fibres [\%] }\end{array}$} & \multicolumn{3}{|c|}{ Cured hybrid composite properties [14] } & \multicolumn{7}{|c|}{ Ultimate conditions of non-hybrid FRP-confined concrete } \\
\hline & & & $\begin{array}{l}\text { Elastic modulus } \\
{[\mathrm{GPa}](\mathrm{CoV}[\%])}\end{array}$ & $\begin{array}{l}\text { Tensile strength } \\
\text { [MPa] (CoV [\%]) }\end{array}$ & $\begin{array}{c}\text { Failure strain of } \\
\text { LS fibres [\%] } \\
(\mathrm{CoV}[\%])\end{array}$ & $\begin{array}{c}f_{\mathrm{cc}}[\mathrm{MPa}](\mathrm{CoV} \\
[\%])\end{array}$ & $f_{\mathrm{cc}} / f_{\mathrm{co}}$ & $\begin{array}{c}\varepsilon_{\mathrm{cc}}[\%](\mathrm{CoV} \\
[\%])\end{array}$ & $\varepsilon_{c c} / \varepsilon_{c_{0}{ }^{0 *}}$ & $\begin{array}{c}\text { Lateral failure } \\
\text { strain of LS fibres } \\
{[\%](\mathrm{CoV}[\%])}\end{array}$ & $\begin{array}{c}\text { Lateral failure } \\
\text { strain of HS fibres } \\
{[\%](\mathrm{CoV}[\%])}\end{array}$ & $\begin{array}{c}k_{\varepsilon} \text { at failure of } \\
\text { LS fibres }\end{array}$ \\
\hline \multirow[t]{2}{*}{$\mathrm{C} / \mathrm{B}$} & $1 \mathrm{C} / 1 \mathrm{~B} / 1 \mathrm{C}$ & 74.0 & $218.4(2.84)$ & $2191.4(7.28)$ & $0.99(5.76)$ & $87.4(--)$ & 2.61 & $1.41(--)$ & 7.05 & $0.81(--)$ & -- & 0.82 \\
\hline & $1 \mathrm{~B} / 1 \mathrm{C} / 1 \mathrm{~B}$ & 41.5 & $152.5(5.93)$ & $1950.2(7.51)$ & $1.28(3.46)$ & $73.2(3.01)$ & 2.19 & $0.91(13.74)$ & 4.55 & $1.03(7.54)$ & .- & 0.80 \\
\hline \multirow[t]{2}{*}{$\mathrm{CHM} / \mathrm{B}$} & $1 \mathrm{CHM} / 1 \mathrm{~B} / 1 \mathrm{CHM}$ & 70.8 & $474.1(2.25)$ & $1150.0(14.10)$ & $0.24(11.19)$ & $54.2(8.59)$ & 1.62 & $0.51(17.63)$ & 2.55 & $0.19(25.34)$ & & 0.79 \\
\hline & $1 \mathrm{~B} / 1 \mathrm{CHM} / 1 \mathrm{~B}$ & 37.7 & $297.4(9.29)$ & $1328.0(10.74)$ & $0.39(5.77)$ & $62.9(5.46)$ & 1.88 & $0.99(16.71)$ & 4.95 & $0.39(7.05)$ & $1.17(34.9)$ & 1.00 \\
\hline \multirow[t]{2}{*}{$\mathrm{CHM} / \mathrm{C}$} & $1 \mathrm{CHM} / \mathrm{IC} / \mathrm{lCHM}$ & 63.0 & $489.6(7.39)$ & $1352.5(5.10)$ & $0.27(5.55)$ & $59.7(7.76)$ & 1.78 & $0.48(7.20)$ & 2.40 & $0.19(17.86)$ & -- & 0.70 \\
\hline & $1 \mathrm{C} / 1 \mathrm{CHM} / 1 \mathrm{C}$ & 29.5 & $368.8(6.43)$ & $1937.5(6.79)$ & $0.39(3.59)$ & $79.9(5.01)$ & 2.39 & $0.94(13.95)$ & 4.70 & 0.46 (28.74) & $0.61(22.66)$ & 1.18 \\
\hline \multirow[t]{5}{*}{$\mathrm{C} / \mathrm{G}$} & $1 \mathrm{C} / 1 \mathrm{G} / 1 \mathrm{C}$ & 74.3 & $201.7(9.63)$ & $2176.9(8.55)$ & $1.04(1.92)$ & $81.7(1.48)$ & 2.44 & $1.23(6.00)$ & 6.15 & $0.86(22.99)$ & -- & 0.83 \\
\hline & $1 \mathrm{G} / 3 \mathrm{C} / 1 \mathrm{G}$ & 68.5 & $202.4(2.64)$ & $2216.0(8.77)$ & $1.09(6.26)$ & $119.4(2.66)$ & 3.57 & $2.13(19.54)$ & 10.65 & $1.19(1.35)$ & -- & 1.09 \\
\hline & $1 \mathrm{G} / 1 \mathrm{C} / 1 \mathrm{G} / 1 \mathrm{C} / 1 \mathrm{G}$ & 49.1 & 148.9 (11.75) & $1776.3(10.55)$ & $1.19(3.68)$ & $108.3(7.53)$ & 3.23 & $1.60(8.27)$ & 8.00 & $1.29(12.66)$ & - & 1.08 \\
\hline & $1 \mathrm{G} / 1 \mathrm{C} / 1 \mathrm{G}$ & 42.0 & $146.7(5.92)$ & $1856.0(5.67)$ & $1.27(2.72)$ & $77.5(5.00)$ & 2.31 & $1.23(12.19)$ & 6.15 & $1.27(15.16)$ & -- & 1.00 \\
\hline & $2 \mathrm{G} / 1 \mathrm{C} / 2 \mathrm{G}$ & 26.6 & $110.8(10.21)$ & $1244.4(1.74)$ & $1.18(8.27)$ & $98.3(2.43)$ & 2.94 & $1.64(23.68)$ & 8.20 & $1.44(15.90)$ & -- & 1.22 \\
\hline \multirow[t]{5}{*}{$\mathrm{CHM} / \mathrm{G}$} & $1 \mathrm{CHM} / 1 \mathrm{G} / 1 \mathrm{CHM}$ & 71.2 & $454.5(11.95)$ & 1168.9 (19.49) & $0.26(11.66)$ & $54.7(9.00)$ & 1.63 & $0.39(29.22)$ & 1.95 & $0.21(46.47)$ & -- & 0.81 \\
\hline & $1 \mathrm{G} / 3 \mathrm{CHM} / 1 \mathrm{G}$ & 64.9 & $439.2(7.35)$ & $1053.5(10.14)$ & $0.24(6.43)$ & $74.5(6.12)$ & 2.22 & $0.72(11.63)$ & 3.60 & $0.24(8.31)$ & -- & 1.00 \\
\hline & $1 \mathrm{G} / 1 \mathrm{CHM} / 1 \mathrm{G} / 1 \mathrm{CHM} / 1 \mathrm{G}$ & 45.1 & $318.7(7.33)$ & $1105.8(9.18)$ & $0.35(5.02)$ & $76.6(1.98)$ & 2.29 & $0.77(24.58)$ & 3.85 & $0.37(32.84)$ & $0.90(4.71)$ & 1.06 \\
\hline & $1 \mathrm{G} / 1 \mathrm{CHM} / 1 \mathrm{G}$ & 38.2 & $252.0(8.55)$ & $1054.7(9.11)$ & $0.30(2.39)$ & $63.7(1.70)$ & 1.90 & $0.85(13.86)$ & 4.25 & $0.38(7.71)$ & $1.27(14.54)$ & 1.27 \\
\hline & $2 \mathrm{G} / 1 \mathrm{CHM} / 2 \mathrm{G}$ & 23.6 & $214.3(8.45)$ & 1164.7 (14.47) & $0.33(14.65)$ & $80.5(3.93)$ & 2.40 & $1.22(20.72)$ & 6.10 & $0.39(5.96)$ & $1.49(9.11)$ & 1.18 \\
\hline
\end{tabular}

Note: * the number before letters in series ID shows the number of layers of each material; ** it was assumed $\varepsilon_{\mathrm{c} 0}=0.20$ (according equation (10)). 
Table 7 - Ultimate conditions of hybrid FRP-confined concrete predictions.

\begin{tabular}{|c|c|c|c|c|c|c|c|c|c|c|c|c|c|c|c|c|c|}
\hline \multirow{2}{*}{$\begin{array}{l}\text { Material } \\
\text { combina } \\
\text { tion }\end{array}$} & \multirow[t]{2}{*}{ Series ID } & \multicolumn{3}{|c|}{ Composite tensile strength } & & \multicolumn{2}{|c|}{$f_{\text {uu }}$} & \multicolumn{5}{|c|}{$f_{\text {ce }}$} & \multicolumn{5}{|c|}{$\varepsilon_{\mathrm{ccc}}$} \\
\hline & & $\begin{array}{c}\text { Experimental } \\
\text { [MPa] } \\
(\mathrm{CoV}[\%])\end{array}$ & $\begin{array}{c}\text { Jalalvand } \\
\text { model } \\
{[\mathrm{MPa}]}\end{array}$ & $\begin{array}{c}\mathrm{Bi} . \\
\text { ROM } \\
{[\mathrm{MPa}]}\end{array}$ & $\begin{array}{c}\text { tffip } \\
{[\mathrm{mm}]}\end{array}$ & $\begin{array}{c}\text { Based on } \\
\mathrm{J}-\sigma_{\text {hybrid }} \\
{[\mathrm{MPa}]}\end{array}$ & $\begin{array}{c}\text { Based on } \\
\text { B- } \sigma_{\text {hybrid }} \\
{[\mathrm{MPa}]}\end{array}$ & $\begin{array}{l}\text { Experim. } \\
{[\mathrm{MPa}]} \\
(\mathrm{CoV}[\%])\end{array}$ & $\begin{array}{c}\text { Based on } \\
\text { J-Ghyrid } \\
{[\mathrm{MPa}]}\end{array}$ & $\begin{array}{c}\text { Based on } \\
\text { B- } \text { - } h y \text { brid } \\
\text { [MPa] }\end{array}$ & $\begin{array}{c}\text { Based on } \\
\mathrm{J}-\sigma_{\text {-hybrid }} \\
\text { rel. error } \\
{[\%]}\end{array}$ & $\begin{array}{c}\text { Based on } \\
\text { B- } \sigma_{\text {hyyrorid }} \\
\text { rel. error } \\
{[\%]}\end{array}$ & $\begin{array}{c}\text { Experimental } \\
{[\%]} \\
(\mathrm{CoV}[\%])\end{array}$ & $\begin{array}{c}\text { Based on } \\
\text { J- } \sigma_{\text {hybrid }} \\
{[\%]}\end{array}$ & $\begin{array}{c}\text { Based on } \\
\text { B-- } \text { hybrid } \\
{[\%]}\end{array}$ & $\begin{array}{c}\text { Based on } \\
\text { J-㧫yrid } \\
\text { rel. error } \\
{[\%]}\end{array}$ & $\begin{array}{c}\text { Based on } \\
\text { B- } \text {-hyyrorid } \\
\text { rel. error } \\
{[\%]}\end{array}$ \\
\hline \multirow[t]{2}{*}{$\mathrm{C} / \mathrm{B}$} & $1 \mathrm{C} / 1 \mathrm{~B} / 1 \mathrm{C}$ & $2191.4(7.28)$ & 1957.9 & 2189.3 & 0.60 & 15.7 & 17.6 & $87.4(--)$ & 85.3 & 90.5 & 2.4 & -3.5 & $1.41(--)$ & 1.29 & 1.40 & 8.6 & 0.7 \\
\hline & $1 \mathrm{~B} / \mathrm{C} / 1 \mathrm{~B}$ & $1950.2(7.51)$ & 1996.6 & 1718.4 & 0.54 & 14.3 & 12.3 & $73.2(3.01)$ & 80.5 & 73.3 & -10.0 & -0.2 & 0.91 (13.74) & 1.19 & 1.04 & -30.7 & -14.4 \\
\hline \multirow[t]{2}{*}{$\mathrm{CHM} / \mathrm{B}$} & $1 \mathrm{CHM} / 1 \mathrm{~B} / 1 \mathrm{CHM}$ & $1150.0(14.10)$ & 1131.8 & 1325.4 & 0.54 & 8.1 & 9.5 & $54.2(8.59)$ & 60.1 & 64.2 & -11.0 & -18.6 & 0.51 (17.63) & 0.76 & 0.85 & -49.9 & -66.8 \\
\hline & 1B/1CHM/1B & $1328.0(10.74)$ & 1152.3 & 1398.1 & 0.50 & 7.7 & 9.4 & $62.9(5.46)$ & 59.0 & 63.9 & 6.3 & -1.6 & $0.99(16.71)$ & 0.74 & 0.84 & 25.3 & 14.7 \\
\hline \multirow[t]{2}{*}{$\mathrm{CHM} / \mathrm{C}$} & $1 \mathrm{CHM} / 1 \mathrm{C} / 1 \mathrm{CHM}$ & $1352.5(5.10)$ & 1292.7 & 1350.3 & 0.60 & 10.4 & 10.9 & $59.7(7.76)$ & 67.7 & 68.6 & -13.3 & -14.9 & $0.48(7.20)$ & 0.92 & 0.94 & -92.0 & -96.5 \\
\hline & $1 \mathrm{C} / 1 \mathrm{CHM} / 1 \mathrm{C}$ & $1937.5(6.79)$ & 1544.9 & 1504.5 & 0.64 & 13.1 & 12.8 & $79.9(5.01)$ & 76.6 & 74.8 & 4.1 & 6.4 & $0.94(13.95)$ & 1.11 & 1.07 & -17.8 & -14.0 \\
\hline \multirow[t]{5}{*}{$\mathrm{C} / \mathrm{G}$} & $1 \mathrm{C} / 1 \mathrm{G} / 1 \mathrm{C}$ & $2176.9(8.55)$ & 2005.5 & 2135.1 & 0.60 & 16.0 & 17.1 & $81.7(1.48)$ & 86.3 & 88.8 & -5.6 & -8.7 & $1.23(6.00)$ & 1.31 & 1.36 & -6.5 & -10.9 \\
\hline & $1 \mathrm{G} / 3 \mathrm{C} / \mathrm{G}$ & $2216.0(8.77)$ & 1988.4 & 2013.8 & 0.98 & 25.9 & 26.2 & $119.4(2.66)$ & 118.7 & 118.4 & 0.6 & 0.8 & $2.13(19.54)$ & 1.99 & 1.98 & 6.7 & 6.8 \\
\hline & $1 \mathrm{G} / 1 \mathrm{C} / 1 \mathrm{G} / 1 \mathrm{C} / 1 \mathrm{G}$ & $1776.3(10.55)$ & 1830.5 & 1712.6 & 0.91 & 22.2 & 20.7 & $108.3(7.53)$ & 106.4 & 100.6 & 1.8 & 7.1 & $1.60(8.27)$ & 1.73 & 1.61 & -8.1 & -0.7 \\
\hline & $1 \mathrm{G} / 1 \mathrm{C} / 1 \mathrm{G}$ & $1856.0(5.67)$ & 1820.3 & 1593.6 & 0.53 & 12.9 & 11.3 & $77.5(5.00)$ & 75.9 & 70.0 & 2.1 & 9.7 & $1.23(12.19)$ & 1.09 & 0.97 & 11.2 & 21.0 \\
\hline & $2 \mathrm{G} / 1 \mathrm{C} / 2 \mathrm{G}$ & $1244.4(1.74)$ & 1420.3 & 1335.4 & 0.84 & 15.9 & 14.9 & $98.3(2.43)$ & 85.8 & 81.9 & 12.7 & 16.7 & $1.64(23.68)$ & 1.30 & 1.22 & 20.8 & 25.6 \\
\hline \multirow[t]{5}{*}{$\mathrm{CHM} / \mathrm{G}$} & $1 \mathrm{CHM} / 1 \mathrm{G} / 1 \mathrm{CHM}$ & $1168.9(19.49)$ & 1201.9 & 1313.7 & 0.53 & 8.6 & 9.4 & $54.7(9.00)$ & 61.6 & 63.8 & -12.8 & -16.7 & $0.39(29.22)$ & 0.80 & 0.84 & -104.0 & -115.7 \\
\hline & $1 \mathrm{G} / 3 \mathrm{CHM} / 1 \mathrm{G}$ & $1053.5(10.14)$ & 997.7 & 1218.4 & 0.88 & 11.7 & 14.3 & $74.5(6.12)$ & 71.9 & 79.7 & 3.4 & -7.0 & $0.72(11.63)$ & 1.01 & 1.17 & -40.3 & -63.0 \\
\hline & $1 \mathrm{G} / 1 \mathrm{CHM} / 1 \mathrm{G} / 1 \mathrm{CHM} / 1 \mathrm{G}$ & $1105.8(9.18)$ & 1142.5 & 918.9 & 0.84 & 12.8 & 10.3 & $76.6(1.98)$ & 75.7 & 66.9 & 1.1 & 12.6 & $0.77(24.58)$ & 1.09 & 0.91 & -41.4 & -17.7 \\
\hline & $1 \mathrm{G} / 1 \mathrm{CHM} / 1 \mathrm{G}$ & $1054.7(9.11)$ & 852.4 & 1032.8 & 0.50 & 5.7 & 6.9 & $63.7(1.70)$ & 52.1 & 55.7 & 18.1 & 12.5 & $0.85(13.86)$ & 0.60 & 0.67 & 29.8 & 20.9 \\
\hline & $2 \mathrm{G} / 1 \mathrm{CHM} / 2 \mathrm{G}$ & $1164.7(14.47)$ & 1028.7 & 1276.8 & 0.81 & 11.1 & 13.7 & $80.5(3.93)$ & 69.9 & 77.9 & 13.2 & 3.2 & $1.22(20.72)$ & 0.97 & 1.14 & 20.7 & 6.8 \\
\hline
\end{tabular}


Ribeiro, F.; Sena-Cruz, J.; Branco, F.; Júlio, E. (2018) "Hybrid FRP jacketing for enhanced confinement of circular concrete columns in compression." Construction \& Building Materials, 184: 681-704.

Table 8 - Hybrid effect computed considering different failure strains of non-hybrid composite as reference.

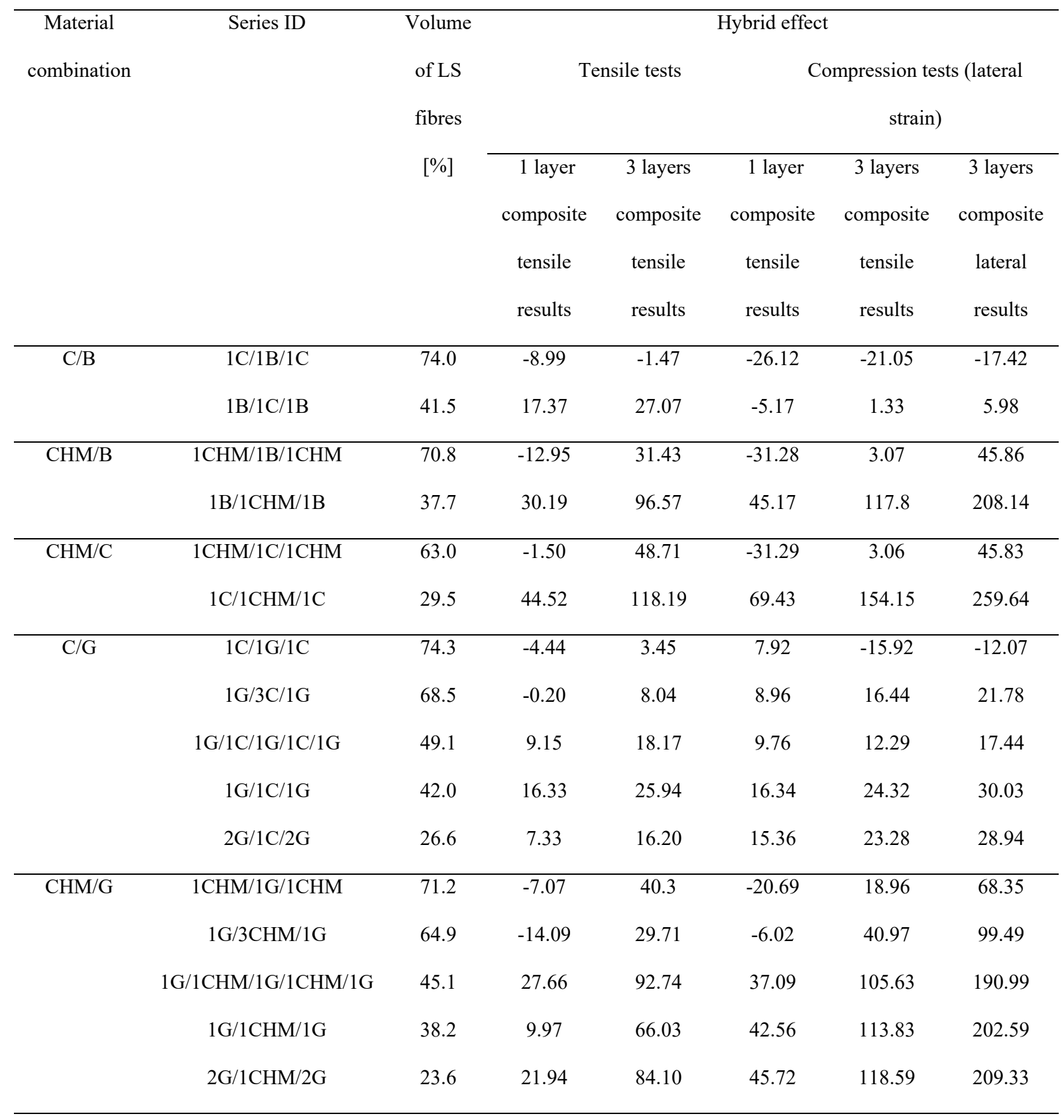


Table 9 - Correlation matrix between different ways of compute hybrid effect (considering different failure strains of non-hybrid composite as reference) and strain reduction factor.

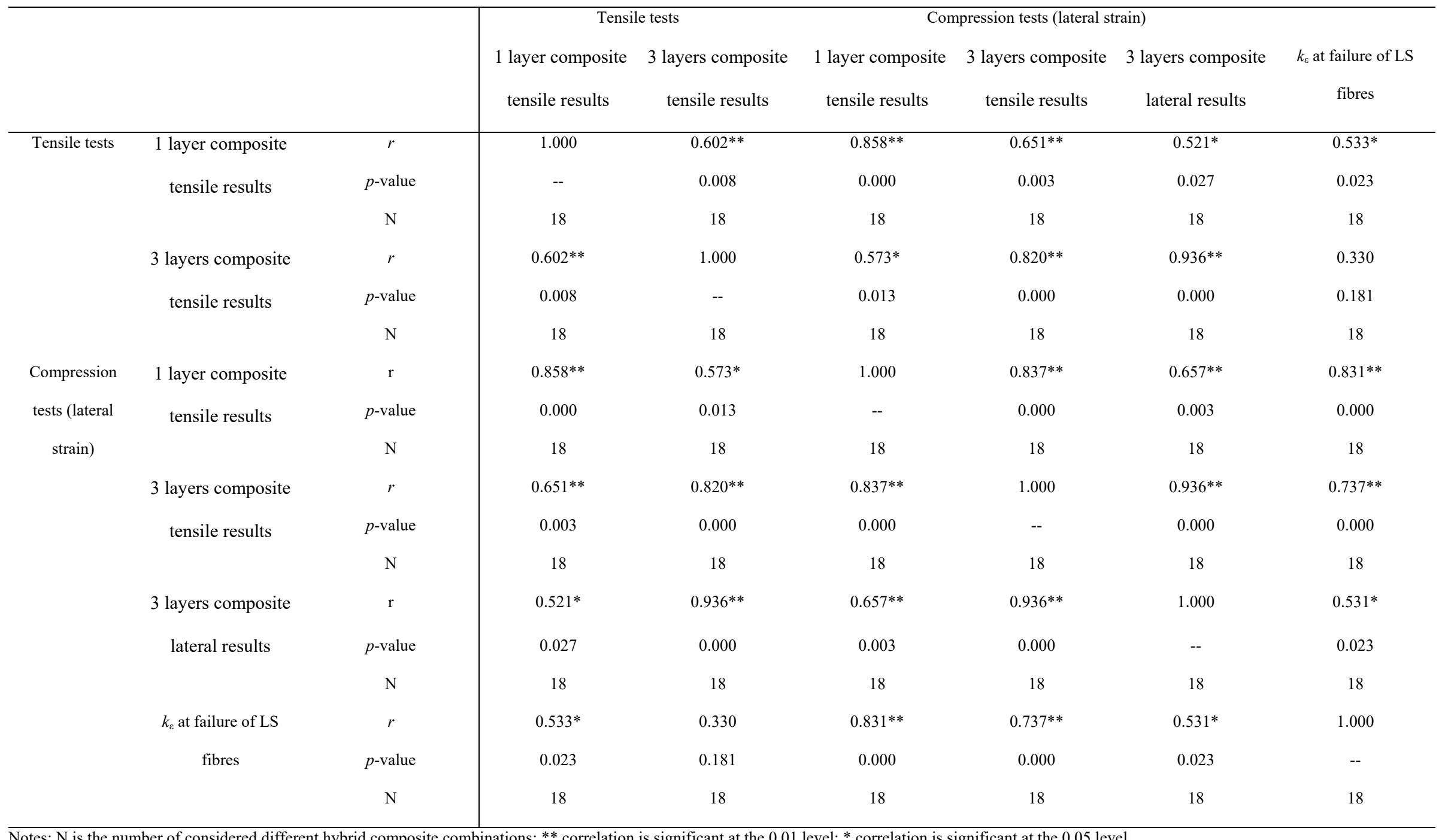

Notes: $\mathrm{N}$ is the number of considered different hybrid composite combinations; ${ }^{* *}$ correlation is significant at the 0.01 level; * correlation is significant at the 0.05 level. 
Ribeiro, F.; Sena-Cruz, J.; Branco, F.; Júlio, E. (2018) "Hybrid FRP jacketing for enhanced confinement of circular concrete columns in compression." Construction \& Building Materials, 184: 681-704.

\section{List of Figures}

Figure 1 - Illustration of nonlinear pseudo-ductile tensile behaviour of hybrid composite and definition of 'yield' stress and pseudo-ductile strain.

Figure 2 - Axial compressive test: (a) illustration of the test and (b) geometry of specimen (dimensions in $\mathrm{mm}$ ).

Figure 3 - Layers, LVDT and strain gauge arrangement: (a) hybrid jackets with 3 layers and (b) hybrid jackets with 5 layers. Note: different colours in the illustrated hybrid jackets are a schematic representation of a possible stacking sequence of two different reinforcing materials.

Figure 4 - Scatter diagrams and mean values of the non-hybrid composites confined concrete: (a) ultimate axial compressive stress; (b) ultimate axial strain and (c) hoop rupture strain of FRP.

Figure 5 - Lateral strain-axial strain curves: (a) basalt; (b) glass; (c) ST carbon; (d) HM carbon composite confined concrete.

Figure 6 - Axial stress-strain curves: (a) basalt; (b) glass; (c) ST carbon; (d) HM carbon composite confined concrete.

Figure 7 - Failure modes of non-hybrid FRP-confined concrete: (a) basalt; (b) glass; (c) ST carbon and (d) HM carbon.

Figure 8 - Variation of strength enhancement ratio with confinement ratio: (a) $f_{\mathrm{u}}$ based on J- $\sigma_{\text {hybrid }}$; (b) $f_{\mathrm{u}}$ based on B- $\sigma_{\text {hybrid. }}$ 46

Figure 9 - Variation of strain enhancement ratio with confinement ratio: (a) $f_{\mathrm{lu}}$ based on J- $\sigma_{\text {hybrid }}$; (b) $f_{\mathrm{u}}$ based on B- $\sigma_{\text {hybrid. }}$ .47

Figure 10 - Comparison between uniaxial tensile and lateral failure strains of LS fibres of the: (a) HM carbon/glass; (b) ST carbon/glass; (c) HM carbon/basalt; (d) ST carbon/basalt and (e) HM carbon/ST carbon composites.

Figure 11 - Illustration of different stages of lateral strain-axial strain curves of specimens with pseudo-ductile behaviour. .49

Figure 12 - Lateral strain-axial strain curves of CHM/G combinations: experimental versus predicted values.50 
Figure 13 - Lateral strain-axial strain curves of $\mathrm{C} / \mathrm{G}$ combinations: experimental versus predicted values. ..... 51

Figure 14 - Lateral strain-axial strain curves of CHM/B combinations: experimental versus predicted values.52

Figure 15 - Lateral strain-axial strain curves of C/B combinations: experimental versus predicted values....... 53

Figure 16 - Lateral strain-axial strain curves of CHM/C combinations: experimental versus predicted values.54

Figure 17 - Stress-strain curves of CHM/G combinations: experimental versus predicted values. 55

Figure 18 - Stress-strain curves of C/G combinations: experimental versus predicted values. .56

Figure 19 - Stress-strain curves of CHM/B combinations: experimental versus predicted values. .57

Figure 20 - Stress-strain curves of $\mathrm{C} / \mathrm{B}$ combinations: experimental versus predicted values. .58

Figure 21 - Stress-strain curves of CHM/C combinations: experimental versus predicted values. 59

Figure 22 - Failure modes of HM carbon/glass FRP-confined concrete: (a) $2 \mathrm{G} / 1 \mathrm{CHM} / 2 \mathrm{G}$ - view 1; (b) 2G/1CHM/2G - view 2; (c) $1 \mathrm{G} / 1 \mathrm{CHM} / 1 \mathrm{G}$; (d) $1 \mathrm{G} / 1 \mathrm{CHM} / 1 \mathrm{G} / 1 \mathrm{CHM} / 1 \mathrm{G}$; (e) $1 \mathrm{G} / 3 \mathrm{CHM} / 1 \mathrm{G}$ and (f) $1 \mathrm{CHM} / 1 \mathrm{G} / 1 \mathrm{CHM}$ 60

Figure 23 - Failure modes of ST carbon/glass FRP-confined concrete: (a) 2G/1C/2G; (b) 1G/1C/1G; (c) $1 \mathrm{G} / 1 \mathrm{C} / 1 \mathrm{G} / 1 \mathrm{C} / 1 \mathrm{G} ;$ (d) $1 \mathrm{G} / 3 \mathrm{C} / 1 \mathrm{G}$ and (e) $1 \mathrm{C} / 1 \mathrm{G} / 1 \mathrm{C}$ 61 
Ribeiro, F.; Sena-Cruz, J.; Branco, F.; Júlio, E. (2018) "Hybrid FRP jacketing for enhanced confinement of circular concrete columns in compression." Construction \& Building Materials, 184: 681-704.

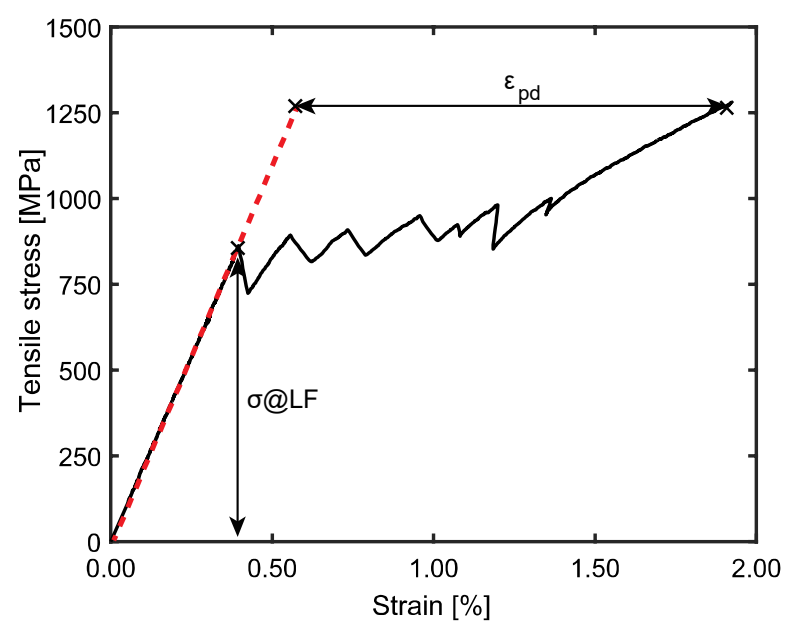

Figure 1 - Illustration of nonlinear pseudo-ductile tensile behaviour of hybrid composite and definition of 'yield' stress and pseudo-ductile strain. 
Ribeiro, F.; Sena-Cruz, J.; Branco, F.; Júlio, E. (2018) "Hybrid FRP jacketing for enhanced confinement of circular concrete columns in compression." Construction \& Building Materials, 184: 681-704.

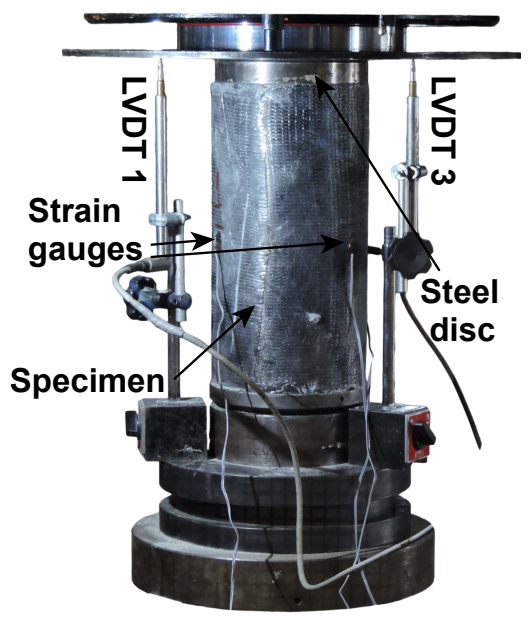

(a)

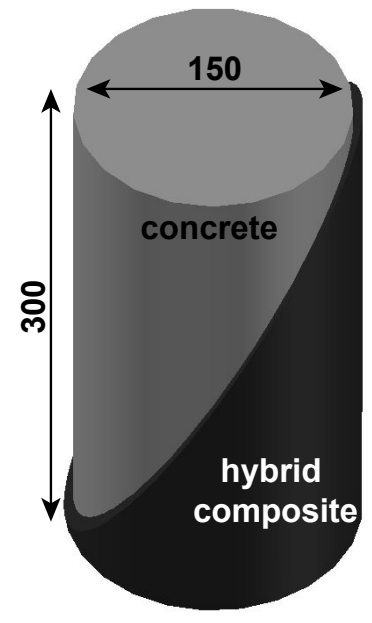

(b)

Figure 2 - Axial compressive test: (a) illustration of the test and (b) geometry of specimen (dimensions in $\mathrm{mm}$ ). 


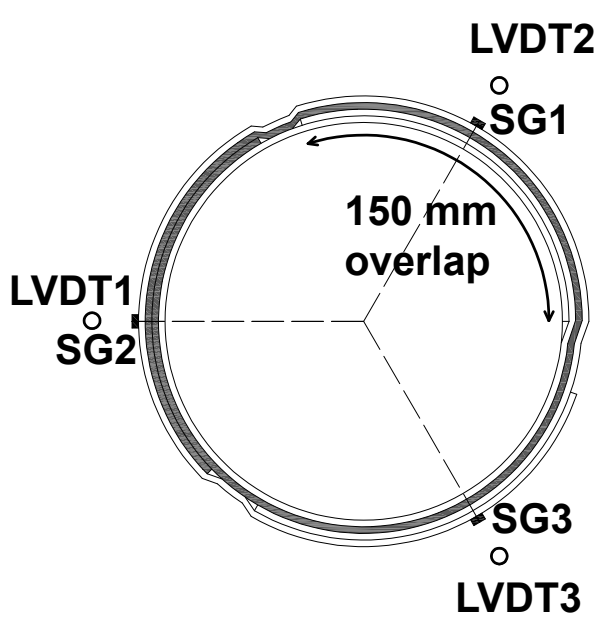

(a)

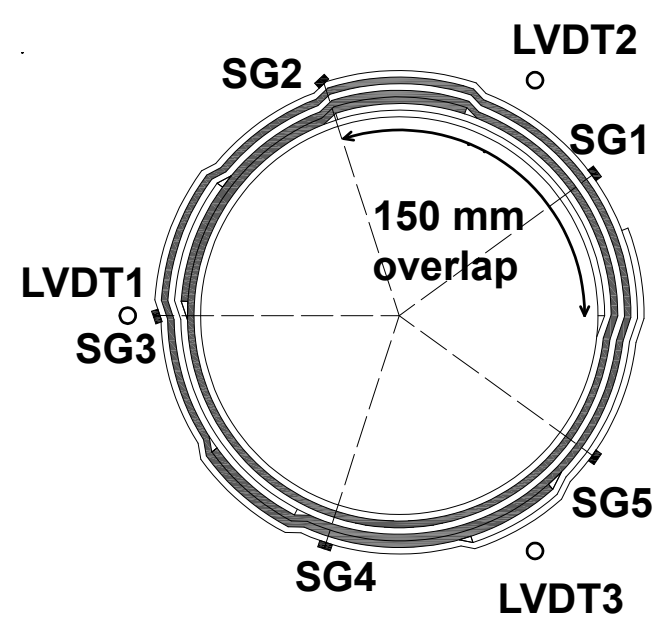

(b)

Figure 3 - Layers, LVDT and strain gauge arrangement: (a) hybrid jackets with 3 layers and (b) hybrid jackets with 5 layers. Note: different colours in the illustrated hybrid jackets are a schematic representation of a possible stacking sequence of two different reinforcing materials. 
Ribeiro, F.; Sena-Cruz, J.; Branco, F.; Júlio, E. (2018) "Hybrid FRP jacketing for enhanced confinement of circular concrete columns in compression." Construction \& Building Materials, 184: 681-704.

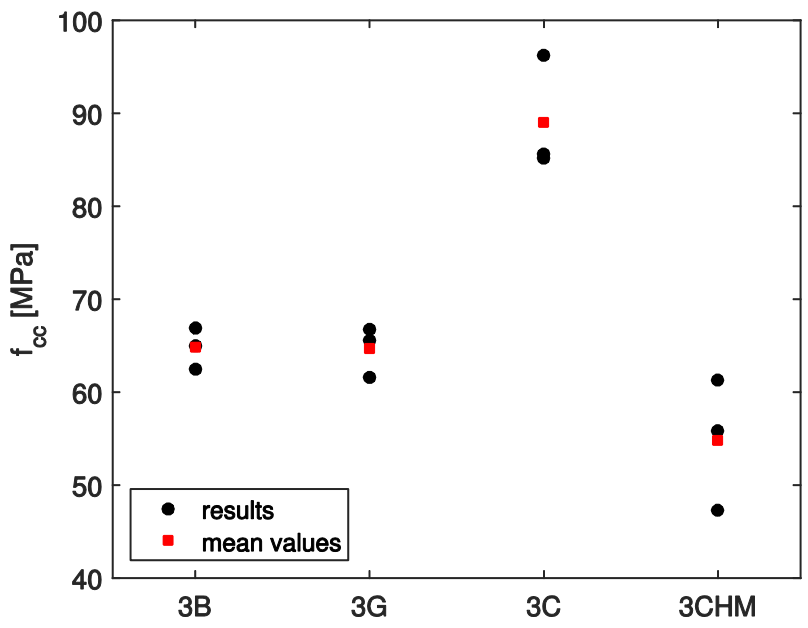

(a)

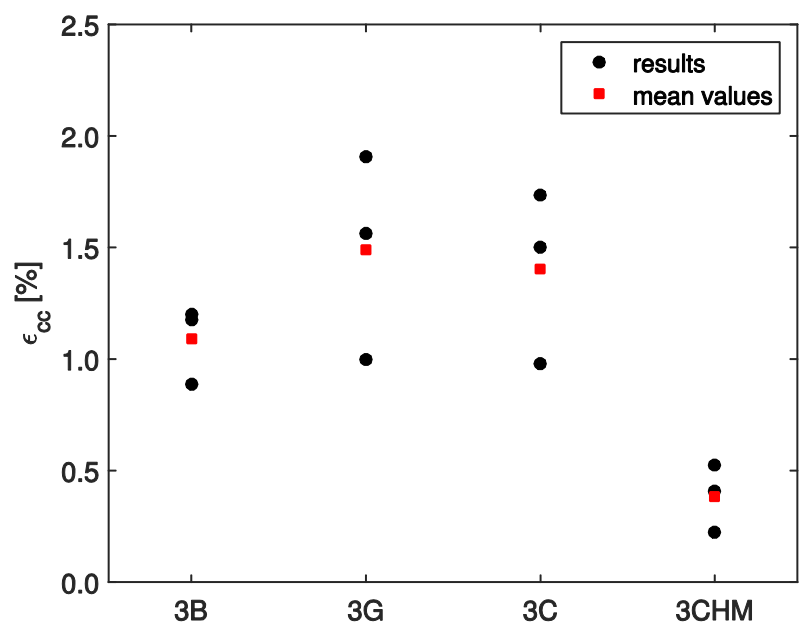

(b)

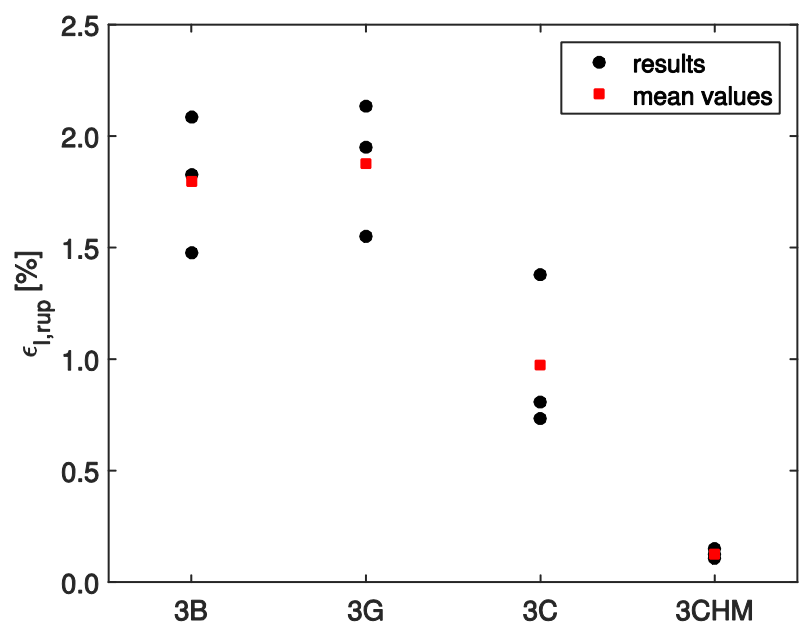

(c)

Figure 4 - Scatter diagrams and mean values of the non-hybrid composites confined concrete: (a) ultimate axial compressive stress; (b) ultimate axial strain and (c) hoop rupture strain of FRP. 
Ribeiro, F.; Sena-Cruz, J.; Branco, F.; Júlio, E. (2018) "Hybrid FRP jacketing for enhanced confinement of circular concrete columns in compression." Construction \& Building Materials, 184: 681-704.

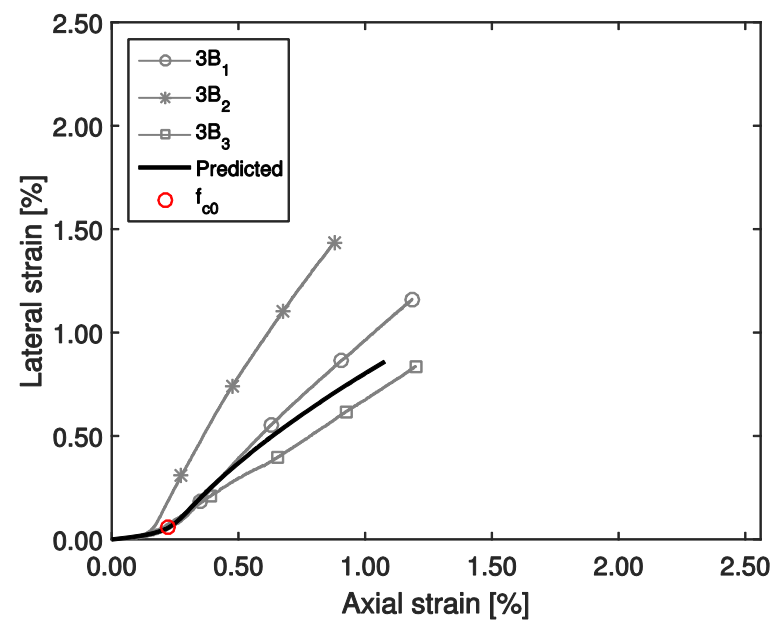

(a)

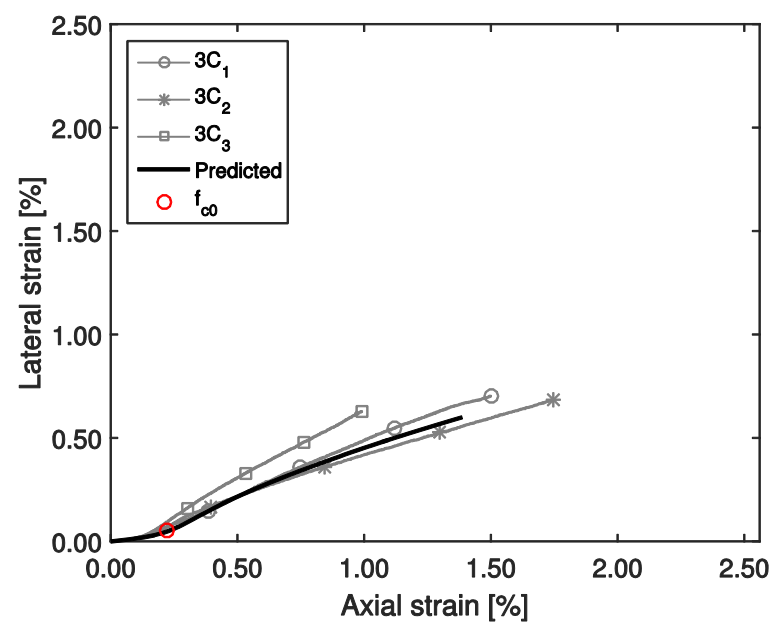

(c)

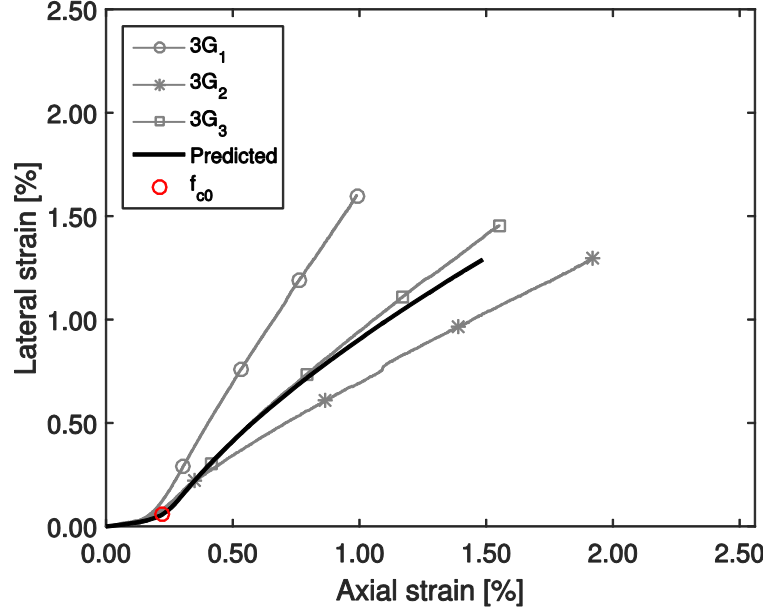

(b)

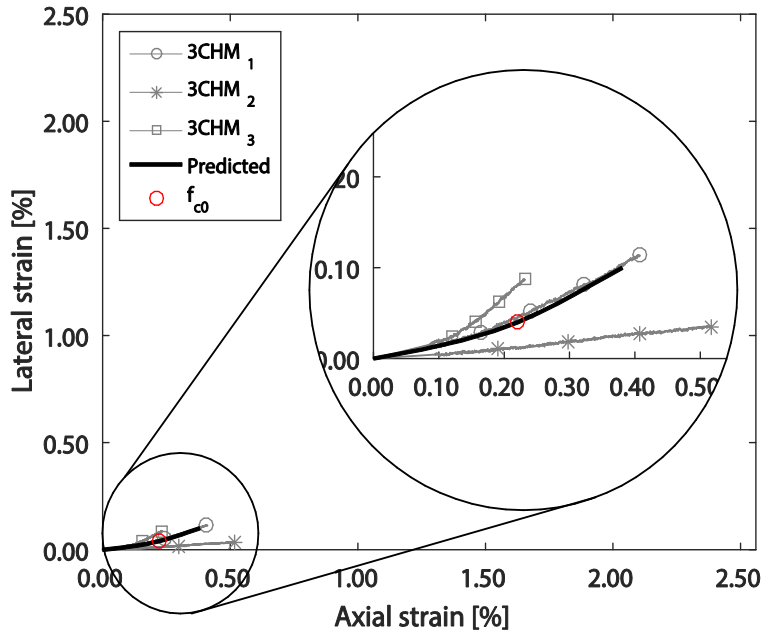

(d)

Figure 5 - Lateral strain-axial strain curves: (a) basalt; (b) glass; (c) ST carbon; (d) HM carbon composite confined concrete. 
Ribeiro, F.; Sena-Cruz, J.; Branco, F.; Júlio, E. (2018) "Hybrid FRP jacketing for enhanced confinement of circular concrete columns in compression." Construction \& Building Materials, 184: 681-704.

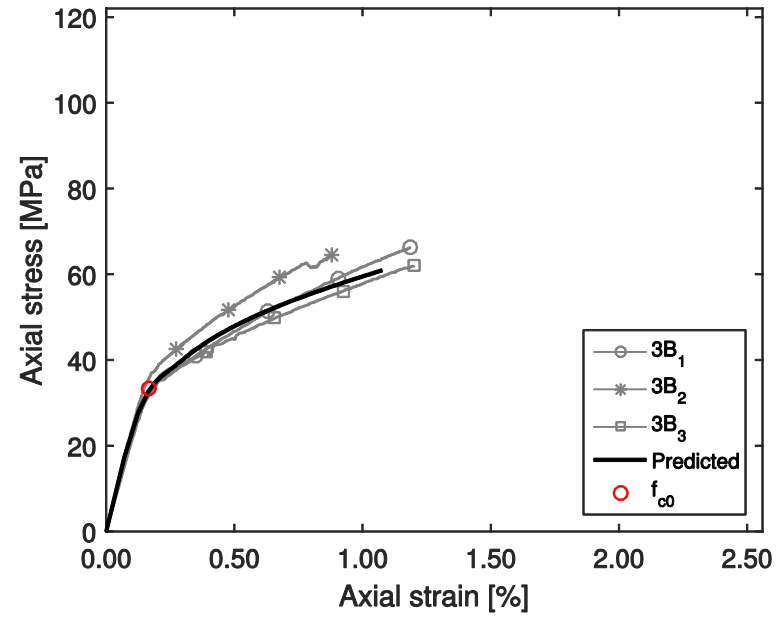

(a)

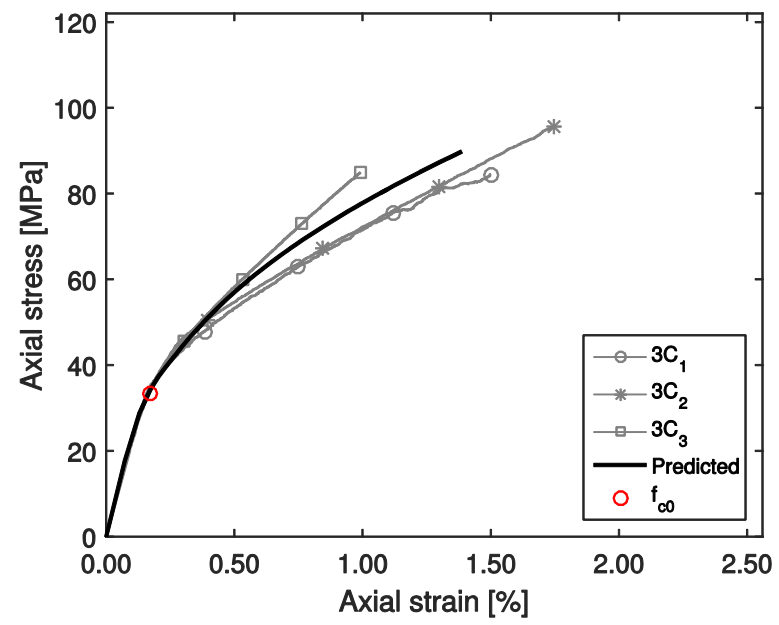

(c)

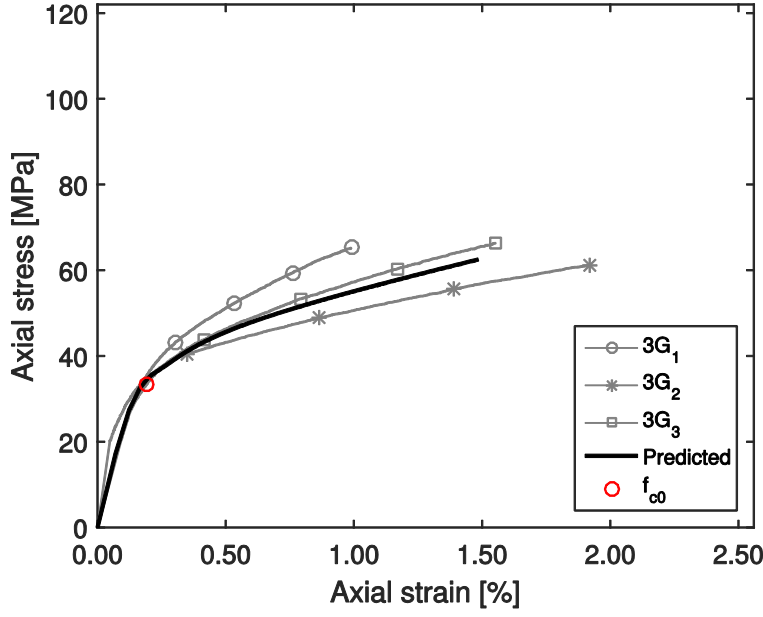

(b)

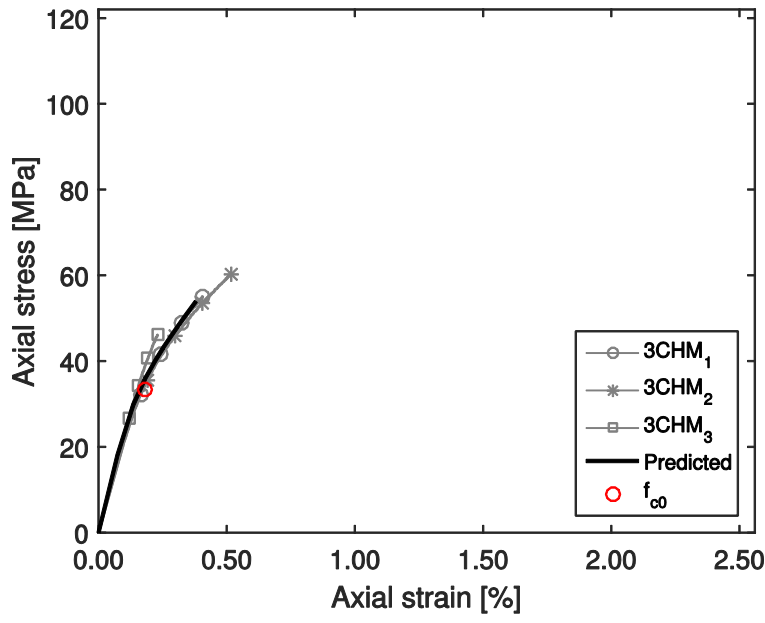

(d)

Figure 6 - Axial stress-strain curves: (a) basalt; (b) glass; (c) ST carbon; (d) HM carbon composite confined concrete. 


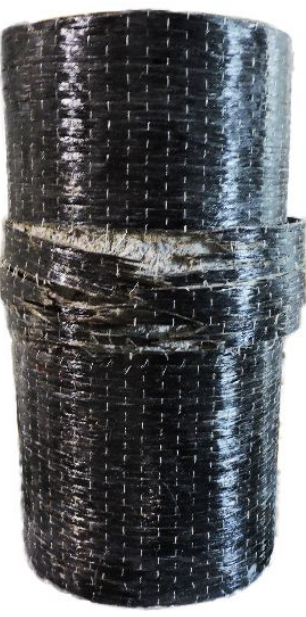

(a)

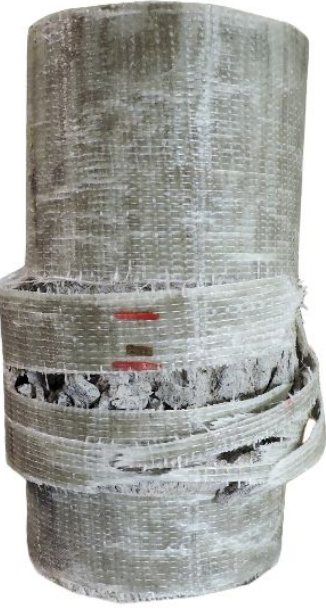

(b)

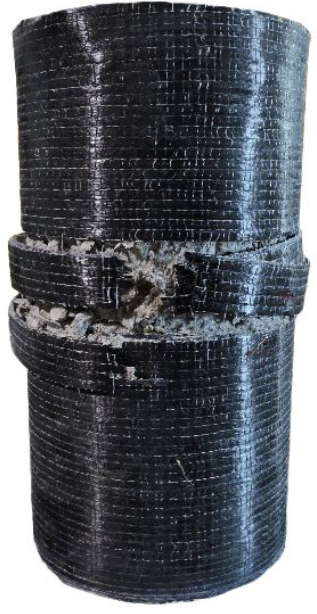

(c)

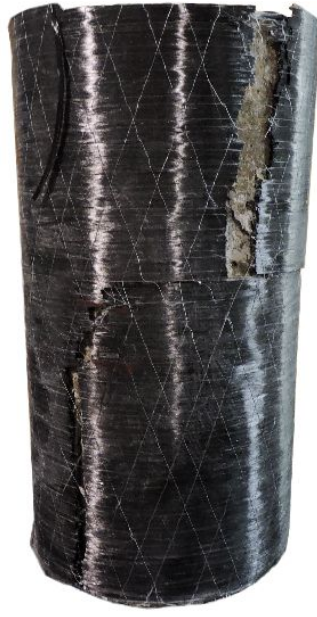

(d)

Figure 7 - Failure modes of non-hybrid FRP-confined concrete: (a) basalt; (b) glass; (c) ST carbon and (d) HM carbon. 
Ribeiro, F.; Sena-Cruz, J.; Branco, F.; Júlio, E. (2018) "Hybrid FRP jacketing for enhanced confinement of circular concrete columns in compression." Construction \& Building Materials, 184: 681-704.

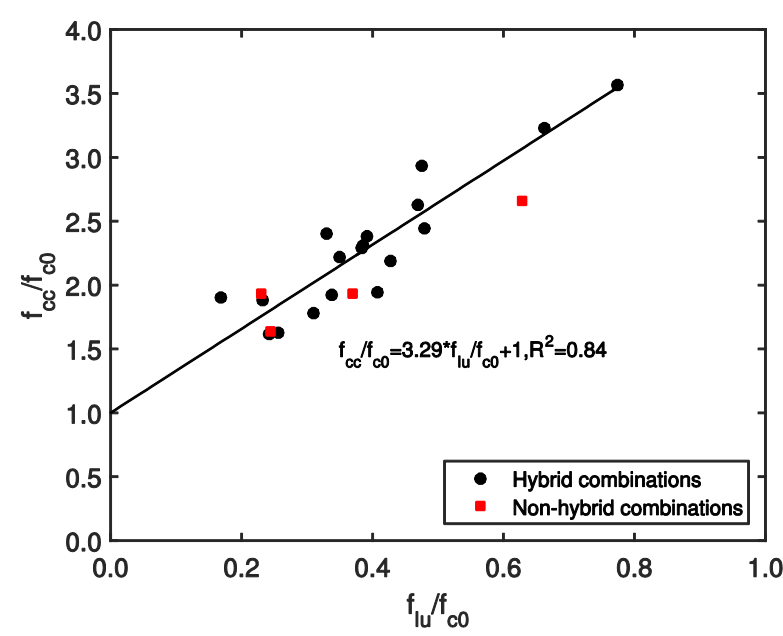

(a)

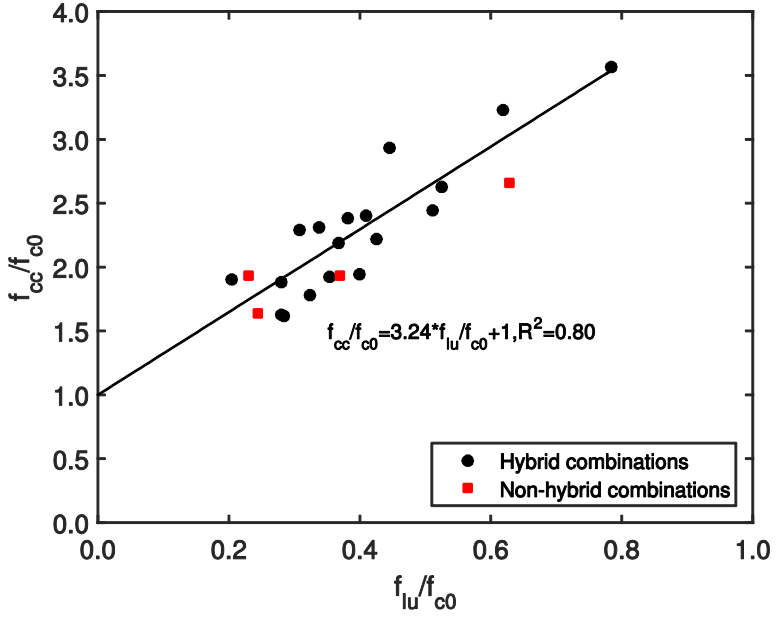

(b)

Figure 8 - Variation of strength enhancement ratio with confinement ratio: (a) $f_{\mathrm{lu}}$ based on J- $\sigma_{\text {hybrid }}$; (b) $f_{\mathrm{u}}$ based on B- $\sigma_{\text {hybrid. }}$. 
Ribeiro, F.; Sena-Cruz, J.; Branco, F.; Júlio, E. (2018) "Hybrid FRP jacketing for enhanced confinement of circular concrete columns in compression." Construction \& Building Materials, 184: 681-704.

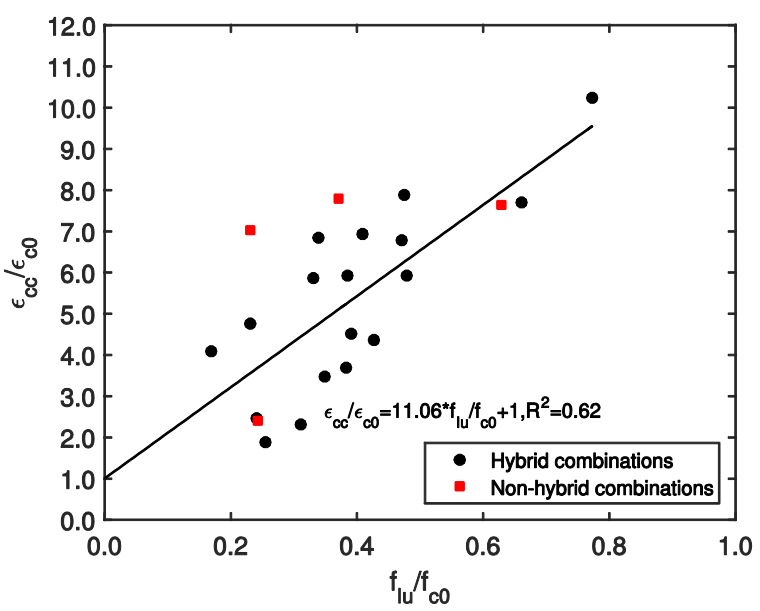

(a)

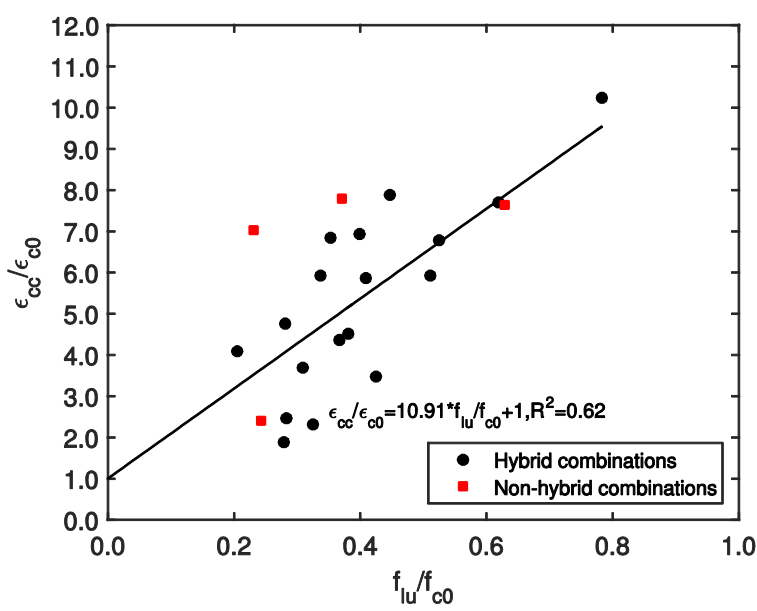

(b)

Figure 9 - Variation of strain enhancement ratio with confinement ratio: (a) $f_{\mathrm{lu}}$ based on J- $\sigma_{\text {hybrid }}$; (b) $f_{\mathrm{lu}}$ based on B- $\sigma_{\text {hybrid. }}$. 


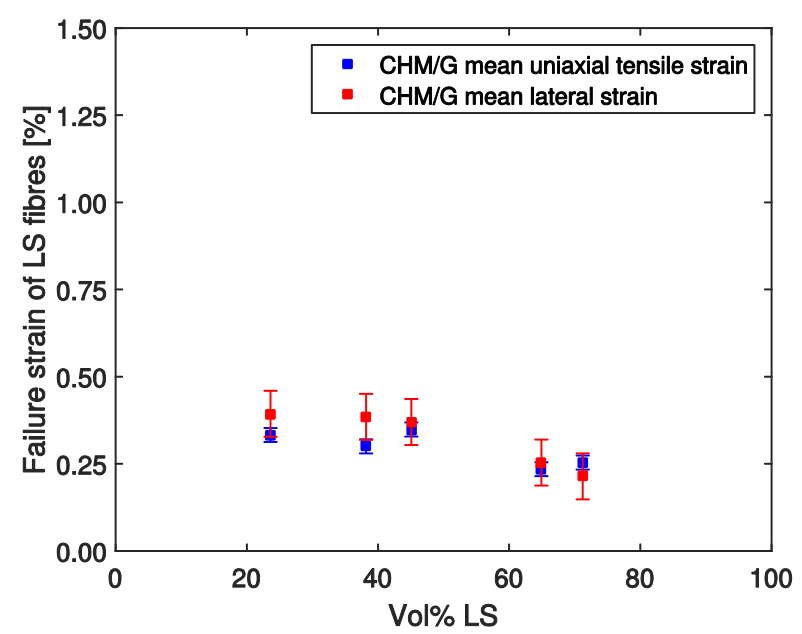

(a)

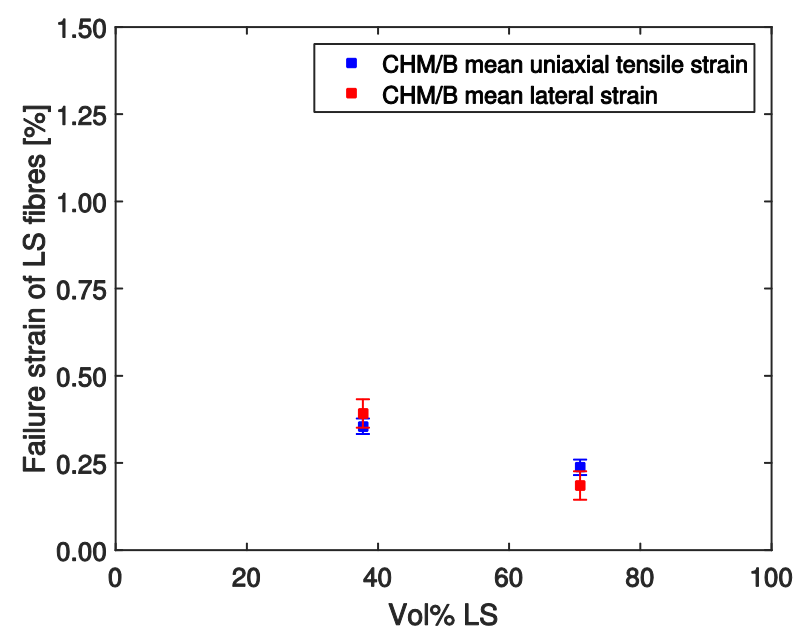

(c)

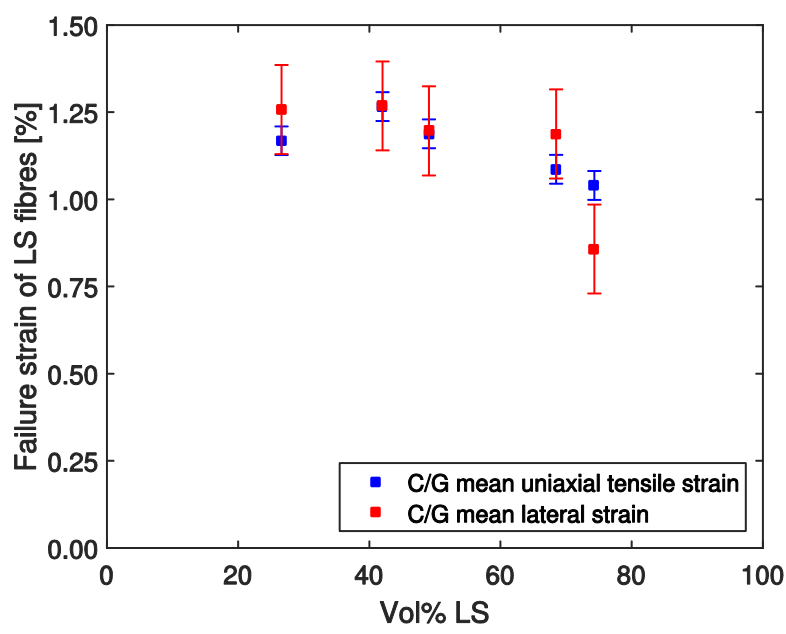

(b)

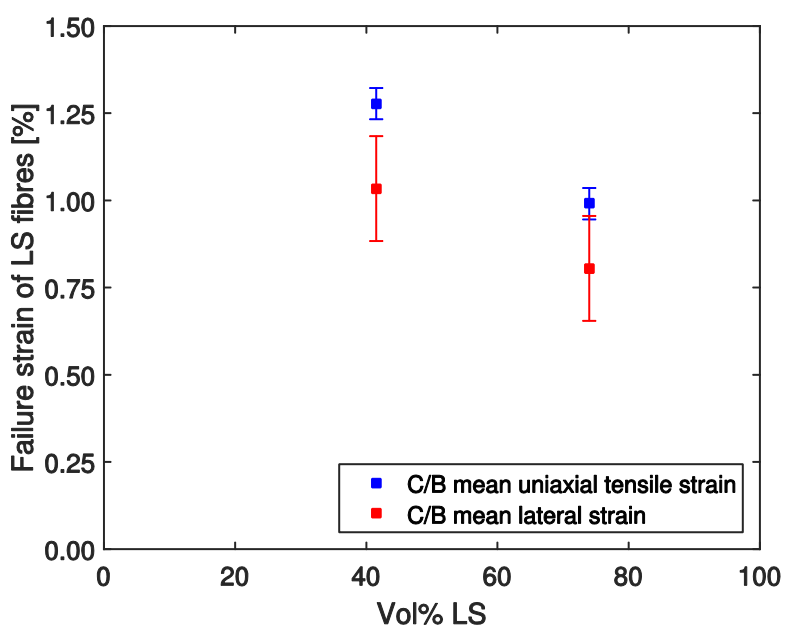

(d)

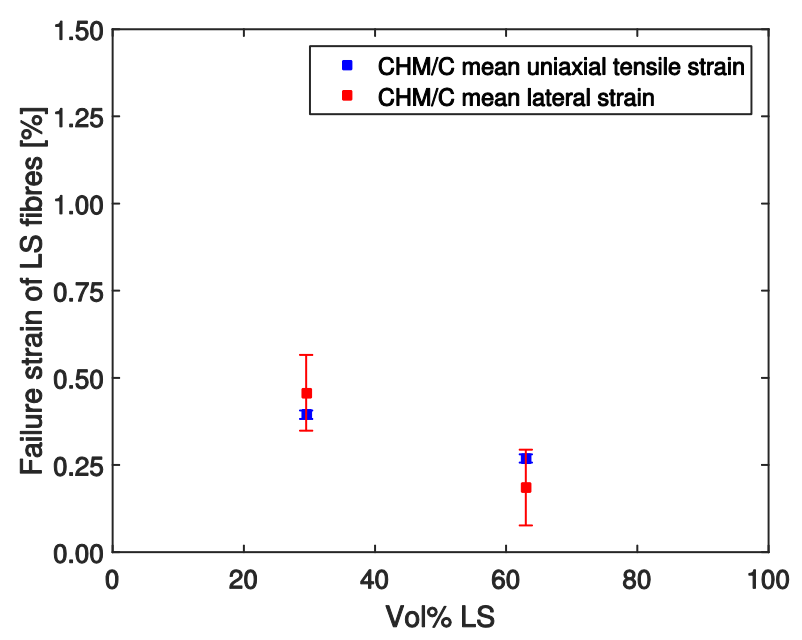

(e)

Figure 10 - Comparison between uniaxial tensile and lateral failure strains of LS fibres of the: (a) HM carbon/glass; (b) ST carbon/glass; (c) HM carbon/basalt; (d) ST carbon/basalt and (e) HM carbon/ST carbon composites 
Ribeiro, F.; Sena-Cruz, J.; Branco, F.; Júlio, E. (2018) "Hybrid FRP jacketing for enhanced confinement of circular concrete columns in compression." Construction \& Building Materials, 184: 681-704.

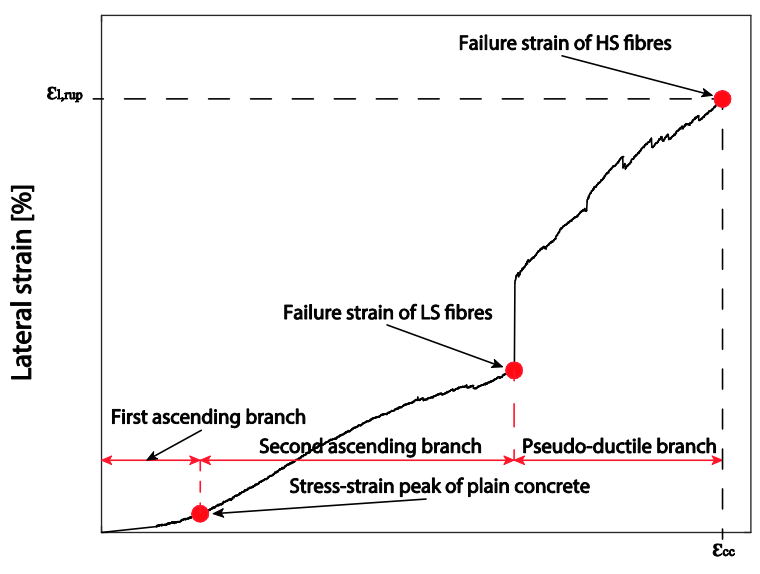

Axial strain [\%]

Figure 11 - Illustration of different stages of lateral strain-axial strain curves of specimens with pseudo-ductile behaviour. 
Ribeiro, F.; Sena-Cruz, J.; Branco, F.; Júlio, E. (2018) "Hybrid FRP jacketing for enhanced confinement of circular concrete columns in compression." Construction \& Building Materials, 184: 681-704.

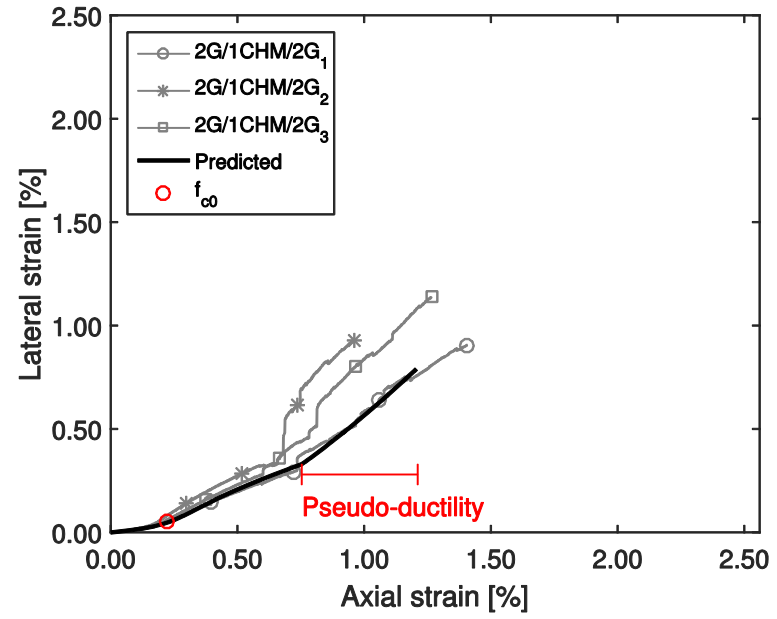

(a)

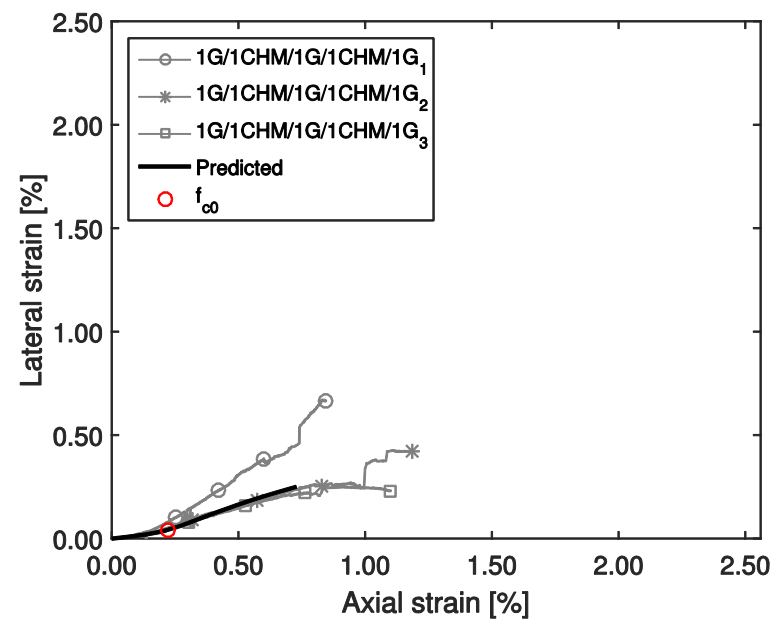

(c)

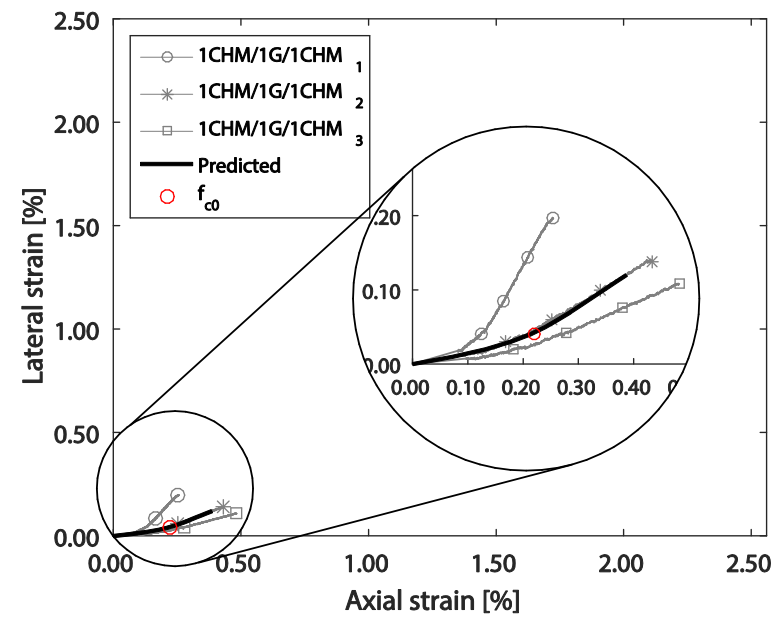

(e)

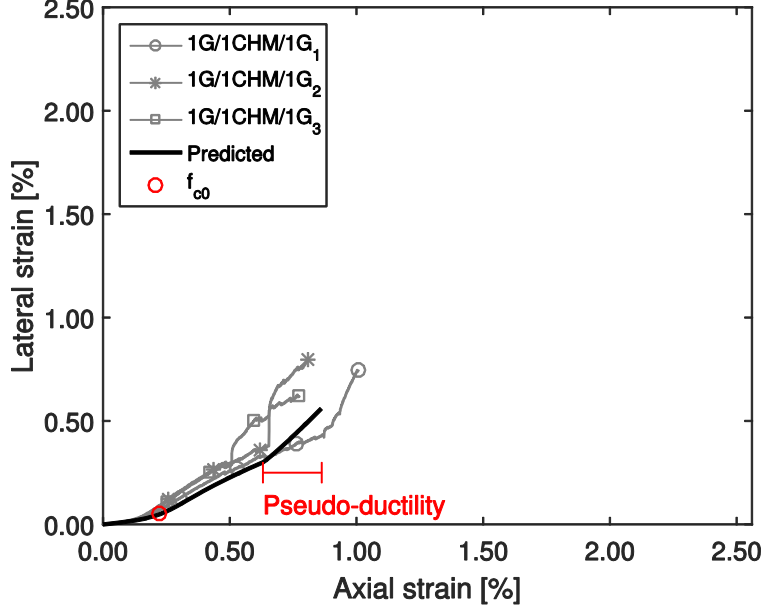

(b)

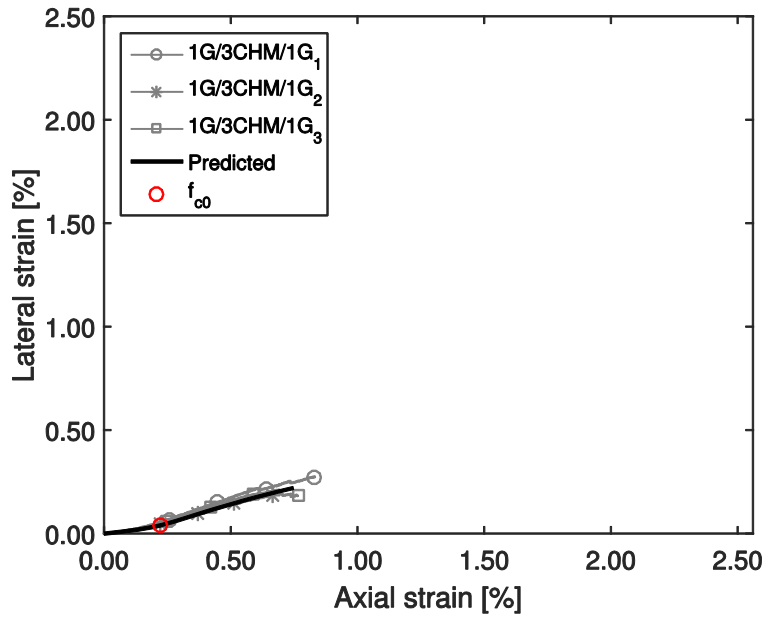

(d) 
Ribeiro, F.; Sena-Cruz, J.; Branco, F.; Júlio, E. (2018) "Hybrid FRP jacketing for enhanced confinement of circular concrete columns in compression." Construction \& Building Materials, 184: 681-704.

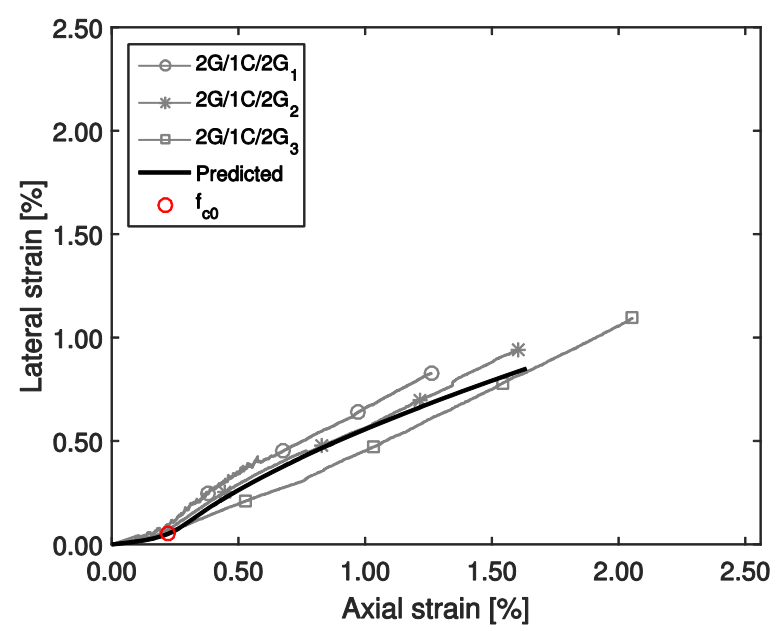

(a)

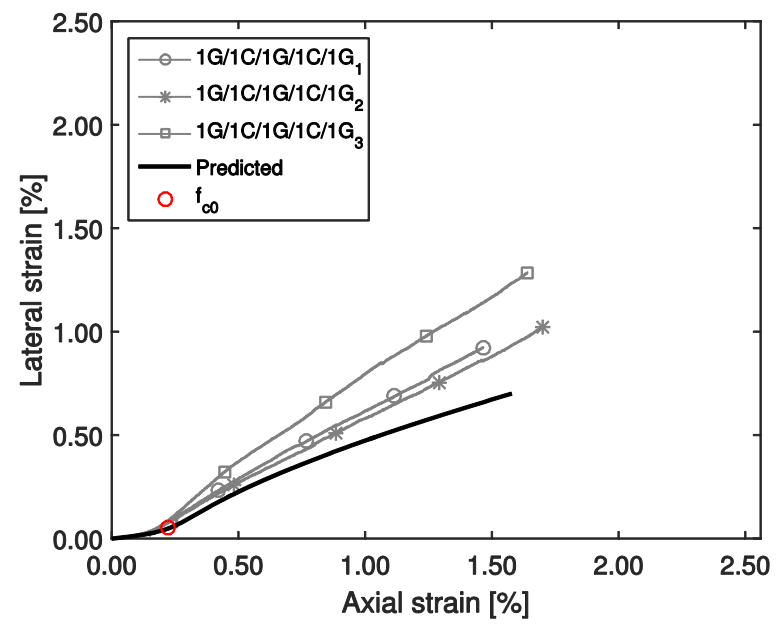

(c)

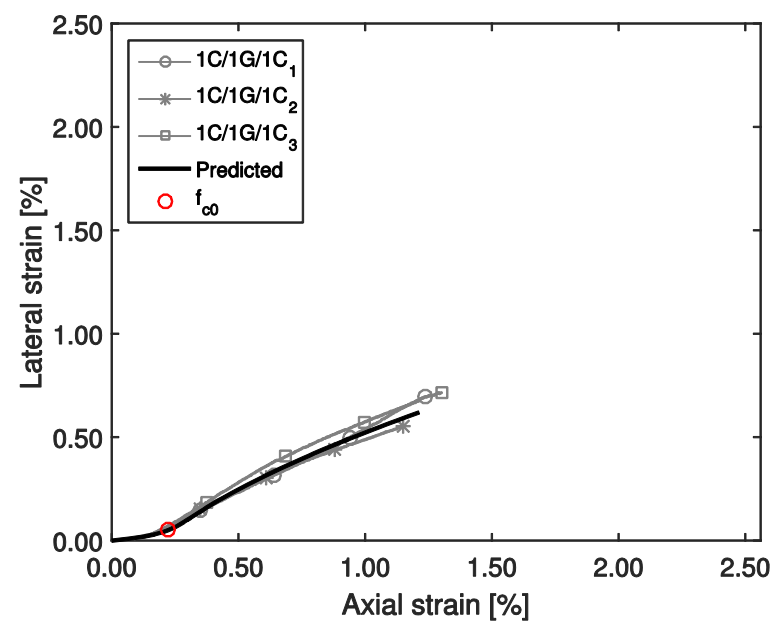

(e)

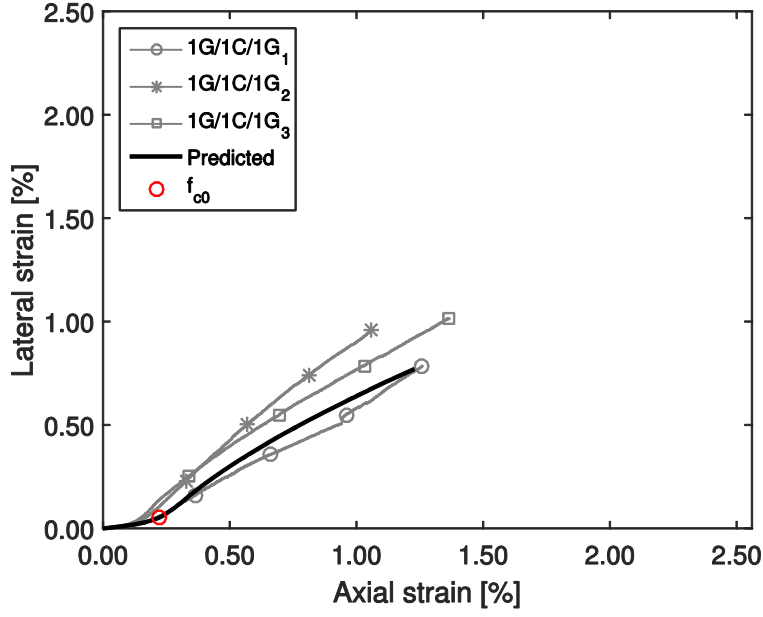

(b)

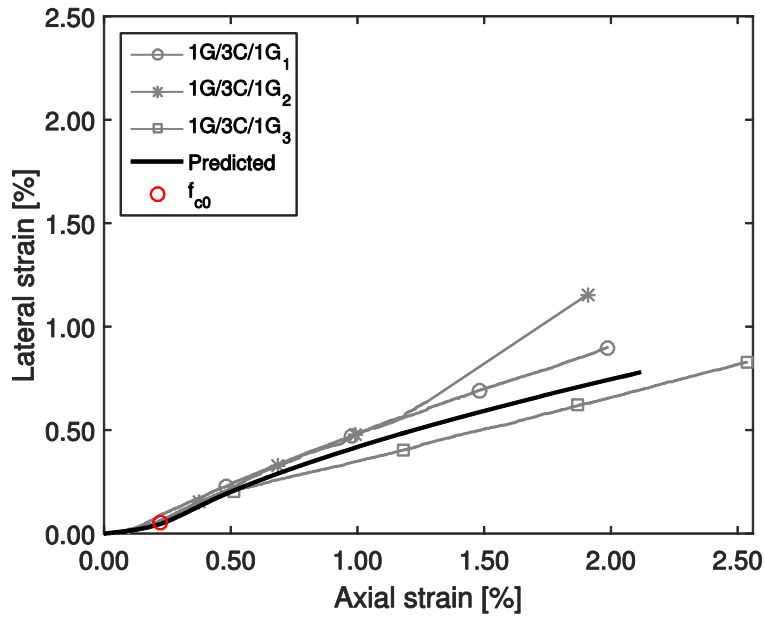

(d) 
Ribeiro, F.; Sena-Cruz, J.; Branco, F.; Júlio, E. (2018) "Hybrid FRP jacketing for enhanced confinement of circular concrete columns in compression." Construction \& Building Materials, 184: 681-704.

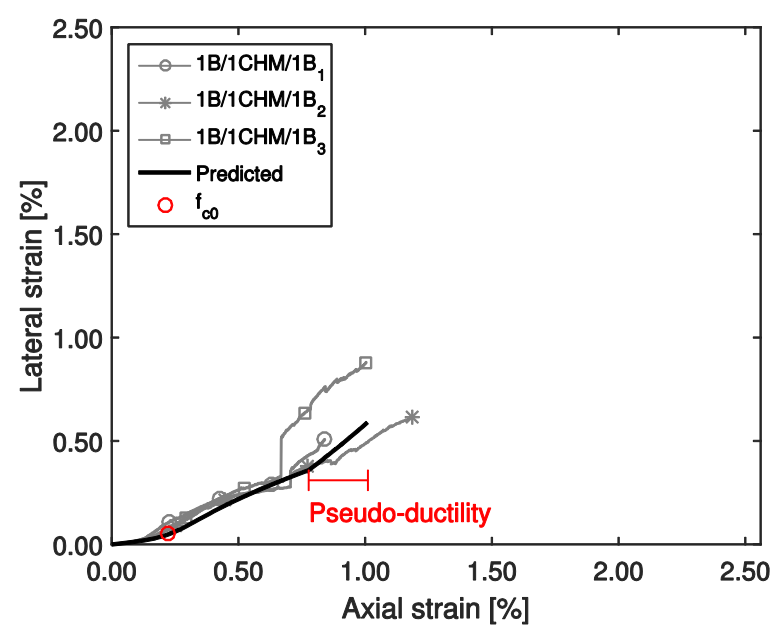

(a)

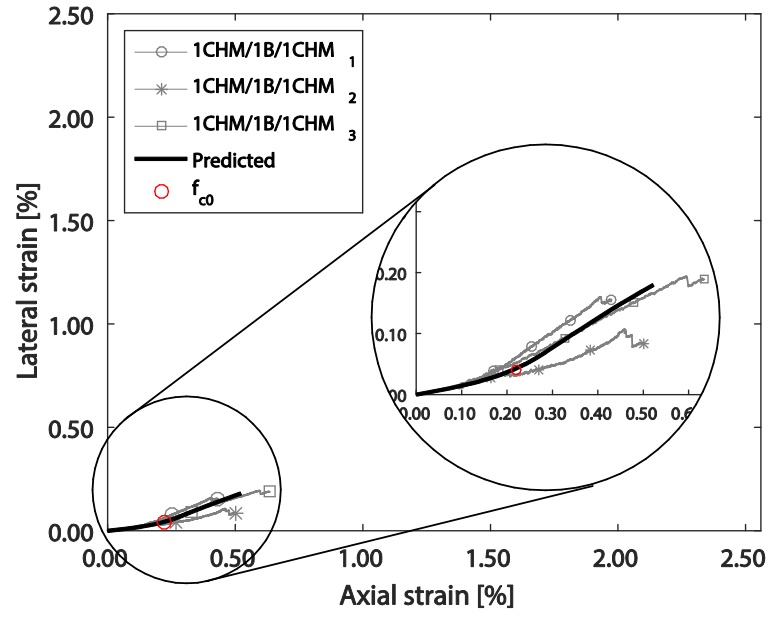

(b)

Figure 14 - Lateral strain-axial strain curves of CHM/B combinations: experimental versus predicted values. 
Ribeiro, F.; Sena-Cruz, J.; Branco, F.; Júlio, E. (2018) "Hybrid FRP jacketing for enhanced confinement of circular concrete columns in compression." Construction \& Building Materials, 184: 681-704.

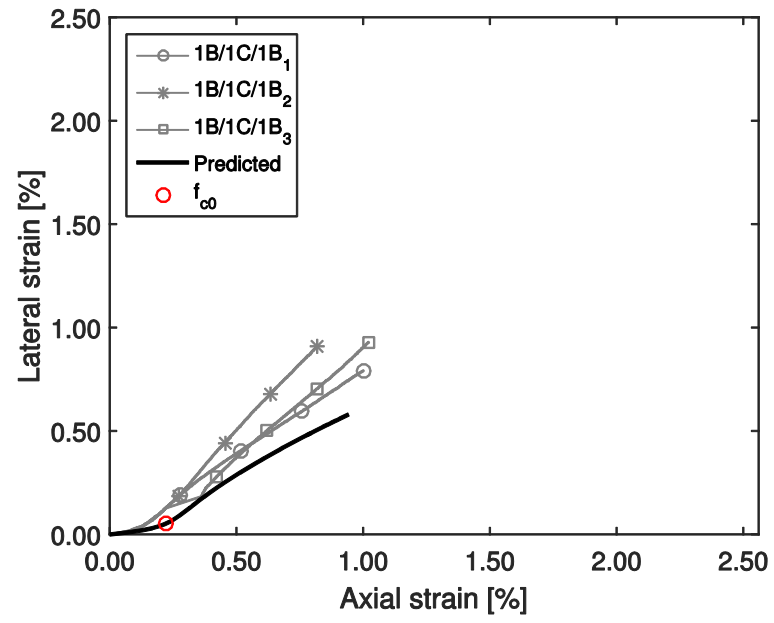

(a)

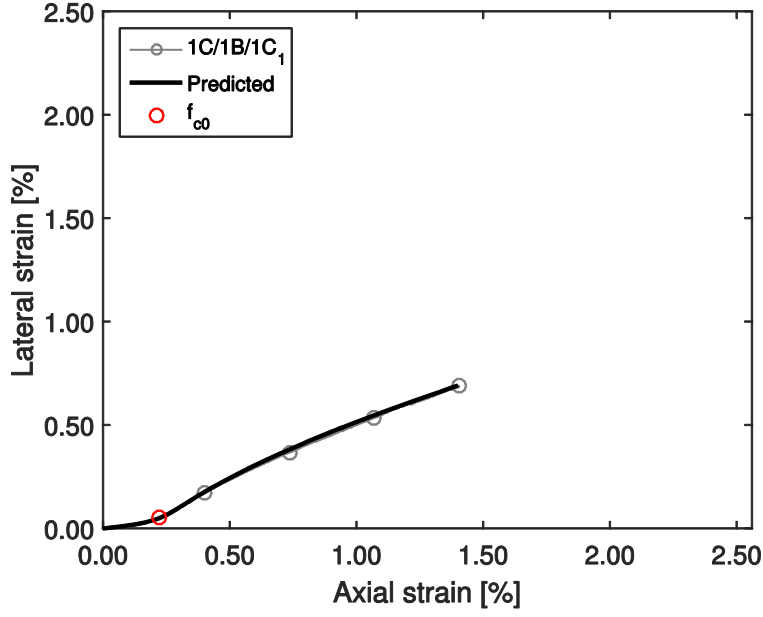

(b)

Figure 15 - Lateral strain-axial strain curves of C/B combinations: experimental versus predicted values. 
Ribeiro, F.; Sena-Cruz, J.; Branco, F.; Júlio, E. (2018) "Hybrid FRP jacketing for enhanced confinement of circular concrete columns in compression." Construction \& Building Materials, 184: 681-704.

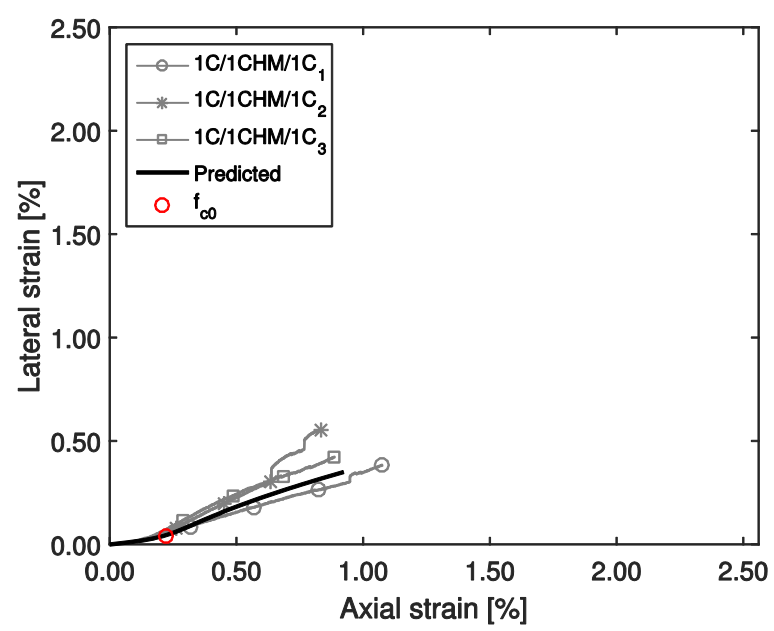

(a)

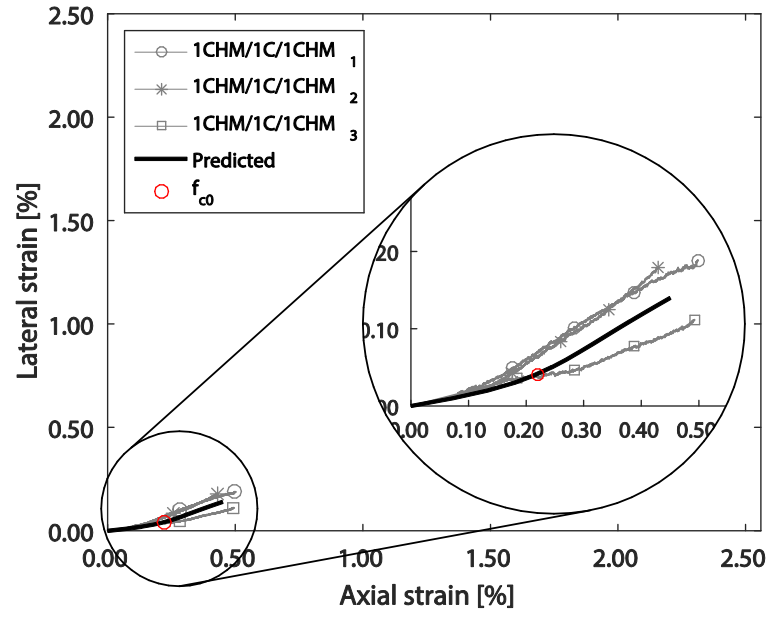

(b)

Figure 16 - Lateral strain-axial strain curves of CHM/C combinations: experimental versus predicted values. 
Ribeiro, F.; Sena-Cruz, J.; Branco, F.; Júlio, E. (2018) "Hybrid FRP jacketing for enhanced confinement of circular concrete columns in compression." Construction \& Building Materials, 184: 681-704.

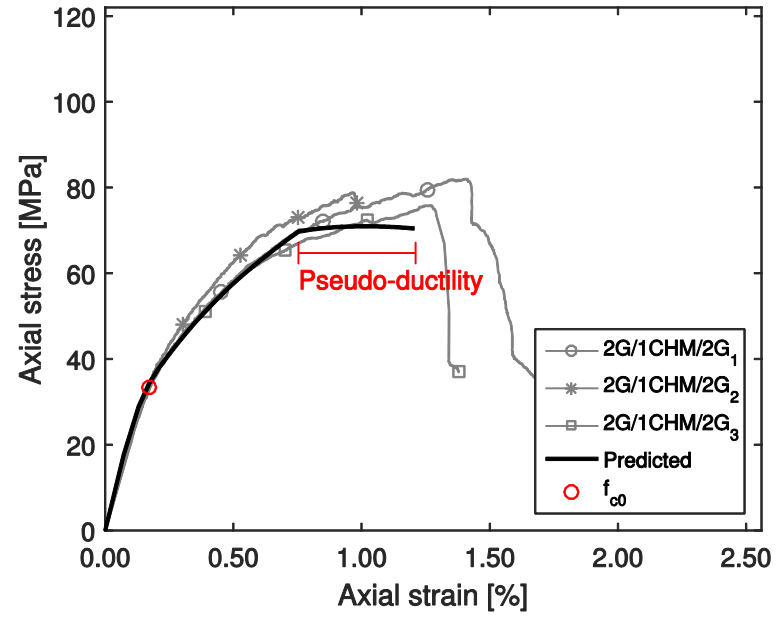

(a)

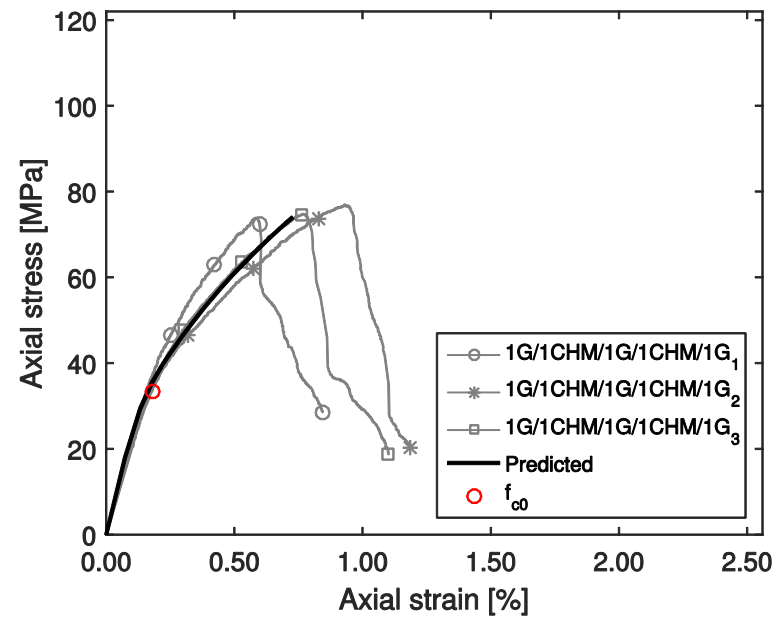

(c)

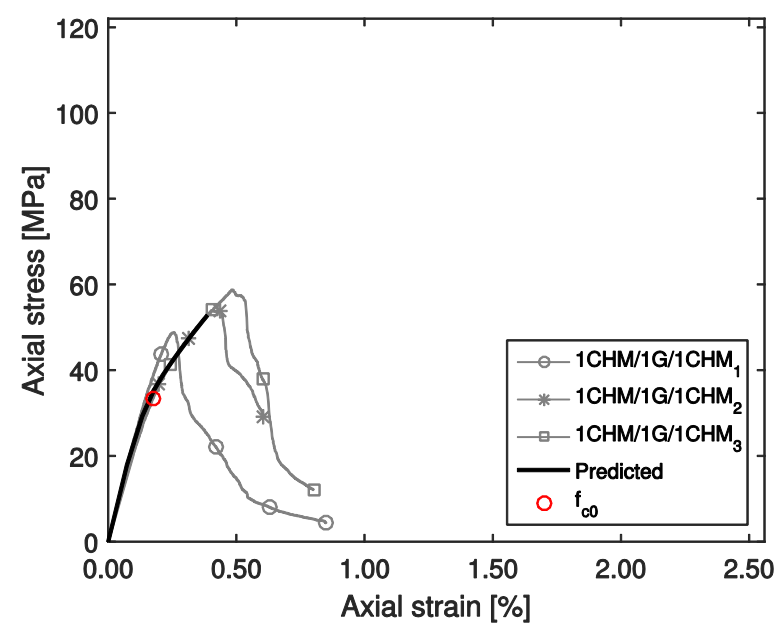

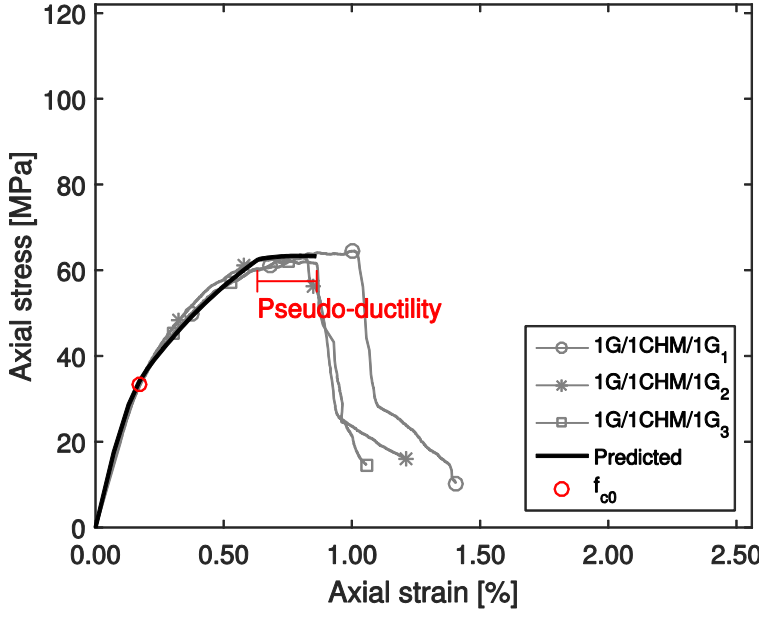

(b)

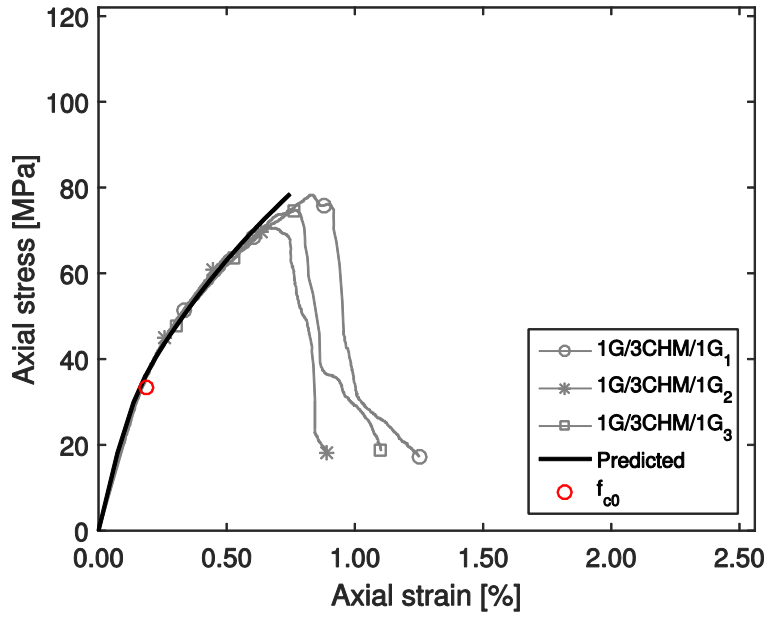

(d)

(e)

Figure 17 - Stress-strain curves of $\mathrm{CHM} / \mathrm{G}$ combinations: experimental versus predicted values. 
Ribeiro, F.; Sena-Cruz, J.; Branco, F.; Júlio, E. (2018) "Hybrid FRP jacketing for enhanced confinement of circular concrete columns in compression." Construction \& Building Materials, 184: 681-704.

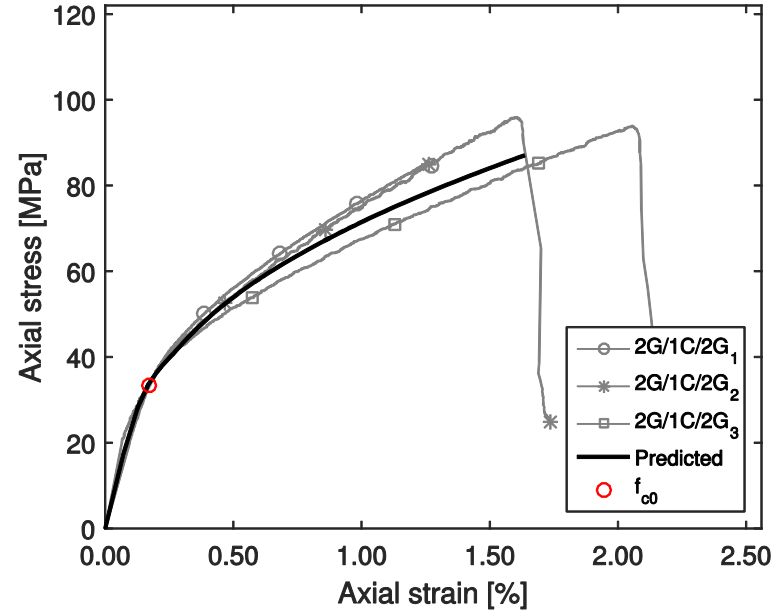

(a)

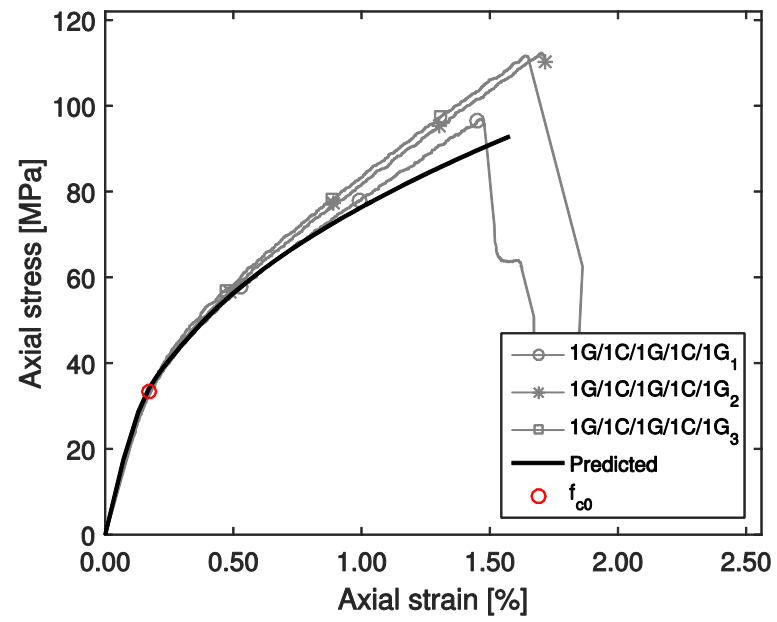

(c)

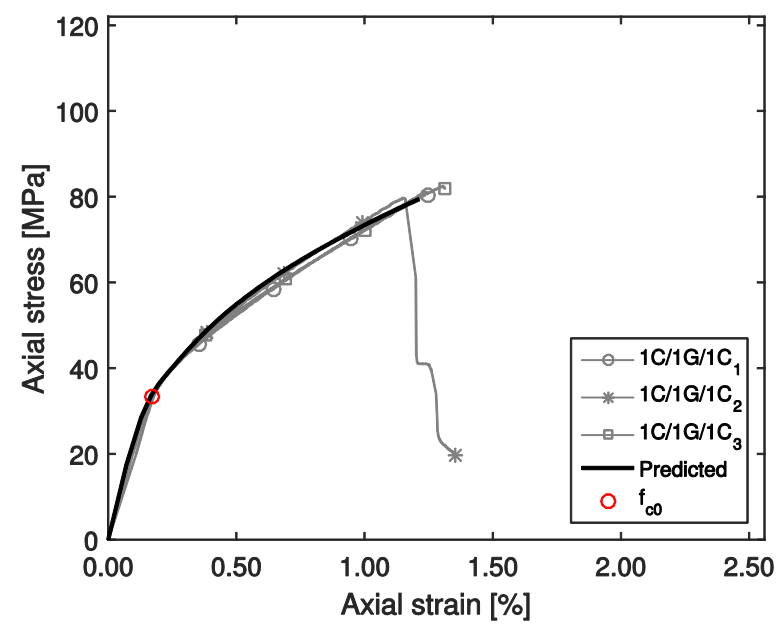

(e)

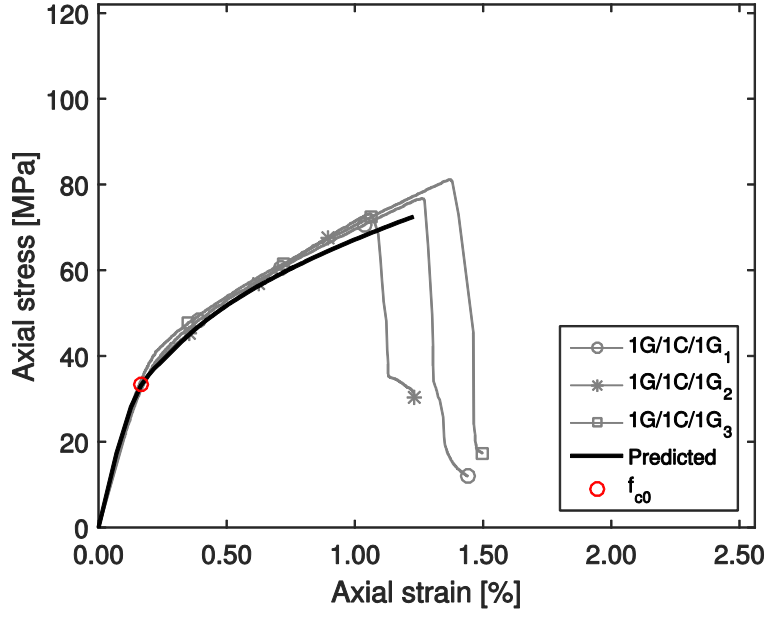

(b)

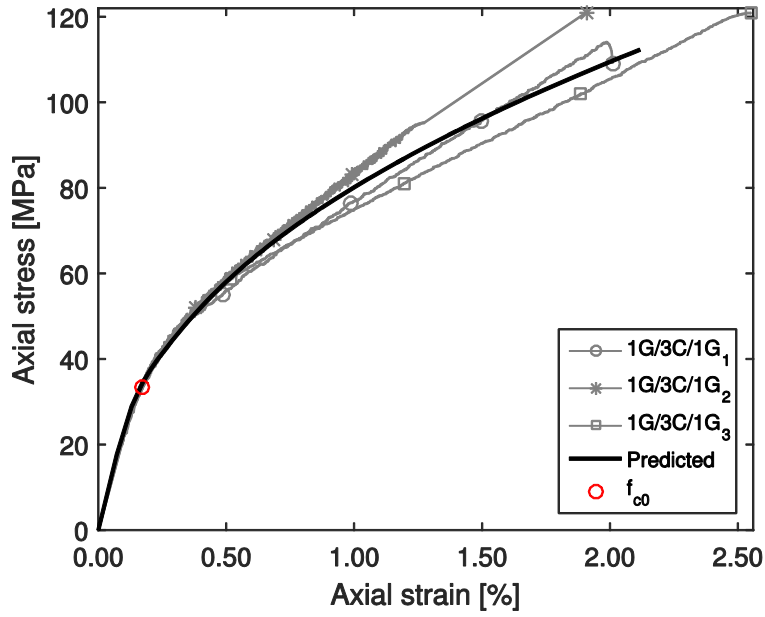

(d)

Figure 18 - Stress-strain curves of $\mathrm{C} / \mathrm{G}$ combinations: experimental versus predicted values. 
Ribeiro, F.; Sena-Cruz, J.; Branco, F.; Júlio, E. (2018) "Hybrid FRP jacketing for enhanced confinement of circular concrete columns in compression." Construction \& Building Materials, 184: 681-704.

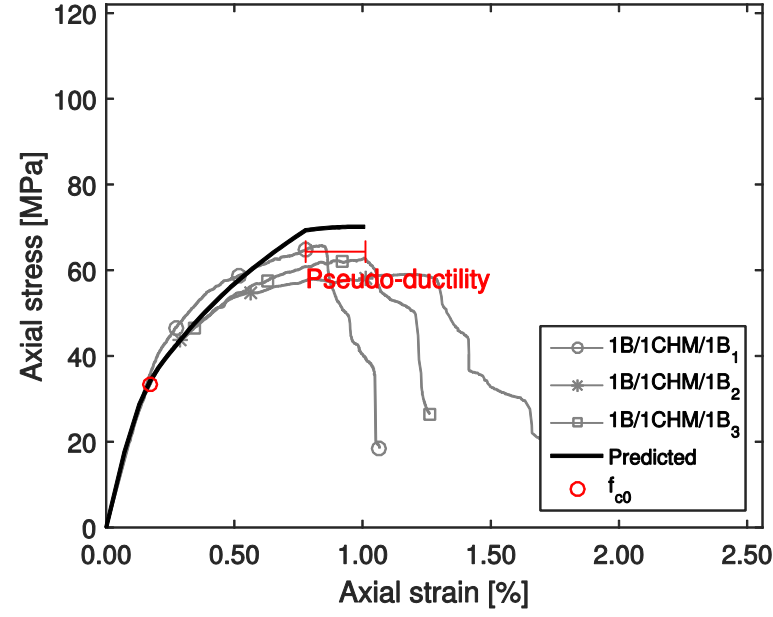

(a)

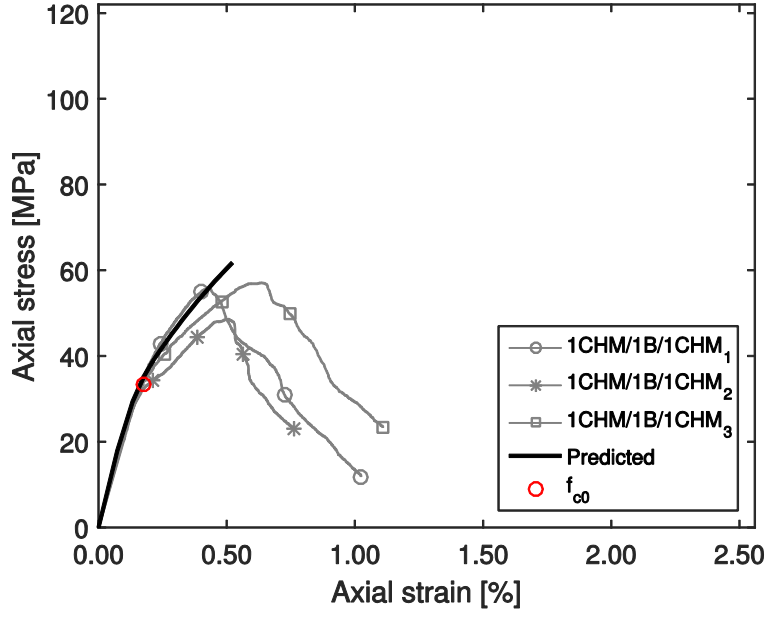

(b)

Figure 19 - Stress-strain curves of CHM/B combinations: experimental versus predicted values. 
Ribeiro, F.; Sena-Cruz, J.; Branco, F.; Júlio, E. (2018) "Hybrid FRP jacketing for enhanced confinement of circular concrete columns in compression." Construction \& Building Materials, 184: 681-704.

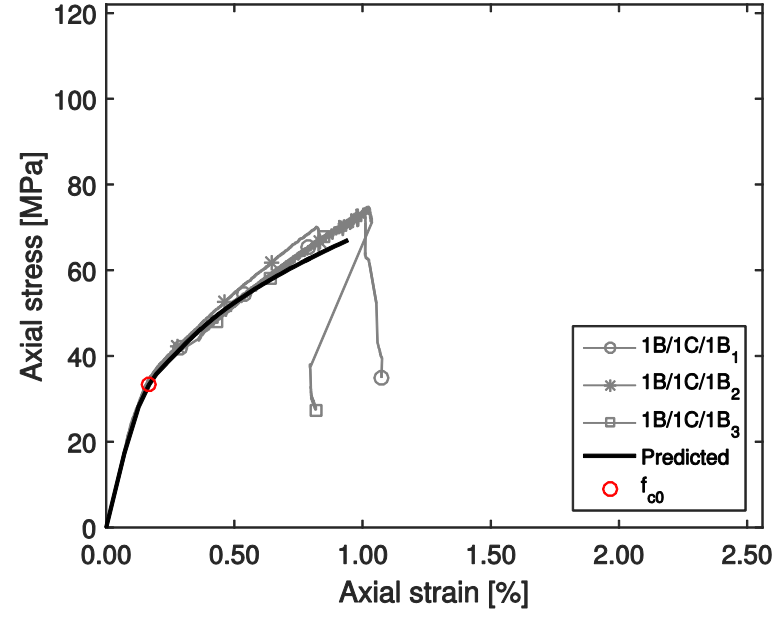

(a)

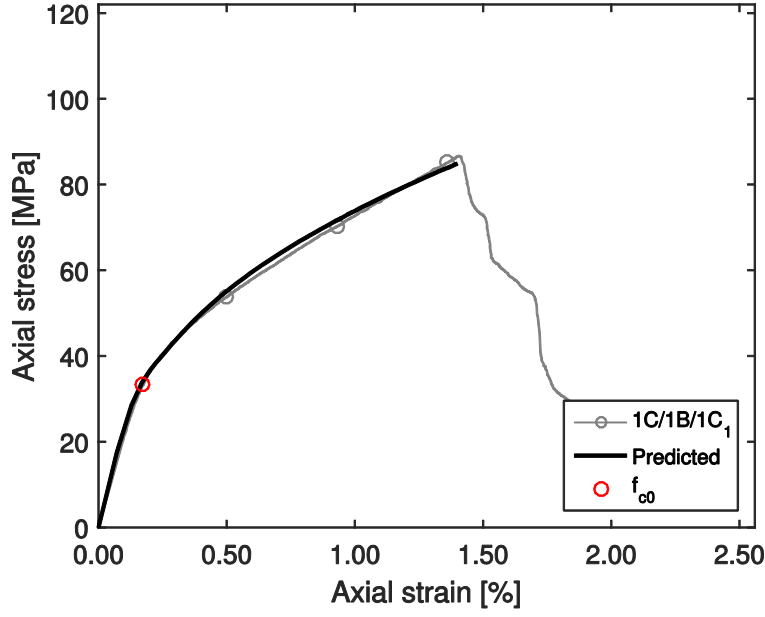

(b)

Figure 20 - Stress-strain curves of C/B combinations: experimental versus predicted values. 
Ribeiro, F.; Sena-Cruz, J.; Branco, F.; Júlio, E. (2018) "Hybrid FRP jacketing for enhanced confinement of circular concrete columns in compression." Construction \& Building Materials, 184: 681-704.

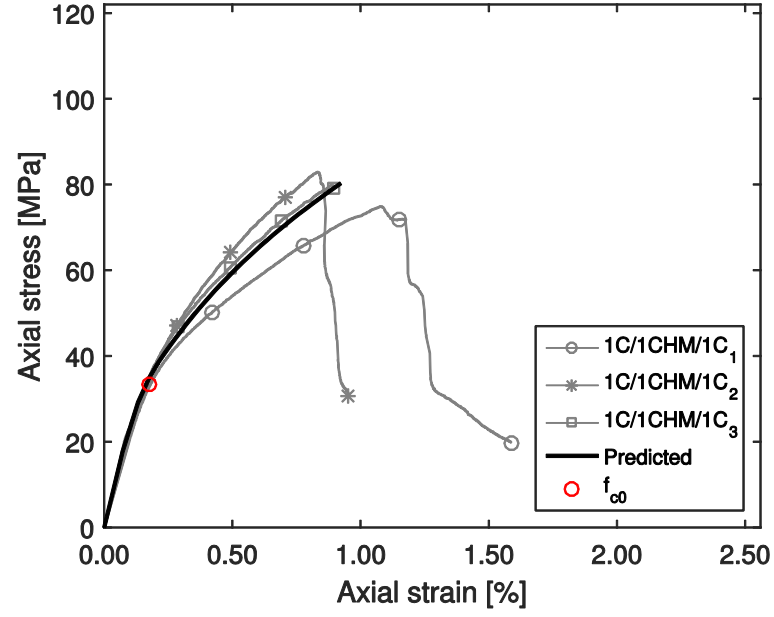

(a)

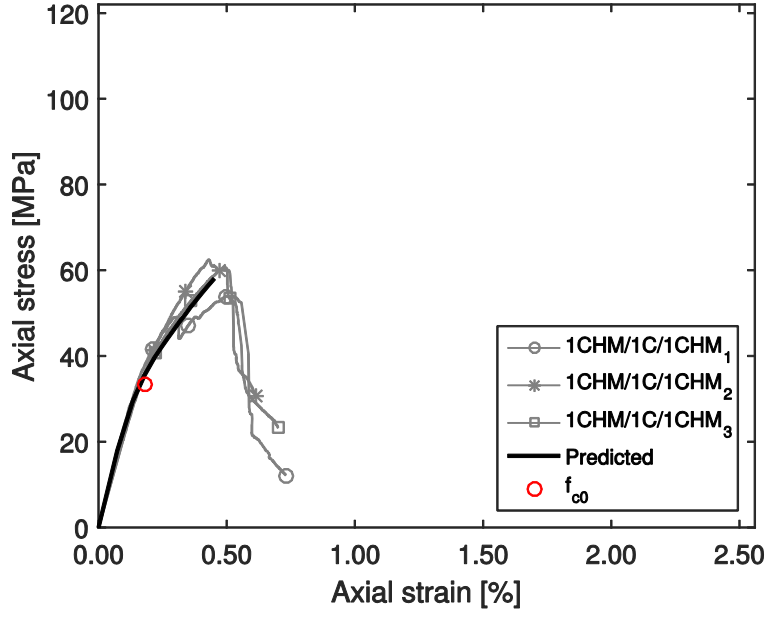

(b)

Figure 21 - Stress-strain curves of CHM/C combinations: experimental versus predicted values. 


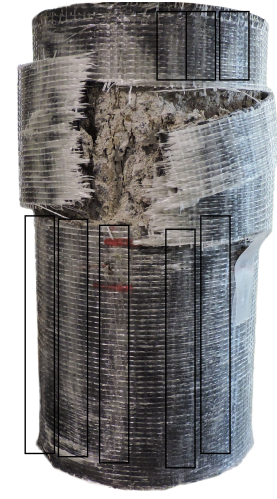

(a)

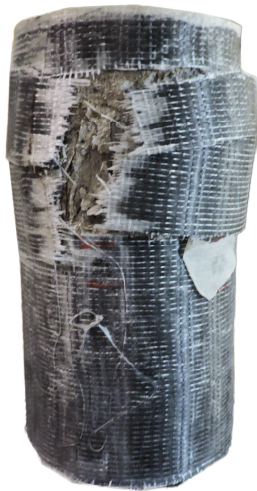

(d)

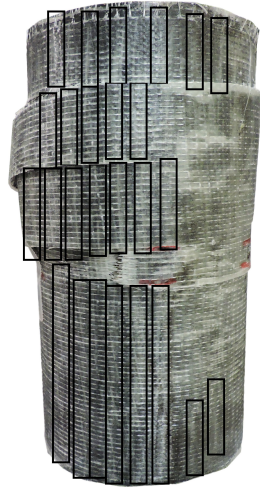

(b)

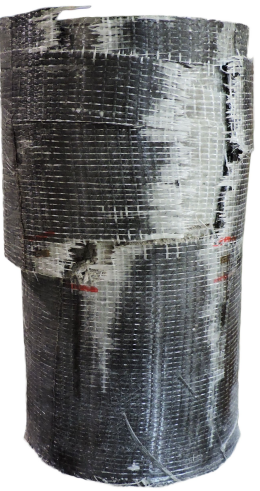

(e)

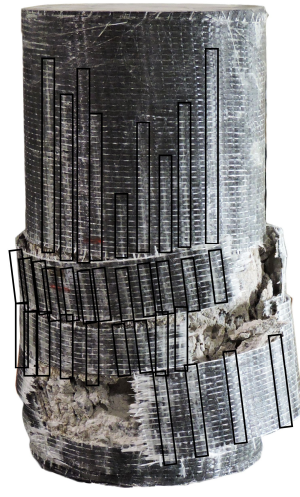

(c)

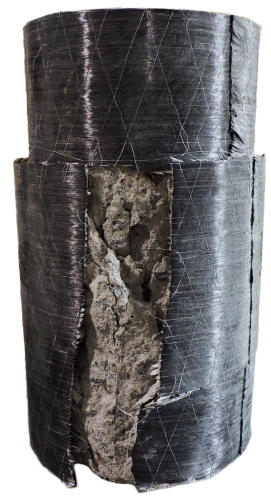

(f)

Figure 22 - Failure modes of HM carbon/glass FRP-confined concrete: (a) 2G/1CHM/2G - view 1; (b) $2 \mathrm{G} / 1 \mathrm{CHM} / 2 \mathrm{G}$ - view 2; (c) $1 \mathrm{G} / 1 \mathrm{CHM} / 1 \mathrm{G}$; (d) $1 \mathrm{G} / 1 \mathrm{CHM} / 1 \mathrm{G} / 1 \mathrm{CHM} / 1 \mathrm{G}$; (e) $1 \mathrm{G} / 3 \mathrm{CHM} / 1 \mathrm{G}$ and (f) $1 \mathrm{CHM} / 1 \mathrm{G} / 1 \mathrm{CHM}$. 


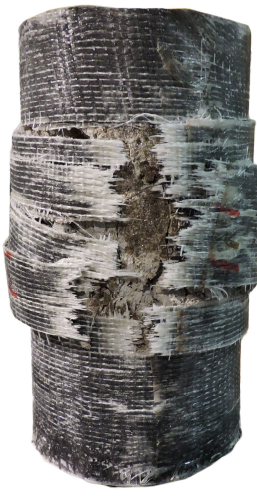

(a)

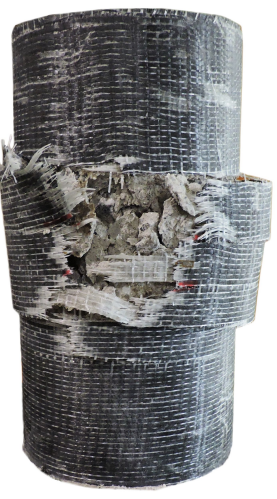

(b)

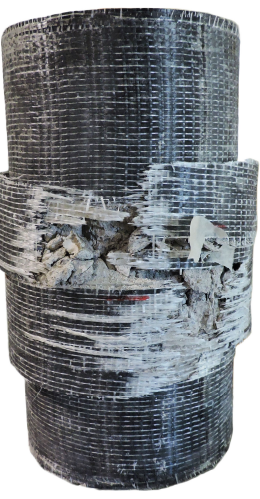

(c)

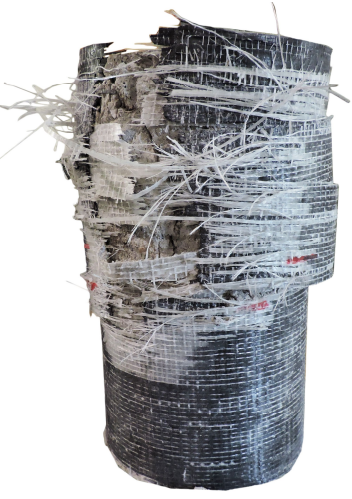

(d)

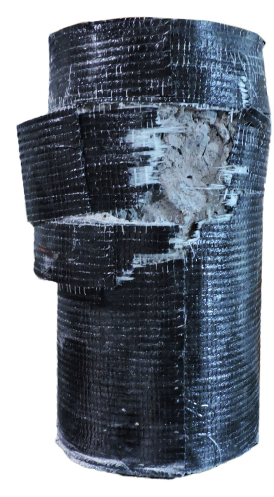

(e)

Figure 23 - Failure modes of ST carbon/glass FRP-confined concrete: (a) 2G/1C/2G; (b) 1G/1C/1G; (c) $1 \mathrm{G} / 1 \mathrm{C} / 1 \mathrm{G} / 1 \mathrm{C} / 1 \mathrm{G}$; (d) $1 \mathrm{G} / 3 \mathrm{C} / 1 \mathrm{G}$ and (e) $1 \mathrm{C} / 1 \mathrm{G} / 1 \mathrm{C}$. 